ELOI RUFATO JUNIOR

\title{
APLICAÇÃO DE SISTEMA ESPECIALISTA PARA LOCALIZAÇÃO DE DEFEITOS EM REDES DE DISTRIBUIÇÃO
}

SÃo PAULO

2015 
Relatório de defesa pública de Tese do(a) Senhor(a) Elói Rufato Júnior no Programa: Engenharia Elétrica, do(a) Escola Politécnica da Universidade de São Paulo.

Aos 16 dias do mês de julho de 2015, no(a) realizou-se a Defesa da Tese do(a) Senhor(a) Elói Rufato Júnior, apresentada para a obtenção do título de Doutor intitulada:

"Aplicação de sistema especialista para localização de defeitos em redes de distribuição"

Após declarada aberta a sessão, o(a) Sr(a) Presidente passa a palavra ao candidato para exposição e a seguir aos examinadores para as devidas arguições que se desenvolvem nos termos regimentais. Em seguida, a Comissão Julgadora proclama o resultado:

$\begin{array}{llll}\text { Nome dos Participantes da Banca } & \text { Função } & \text { Sigla da CPG Resultado } \\ \text { Carlos Marcio Vieira Tahan } & \text { Presidente } & \text { EP - USP } \\ \text { Carlos César Barioni de Oliveira } & \text { Titular } & \text { Externo } \\ \text { Marcos Roberto Gouvea } & \text { Titular } & \text { EP - USP } \\ \text { Denis Vinicius Coury } & \text { Titular } & \text { EESC - USP } \\ \text { Mario Oleskovicz } & \text { Titular } & \text { EESC - USP } & \text { APROVADOD }\end{array}$

Resultado Final: a mavado

Parecer da Comissão Julgadora *

Eu, Elias Alves de Almeida com os(as) Senhores(as). São Paulo, ars 10 dias do mês de julho de 2015
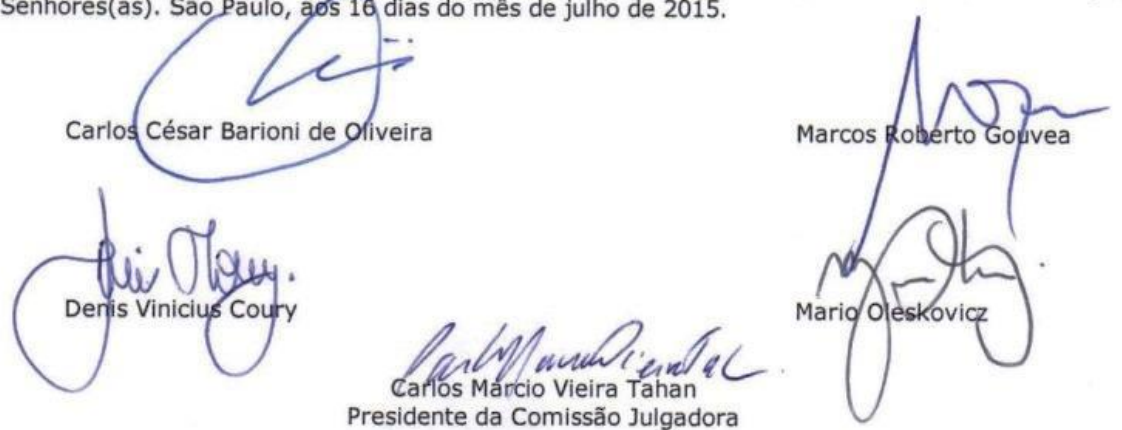

* Obs: Se o candidato for reprovado por algum dos membros, o preenchimento do parecer é obrigatório.

A defesa foi homologada pela Comissão de Pós-Graduação em e, portanto, o(a) aluno(a) faz jus ao título de Doutor em Ciências obtido no Programa Engenharia Elétrica - Área de concentração: Sistemas de Potência.

Presidente da Comissão de Pós-Graduação 


\section{ELOI RUFATO JUNIOR}

\section{APLICAÇÃO DE SISTEMA ESPECIALISTA PARA LOCALIZAÇÃO DE DEFEITOS EM REDES DE DISTRIBUIÇÃO}

Tese apresentada à Escola Politécnica da Universidade de São Paulo para obtenção do título de Doutor em Ciências

Área de Concentração:

Sistemas de Potência

Orientador: Prof. Doutor

Carlos Marcio Vieira Tahan

SÃo PAULO 
Este exemplar foi revisado e corrigido em relação à versão original, sob responsabilidade única do autor e com a anuência de seu orientador.

São Paulo de de

Assinatura do autor:

Assinatura do orientador:

Rufato Junior, Eloi.

Aplicação de sistema especialista para localização de defeitos em redes de distribuição / E. Rufato Junior - versão corr -- São Paulo, 2015. $103 \mathrm{p}$.

Tese (Doutorado) - Escola Politécnica da Universidade de São Paulo. Departamento de Engenharia de Energia e Automação Elétricas.

1.Sistemas elétricos de potência 2. Proteção de sistemas elétricos 3. Relés 4. Distribuição de energia elétrica 5 . Localização de faltas I.Universidade de São Paulo. Escola Politécnica. Departamento de Engenharia de Energia e Automação Elétricas II.t. 
Dedico este trabalho a quem sempre me incentivou, meus pais, Eloi e Eunice. E principalmente à Marli, minha amada esposa, e nossos filhos Leonardo e Fernando, pela compreensão nas horas que passamos distantes. 


\section{AGRADECIMENTOS}

Agradeço ao nosso Pai Eterno.

Ao Prof. Dr. Carlos Marcio Vieira Tahan pela sua orientação e experiência no Sistema Elétrico de Potência, que foram importantíssimas para a realização e finalização deste trabalho.

Ao Prof. Dr. Carlos César Barioni de Oliveira pelas suas orientações para tornar este trabalho concluído e no desenvolvimento de outros trabalhos relativos ao assunto. Ao Prof. Dr. Marcos Roberto Gouvea pelo seu auxílio no desenvolvimento deste trabalho e, principalmente pelo seu conhecimento do Sistema Elétrico de Potência nacional.

Ao Prof. Dr. Eduardo César Senger pelo auxílio durante suas aulas e esclarecimentos sobre o tema desenvolvido.

Ao Prof. Dr. Ernesto João Robba pelas suas orientações e esclarecimentos de dúvidas.

Ao Prof. Alden Uehara Antunes que muito me auxiliou no desenvolvimento de todo este trabalho, principalmente no desenvolvimento da ferramenta computacional para localização de defeitos.

Ao Mestre Marcos Koheler que colaborou nos trabalhos de pesquisa e desenvolvimento de Localização de Defeitos e Análises dos parâmetros de relés de proteção, os quais foram utilizados no desenvolvimento deste trabalho.

A todos os Professores da Universidade de São Paulo, da Escola Politécnica, das áreas Elétrica, Civil, Mecânica e Química, nas quais foram cursadas as disciplinas para realização deste trabalho.

À COPEL - Companhia Paranaense de Energia, objeto de estudo desta, em especial ao corpo gerencial, por ter me proporcionado a oportunidade de realizar o curso de doutorado e de desenvolver este trabalho que será utilizado na empresa pelos profissionais das áreas afins.

Esta tese foi desenvolvida com base em um projeto de P\&D gerenciado pela ANEEL e pela Copel. 
"Um trabalho bem feito é o mais alto testemunho que podemos dar de nosso caráter."

Orison Sweet Marden 


\section{RESUMO}

Com o objetivo de orientar e agilizar a busca do local de curto circuitos em redes primárias aéreas de distribuição de energia, esta pesquisa propõe uma metodologia para localização de áreas com maior probabilidade de ser sede do defeito, utilizando variáveis Heurísticas. A metodologia Heurística se aplica em problemas que envolvem variáveis com incertezas, que podem ser avaliadas por meio de recursos empíricos e na experiência de especialistas. Dentre as variáveis influentes no cálculo de curto circuito, foram consideradas como mais relevantes: a resistência de defeito, a tensão pré falta, a impedância do sistema equivalente a montante da subestação e a impedância da rede. A metodologia proposta se fundamenta no conhecimento das correntes e tensões oscilografadas no barramento da subestação por ocasião da ocorrência de um curto circuito e, por outro lado no pré-calculo de correntes de curto circuito heurísticas ao longo da rede. No âmbito da pesquisa foram realizados testes de campo para levantamento da variável heurística "resistência de defeito", resumidos neste texto e documentados no CD - ROM em anexo. Foi desenvolvido um software que permitiu a efetiva aplicação da proposta desta pesquisa em vários alimentadores de uma Distribuidora, cujos resultados comprovaram a eficiência da metodologia.

Palavras-chave: Sistemas Elétricos de Potência. Proteção de Sistemas Elétricos. Relés. Distribuição de Energia Elétrica, Localização de Faltas. 


\begin{abstract}
With the aim of guiding and speeding up the search of a short circuits place in primary networks of energy distribution this research proposes a methodology for locating higher probability areas of fault, making use of Heuristic variables. The Heuristic methodology is applied in problems that involve variables with uncertainties, which can be evaluated with empirical tools and specialists' experience. Among the influential variables in the short circuit calculation, as most relevant were considered: the fault's resistance, the pre fault tension, the equivalent system impedance upstream of the substation and the electrical grid impedance. The proposed methodology relies on the knowledge of currents and tensions oscillografed in the substation bus in consequence of a short circuit and, in another way on the pre calculation of heuristic short circuit currents along the grid. In the research scope field tests were performed with the aim of collecting the 'fault resistance' heuristic variable, resumed in this text and documented on the CD-ROM attached. A software that allowed the actual implementation of this research's purpose in various feeders of a distributor has been developed, with results that confirmed the efficiency of this methodology.
\end{abstract}

Keywords: Electric Power Systems. Protection of Electrical Systems. Relays. Distribution Systems, Faut Location. 


\section{LISTA DE ABREVIATURAS, SIGLAS E UNIDADES}

A

A/D

$\mathrm{A} / \mathrm{m}$

ABNT

ANEEL

ANSI

$\mathrm{BCl}$

BS

CA

$\mathrm{CC}$

c.c.

CLP

CPU

DEC

DFR

DLP

DNP

DSP

EC

EFT

EMC

$\mathrm{f}$

FEC

GE

GVR

IA, IB, IC, IN

ICC

IEC

IED

IEEE

IRV

ISO
- Ampéres

- Analógico - Digital

- Ampéres/metro

- Associação Brasileira de Normas Técnicas

- Agência Nacional de Energia Elétrica

- American National Standards Institute

- Injeção de Corrente de Rádio Frequência

- British Standard

- Corrente Alternada

- Corrente Contínua

- Curto circuito

- Controlador Lógico Programável

- Unidade Central de Processamento

- Duração Equivalente por Consumidor

- Registrador Digital de Sinais

- Proteção Digital de Linha

- Distribute Network Protocol

- Processador de Sinal Digital

- Estação de Chaves

- Transiente Elétrico Rápido

- Compatibilidade Eletro Magnética

- Frequência

- Frequência Equivalente por Consumidor

- General Electric

- Modelo de religador da Whipp\&Bourne

- Correntes de Fase e de Neutro

- Corrente de Curto Circuito

- International Eletrotechnical Commission

- Dispositivo Eletrônico Inteligente

- Institute of Electrical and Electronic Engineers

- Modelo de relé de Sobre corrente - ZIV

- International Organization for Standardization 


$\begin{array}{ll}\text { MTBF } & \text { - Mínimo Tempo entre Falhas } \\ \text { PCH } & \text { - Pequena Central Hidroelétrica } \\ \text { PCT } & \text { - Pequena Central Térmica } \\ \text { RMS } & \text { - Root Mean Square } \\ \text { RQE } & \text { - Registrador de Qualidade de Energia } \\ \text { RTU } & \text { - Remote Terminal Unit } \\ \text { S } & \text { - Segundos } \\ \text { SCADA } & \text { - Supervisory Control And Data Acquisition } \\ \text { SE } & \text { - Subestação } \\ \text { SEF } & \text { - Sensitive Earth Fault } \\ \text { SEL } & \text { - Schweitzer Engineering Laboratories } \\ \text { SEP } & \text { - Sistema Elétrico de Potência } \\ \text { SF6 } & \text { - Hexafluoreto de Enxofre } \\ \text { SFC } & \text { - Sequential Function Chart } \\ \text { TC } & \text { - Transformador de Corrente } \\ \text { TFD } & \text { - Transformada Discreta de Fourier } \\ \text { THD } & \text { - Total Harmonic Distortion } \\ \text { TIR } & \text { - Taxa Interna de Retorno } \\ \text { TP } & - \text { Transformador de Potencial } \\ \text { UAC } & \text { - Unidade de Aquisição e Controle } \\ \text { UCC } & \text { - Unidade Central de Controle } \\ \text { UTR } & \text { - Unidade Terminal Remota } \\ \text { V } & \text { - Volts } \\ \text { VA, VB,VC } & \text { - Tensões de Fase A, B e C } \\ \text { VN } & \text { - Tensão de Neutro } \\ \text { VF } & \text { - Tensão de Fase } \\ \text { VPL } & \text { - Valor Presente Líquido } \\ & \end{array}$




\section{LISTA DE FIGURAS}

Figura 1 - Sistema de distribuição de 25 kV da Saskpower, Canadá.......................20

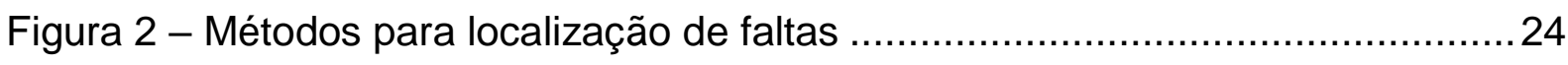

Figura 3 - Contornos de Vulnerabilidade ......................................................25

Figura 4 - Contorno de quedas de tensão para 3 pontos de medição ....................26

Figura 5 - Exemplo do aumento do nível de curto-circuito em função da contribuição

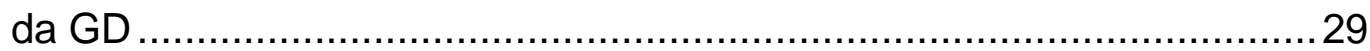

Figura 6 - Representação do sistema de distribuição a montante ..........................36

Figura 7 - Grau de pertinência em função dos valores possíveis da variável ..........37

Figura 8 - Grau de pertinência em função dos valores possíveis da solução ...........38

Figura 9 - Fluxograma das etapas da metodologia desenvolvida .........................42

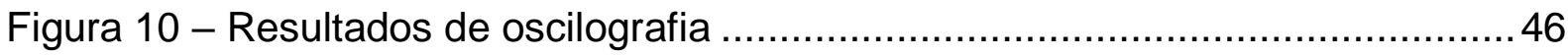

Figura 11 - Curto circuito fase terra - terra, baixa RF ........................................... 49

Figura 12 - Curto circuito fase terra - grama úmida..........................................50

Figura 13 - Curto circuito fase terra - pedra brita e cabo coberto ...........................50

Figura 14 - Curto circuito fase terra - cabo sobre árvore ......................................51

Figura 15 - Curto circuito fase terra - cabo sobre asfalto ……….........................52

Figura 16 - Representação gráfica de um alimentador e do menu .........................54

Figura 17 - Dados de entrada e cálculo de correntes rms ....................................55

Figura 18 - Tela para o cálculo do método determinístico ....................................56

Figura 19 - Resultados obtidos sobre a indicação das áreas prováveis ..................56

Figura 20 - Localizador de defeito (curto-circuito) com método Heurístico ...............57

Figura 21 - Alimentador Anita Garibaldi. Local do defeito (seta) e resultado da aplicação da metodologia heurística (tramos em vermelho $>90 \%$ de

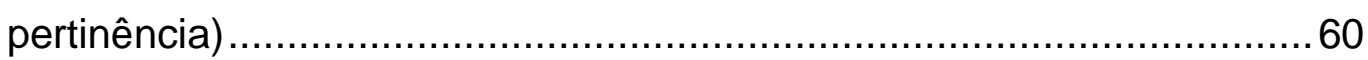

Figura 22 - Alimentador Barreirinha Local do defeito (seta).e resultado da aplicação da

Figura 23 - Alimentador Tanguá. Local do defeito (seta).e resultado da aplicação da

Figura 24 - Alimentador São João Local do defeito (seta) e resultado da aplicação da 
Figura 25 - Alimentador Oswaldo Cruz Local do defeito (seta) e resultado da aplicação da metodologia heurística (tramos em vermelho $>90 \%$ de pertinência)

Figura 26 - Alimentador Eletrofrio Local do defeito (seta) e resultado da aplicação da metodologia heurística (tramos em vermelho $>90 \%$ de pertinência) ......64

Figura 27 - Corrente de c. c. versus potência de c.c. da subestação.........................65

Figura 28 - Corrente de c.c. versus temperatura de operação dos condutores .......66

Figura 29 - Corrente de c.c. versus resistência de defeito ......................................66

Figura 30 - Diagrama unifilar do caso exemplo ……....................................... 80

Figura 31 - Relatório de eventos de um relé digital 351P - Whipp\&Bourne.............89

Figura 32 - Registro de sequência de eventos relé 351P Whipp\&Bourne.................91

Figura 33 - Oscilografia de relé digital - falta fase-terra ....................................93

Figura 34 - Oscilografia de tensões, correntes e digitais ...................................93

Figura 35 - Oscilografia de uma falta entre fases ............................................94

Figura 36 - Configuração do sistema de testes ..............................................97

Figura 37 - Pequena Central Hidroelétrica - PCH...........................................97

Figura 38 - Proteções Mínimas para Conexão de GD ...........................................98

Figura 39 - Oscilografia de correntes e tensões - teste 4 …............................. 100

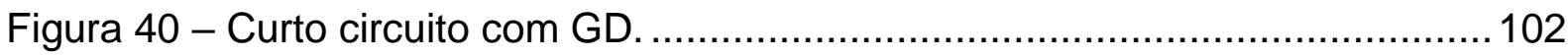

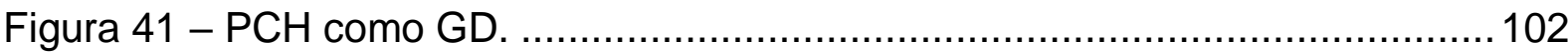




\section{LISTA DE TABELAS}

Tabela 1 - Resumo dos aspectos dos métodos de localização de faltas analisados 21

Tabela 2 - Influência da resistência de falta na classificação de barras....................22

Tabela 3 - Distribuição de faltas no sistema de distribuição ...................................34

Tabela 4 - Percentagem de faltas no sistema de distribuição ................................... 34

Tabela 5 - Valores de pertinências resultantes superiores a $0,6 \ldots \ldots \ldots \ldots \ldots \ldots \ldots \ldots \ldots . . . .45$

Tabela 6 - Valores de corrente em pu para os trechos em diferentes condições (A

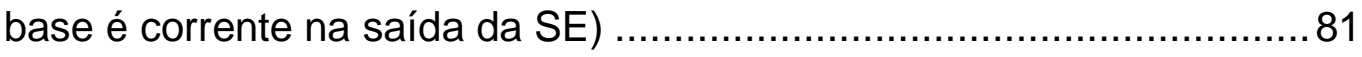

Tabela 7 - Informação da pertinência e valores para i e j …................................... 82

Tabela 8 - Valores finais da pertinência total e dos valores resultantes................... 82

Tabela 9 - Pertinências totais e multiplicadores da corrente para os 5 curto circuitos 83

Tabela 10 - Parte dos 35 valores de corrente de curto-circuito .............................. 85

Tabela 11 - Parâmetros dos cabos utilizados no alimentador estudado ..................87

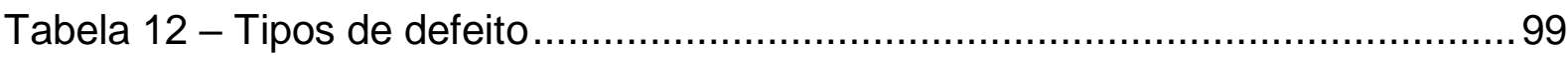

Tabela 13 - Tempos de atuação dos relés de proteção........................................101 


\section{SUMÁRIO}

1 INTRODUÇÃO

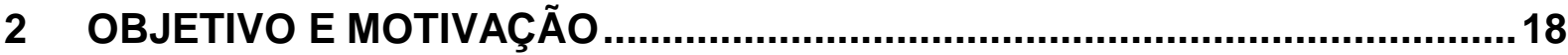

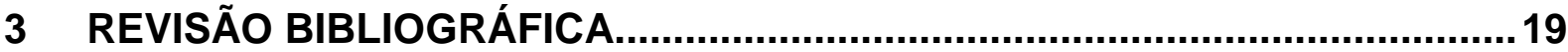

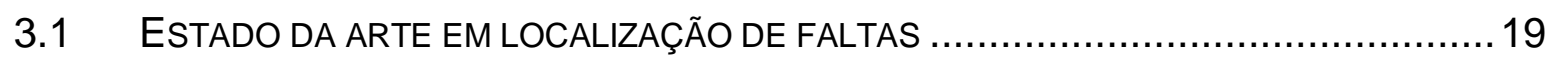

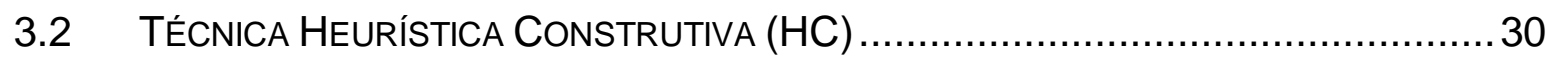

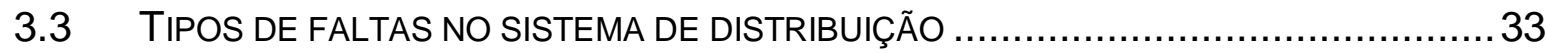

3.4 REPRESENTAÇÃO DO SISTEMA A MONTANTE DA REDE PRIMÁRIA .......................34

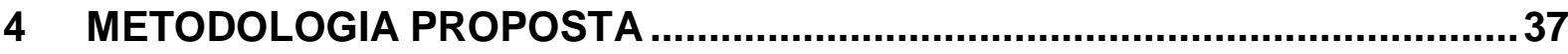

4.1 PROCEDIMENTOS HEURÍSTICOS EM PROBLEMAS COM INCERTEZAS .....................37

4.2 FONTES DE INCERTEZAS NO CÁLCULO DE CURTO-CIRCUITO..............................38

4.3 FORMULAÇÃO DO PROBLEMA E ENCAMINHAMENTO DA SOLUÇÃO.......................41

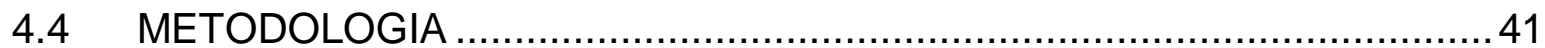

5 AVALIAÇÃO EXPERIMENTAL DE RESISTÊNCIA DE DEFEITO ....................48

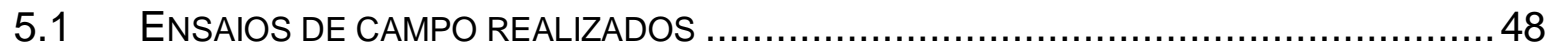

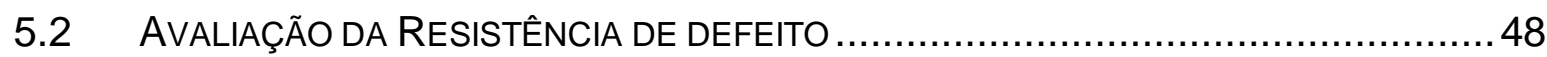

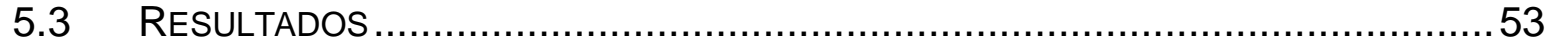

6 FERRAMENTA PARA APLICAÇÃO DA METODOLOGIA …..........................54

$7 \quad$ ESTUDO DE CASO

7.1 LoCALIZAÇÃo de DefEITOS REGISTRAdos EM ALIMENTADORES.......................59

7.2 Estudo PARAMÉTRICOS DE VARIÁVEIS HEURÍSTICAS ......................................64

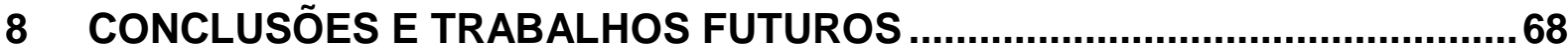

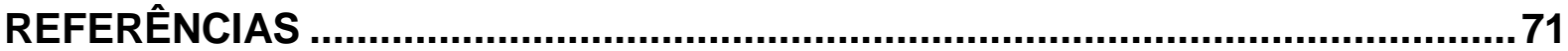

ANEXOS

ANEXO A: PUBLICAÇÕES ORIUNDAS DESTA PESQUISA...............................78

ANEXO B: CASO EXEMPLO

ANEXO C: DADOS UTILIZADOS NOS CASOS DE APLICAÇÃO DA FERRAMENTA. 
ANEXO D: DADOS OSCILOGRÁFICOS CONTIDOS NOS RELÉS DE PROTEÇÃO. 88 ANEXO E - ENSAIOS EXPERIMENTAIS COM GERAÇÃO DISTRIBUIDA.............96 


\section{INTRODUÇÃO}

A ANEEL - Agência Nacional de Energia Elétrica tem expressado o anseio da sociedade através de requisitos de continuidade do serviço de energia elétrica por meio de metas cada vez mais arrojadas. Isto evidencia que as Distribuidoras de energia necessitam buscar tecnologias que reduzam os tempos de atendimento no caso de falhas no sistema, sem prejuízo da segurança. Deste modo este trabalho prioriza o desenvolvimento de técnicas para redução do tempo de localização de defeitos, o qual, representa a maior parcela do índice que mede a continuidade: DEC - Duração equivalente de interrupção por consumidor.

Por outro lado, os relés digitais tem sido utilizados maciçamente nas subestações que alimentam os sistemas de distribuição de energia, graças a redução de custos proporcionados pela escala de produção e avanço tecnológico de equipamentos micro processados. Além da finalidade precípuo de proteção, esses equipamentos oferecem várias outras funcionalidades, dentre as quais o armazenamento de oscilografias de eventos.

A necessidade de redução do período de tempo para atendimento de ocorrências aliada às facilidades oferecidas pelos relés micro processados tem motivado o desenvolvimento de metodologias para agilizar a localização de defeitos na rede. Assim várias pesquisas tem sido realizadas, focadas via de regra, na localização de faltas em sistemas de transmissão de energia.

Dentro desse quadro, esta pesquisa busca contribuir com uma proposta metodológica para localização de faltas em sistema de distribuição, cujas características específicas operacionais, topológicas e de vulnerabilidade se diferenciam das do sistema de transmissão, o que impede a aplicação das metodologias desenvolvidas para este último .

No capítulo 3 é realizada revisão bibliográfica a partir da análise de principais artigos referentes ao problema de localização de faltas no sistema elétrico de potência. $\mathrm{Na}$ 
sequência é apresentada uma análise crítica dos métodos convencionais de cálculo de curto-circuito. Também são enfocados os aspectos básicos de métodos empregados para o tratamento das incertezas.

O capítulo 4 detalha a metodologia utilizada para o tratamento das incertezas inerentes ao cálculo de curto-circuito, baseada em métodos Heurísticos, aplicados na solução de problemas de sistemas de potência. No capítulo 5 há uma breve descrição de vídeos de ensaios de campo, realizados no âmbito desta pesquisa, para avaliação da resistência de defeito. Os vídeos encontram-se na mídia que corresponde ao suplemento desta tese, tendo como título "Testes de curto-circuito com Resistência de Defeito e Testes de curto-circuito com GD" - Geração Distribuída.

A ferramenta computacional, para a aplicação da proposta desta pesquisa, desenvolvida para a localização das áreas com probabilidade de incidência de defeitos em alimentadores primários está apresentada no capítulo 6.

O capítulo 7 contém a análise da aplicação da metodologia proposta nesta pesquisa em casos reais, com o emprego da ferramenta computacional desenvolvida. Esses casos tratam de defeitos ocorridos em alimentadores 13,8 kV da Copel - Companhia Paranaense de Energia, que cedeu gentilmente, as informações para a aplicação, inclusive dados oscilográficos coletados dos relés de proteção desses alimentadores.

O capítulo 8 apresenta as principais conclusões desta pesquisa, bem como propostas de prosseguimento de estudos referentes a temas que, embora identificados no transcorrer dos trabalhos, não foram explorados por não pertencerem ao seu núcleo .

Em anexo são apresentados:

- Anexo A - Publicações oriundas desta pesquisa

- Anexo B - Caso Exemplo

- Anexo C - Dados utilizados nos estudo de casos com aplicação da ferramenta

- Anexo D - Dados oscilográficos contidos em relés de proteção

- Anexo E - Ensaios experimentais com geração distribuída 


\section{OBJETIVO E MOTIVAÇÃO}

O objetivo deste trabalho é apresentar o desenvolvimento de metodologia para localização de regiões de ocorrência de curto-circuito em alimentadores primários de sistemas de distribuição, a partir de conhecimento da correspondente corrente de falta na subestação e de parâmetros pré-estabelecidos. Também são apresentadas as ferramentas para operacionalização da metodologia e diversas aplicações para comprovar sua eficácia.

A metodologia considera incertezas dos parâmetros envolvidos e se fundamenta em recursos de heurística, bem como em medições oscilográficas realizadas em tempo real na subestação que supre o alimentador com defeito.

As motivações principais deste trabalho são:

- a melhoria da qualidade de fornecimento pela redução dos tempos de atendimento de ocorrências em redes primárias contribuindo para a redução metas de continuidade exigida pelo Órgão Regulador, como a melhoria da imagem da Concessionária e;

- a redução dos custos operacionais resultantes da eficiência das equipes de campo, que usualmente dispendem significativos esforços para localização de defeitos, sobretudo em condições climáticas adversas, quando frequentemente ocorrem defeitos.

*O autor observa que colocou nesta tese grande parte de sua experiência como engenheiro de proteção, o que o motivou a deixá-la como herança didática. 


\section{REVISÃO BIBLIOGRÁFICA}

Das publicações analisadas durante a revisão bibliográfica, foram selecionadas as mais representativas para este trabalho de pesquisa e são expostas a seguir.

\subsection{Estado da arte em localização de faltas}

No artigo de Mora-Flórez, Meléndez e Carrillo-Caicedo (2008), os autores fazem uma análise e comparação do desempenho de 10 (dez) métodos de localização de faltas para sistemas de distribuição de energia. Os métodos analisados utilizam apenas medições de tensão e corrente na subestação.

A componente fundamental durante a pré-falta e falta são usados nos métodos para estimar a impedância aparente medida a partir do ponto de medição. O desvio entre impedância de pré-falta e de falta com os parâmetros do sistema são utilizados para estimar a distância até o ponto de falta.

Os modelos de métodos de localização de faltas selecionados pelos autores foram implementados e testados em uma rede de distribuição padrão correspondente a uma rede $25 \mathrm{kV}$ da Saskpower, Canadá. A Figura 1 representa um diagrama unifilar de um alimentador primário de distribuição onde foram simulados os 10 (dez) métodos de localização de faltas.

Nesse mesmo artigo são relatados os resultados dos cenários definidos através dos valores levantados para a localização de defeitos em alguns dos pontos da rede de distribuição. Para a simulação foi utilizado o software ATP - Alternative Transients Program.

Em todos os métodos testados foram considerados apenas defeitos no tronco do alimentador. Além disto, considerou-se tanto a variação da carga com a tensão e corrente, assim como carga como impedância constante. Nos cenários considerados 
neste artigo são simuladas faltas em 10 (dez) nós do alimentador principal, levando em consideração três valores de resistência de falta $(0,05 \Omega, 5 \Omega$ e $25 \Omega)$.

Figura 1 - Sistema de distribuição de 25 kV da Saskpower, Canadá

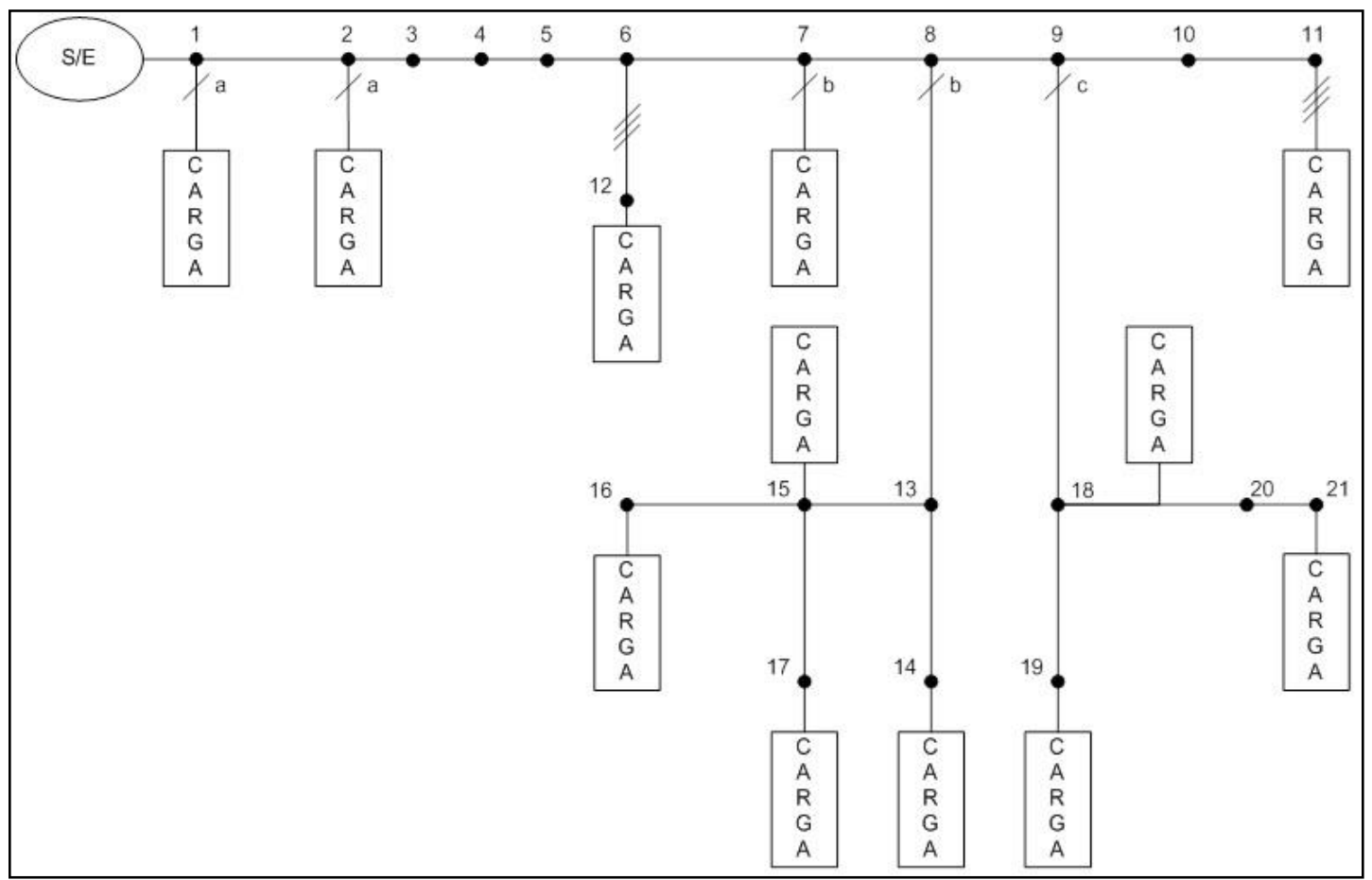

Fonte: (MORA-FLÓREZ, MELÉNDEZ E CARRILLO-CAICEDO, 2008) adaptado.

Na Tabela 1 são apresentados os principais aspectos dos métodos analisados. As variáveis analisadas pelos diversos métodos são: identificação e detecção da falta, processamento do sinal RMS pré e/ou pós falta, componentes simétricas ou componentes de fases, diversos modelos de linha de distribuição, diversos modelos da carga, sistema balanceado ou não.

$\mathrm{Na}$ sequência, são apresentadas as conclusões da pesquisa citada levando em conta o tipo de curto, a resistência de falta e a estimativa de erro em função da distância de localização da falta.

Para curto-circuito monofásico para a terra, os limites para os erros de estimação estão entre $-13,63 \%$ e 10,89\%, sendo os métodos Das (1998) e Choi et al (2004) como os melhores. Esses métodos não são muito influenciados pela distância a partir do ponto de defeito até a subestação de origem do alimentador. 


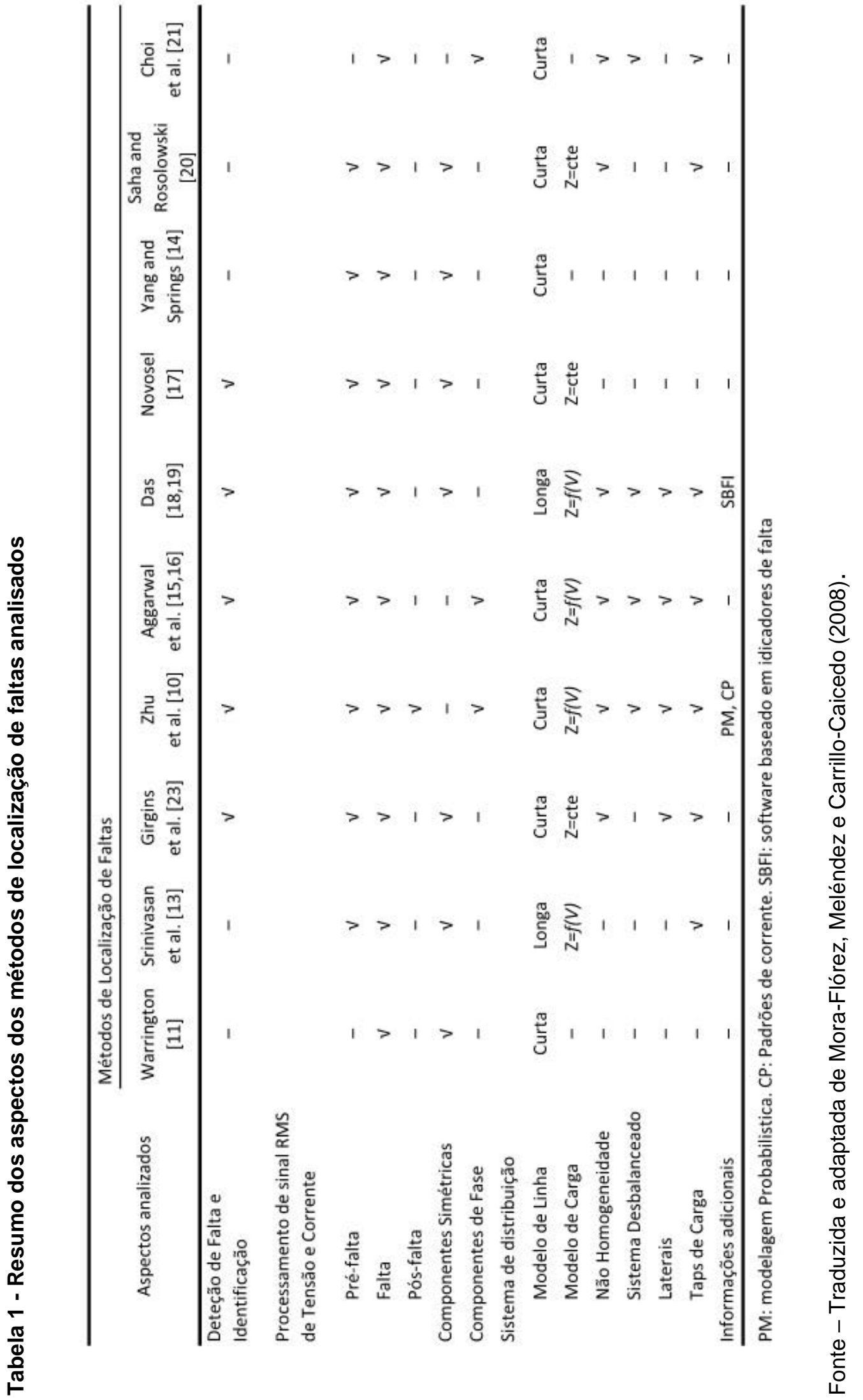


Para curto-circuito entre fase-fase, os métodos têm um desempenho um pouco melhor com erros que variam entre $-3,61 \%$ e $6,45 \%$. Sendo que os métodos propostos por Das (1998) e Girgis (1993) foram os de melhor resultado.

Para curto-circuito trifásico, alguns métodos podem ser aplicados, outros não dependendo das condições deste tipo de falta, sendo que os erros variam entre $1,48 \%$.e 1,97\%, sendo os métodos de Warrington, Srinivasan and St-Jacques e Das os que melhores resultados mostraram.

Como conclusão o método com melhor desempenho global é o proposto por Das (1998).

De acordo com a tese de doutorado de Bíscaro (2013), os valores da resistência de falta influenciam diretamente na eficiência dos algoritmos para localização de faltas em alimentadores radiais. No trabalho desenvolvido por esse autor, foram realizadas simulações de faltas em um alimentador modelo, com faltas na fase A para terra para todas as barras do sistema, variando-se o valor da resistência de falta de 5 ohms até 40 ohms, como pode ser observado na Tabela 2.

Dos 133 casos testados, mostrados na Tabela 2, 129 casos tiveram a probabilidade de $90 \%$ a $100 \%$ de serem localizados, quando a resistência de falta utilizada foi de 5 ohms.

Tabela 2 - Influência da resistência de falta na classificação de barras

\begin{tabular}{cccccc}
\hline $\begin{array}{c}\text { Probabilidade } \\
\text { (\%) }\end{array}$ & $\mathbf{5}$ & $\mathbf{1 0}$ & $\mathbf{2 0}$ & $\mathbf{3 0}$ & $\mathbf{4 0}$ \\
\hline $100-90$ & 129 & 112 & 108 & 96 & 96 \\
$90-80$ & 0 & 1 & 0 & 0 & 0 \\
$80-70$ & 0 & 0 & 0 & 2 & 0 \\
$70-60$ & 0 & 3 & 1 & 3 & 0 \\
$60-50$ & 0 & 10 & 1 & 9 & 0 \\
$50-0$ & 4 & 7 & 23 & 23 & 37 \\
\hline Total & 133 & 133 & $\mathbf{1 3 3}$ & $\mathbf{1 3 3}$ & $\mathbf{1 3 3}$ \\
\hline
\end{tabular}

Fonte: Bíscaro (2013). 
Aumentando a resistência de defeito para 40 ohms, foram localizados 96 casos com $90 \%$ a $100 \%$ de probabilidade, sendo que os demais 37 casos tiveram de $0 \%$ a $50 \%$ de probabilidade de localização.

Conforme conclui o autor dessa tese, observa-se claramente a influência da resistência de falta no resultado da localização do defeito, pois com o aumento desta ocorre uma redução da probabilidade da falta ocorrer na barra indicada. Isso se deve ao fato de que, com o aumento da resistência, os valores das correntes de curto-circuito diminuem, dificultando o processo de classificação das barras em falta.

Adicionalmente, o autor desta tese também realizou simulações de cálculos de correntes de curto-circuito e a localização das faltas nas barras simuladas, com a inserção de geração distribuída (GD) ao longo de um alimentador de distribuição radial. Sendo os mais comuns os geradores síncronos que não possuem controle de tensão (pequenos geradores diretamente conectados à rede).

Estes geradores fornecem uma potência constante para a rede elétrica, sendo modelados nos softwares de simulação como uma carga $P Q$ e fornecem corrente para o sistema de distribuição de energia com potências máximas de 2,0 MVA, que representaram $29,2 \%$ da potência total do circuito. Para geradores de porte maior (até $50 \mathrm{MVA}$ ), em geral, as distribuidoras determinam que devem ser conectadas com alimentadores exclusivos até a subestação mais próxima.

Através das simulações realizadas e apresentadas, o autor conclui que, em geral, a inserção da geração distribuída, com geradores síncronos, não traz grande influência na localização de faltas nos alimentadores de distribuição.

A tese de doutorado de Manassero (2006) mostra que há dois grupos principais de técnicas para a localização de falhas em sistemas de transmissão, conforme a Figura 2:

- grupo 1 - técnicas fundamentadas em ondas viajantes e;

- grupo 2 - técnicas baseadas no cálculo dos fasores de tensões e correntes. 
Estas técnicas utilizam como base registros de sinais coletados por oscilógrafos digitais instalados nos terminais das linhas de transmissão.

Figura 2 - Métodos para localização de faltas

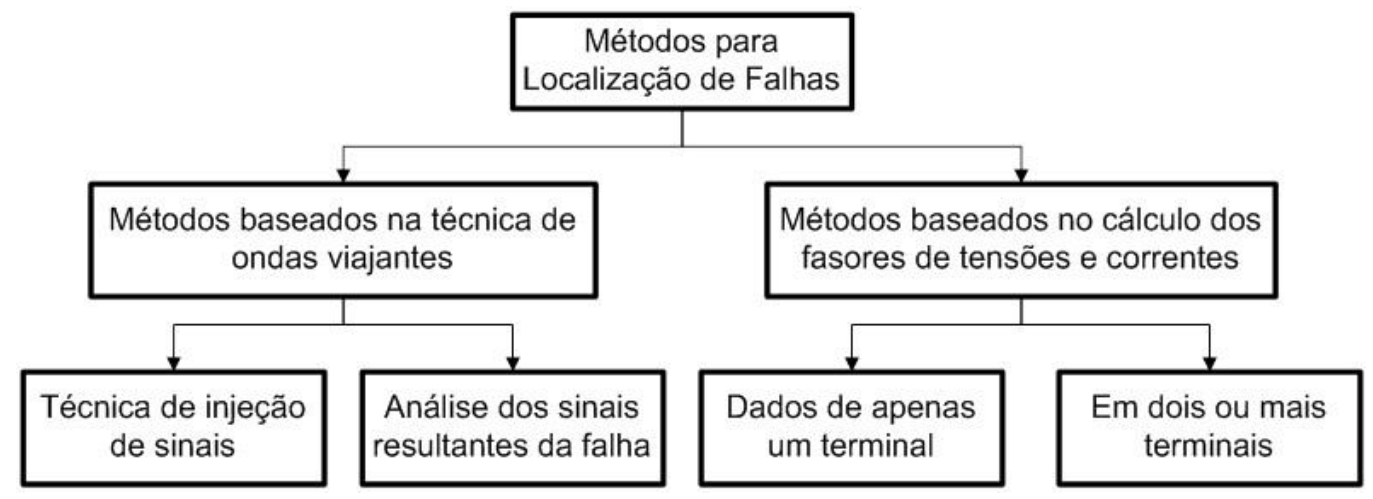

Fonte: (MANASSERO, 2006).

Ambos os grupos são aplicados a sistemas de transmissão não são adequados a sistemas de distribuição pelo grande quantidade de derivações.

No artigo de Galijasevic (2002) é proposto um método de localização de faltas utilizando medições de tensão, focado na redução da mesma tensão. Várias situações de sistemas operacionais (por exemplo, partida de grandes motores elétricos ou a ocorrência de faltas do sistema) podem levar a uma redução da tensão momentânea ou sustentada no sistema.

Para estimar e expressar a probabilidade de que algumas áreas do sistema de energia são afetadas pelo problema da redução de tensão, o conceito de área de vulnerabilidade tem sido desenvolvido e aplicado. Uma falta de curto-circuito, dependendo da localização e tipo, pode causar redução de tensão de diferentes níveis em um local de carga.

Por um lado, para faltas distantes, a carga pode ser submetida apenas a ligeira variação de tensão. Por outro lado, para faltas nas proximidades, a probabilidade de uma carga ser afetada será muito maior. Este fato pode ser convenientemente expresso usando contornos de vulnerabilidade, conforme mostrado na Figura 3. Um contorno de vulnerabilidade envolve os locais de falta para a qual é "nociva" a 
redução de tensão para uma determinada carga.

A ideia básica, proposta pelo autor, consiste em que, após o curto-circuito, a tensão do sistema pós-falta depende do sistema (topologia, elementos) e das características da falta (tipo, localização e parâmetros).

Tudo o mais sendo constante "Ceteris paribus", a redução de tensão é largamente determinada pela localização da falta. Se os valores esperados do afundamento são conhecidos com antecedência, a localização da falta pode ser determinada com base nos afundamentos de tensão medidos em um determinado número de locais.

Figura 3 - Contornos de Vulnerabilidade

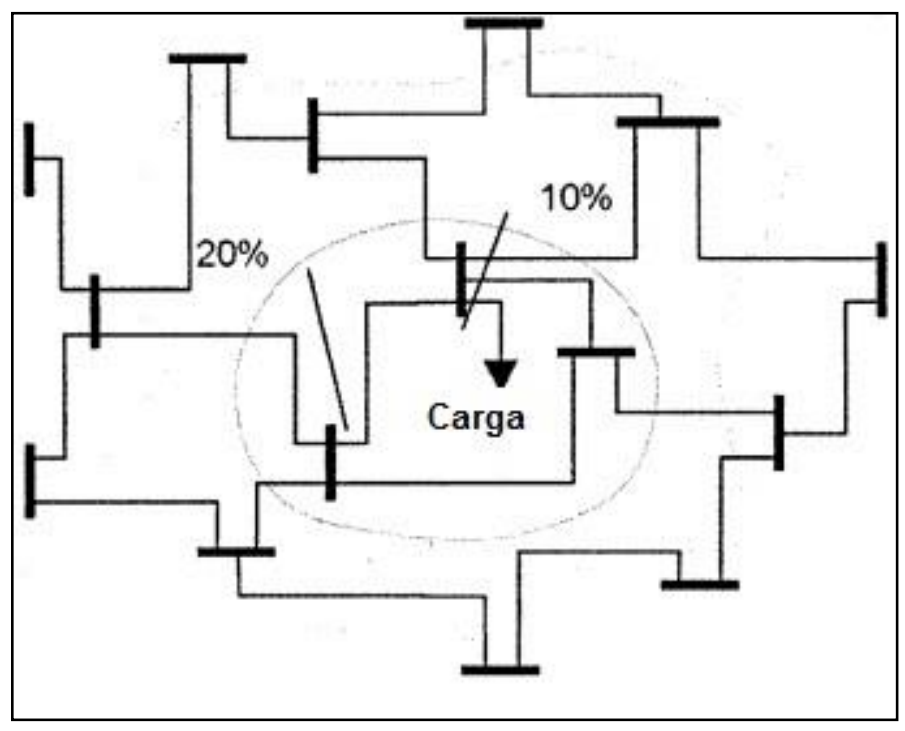

Fonte: (GALIJASEVIC, 2002).

Para ilustrar a ideia, o autor assume que os medidores de tensão são colocados em locais MP1, MP2, MP3 e em um sistema simples, conforme mostrado na Figura 4. 
Figura 4 - Contorno de quedas de tensão para 3 pontos de medição

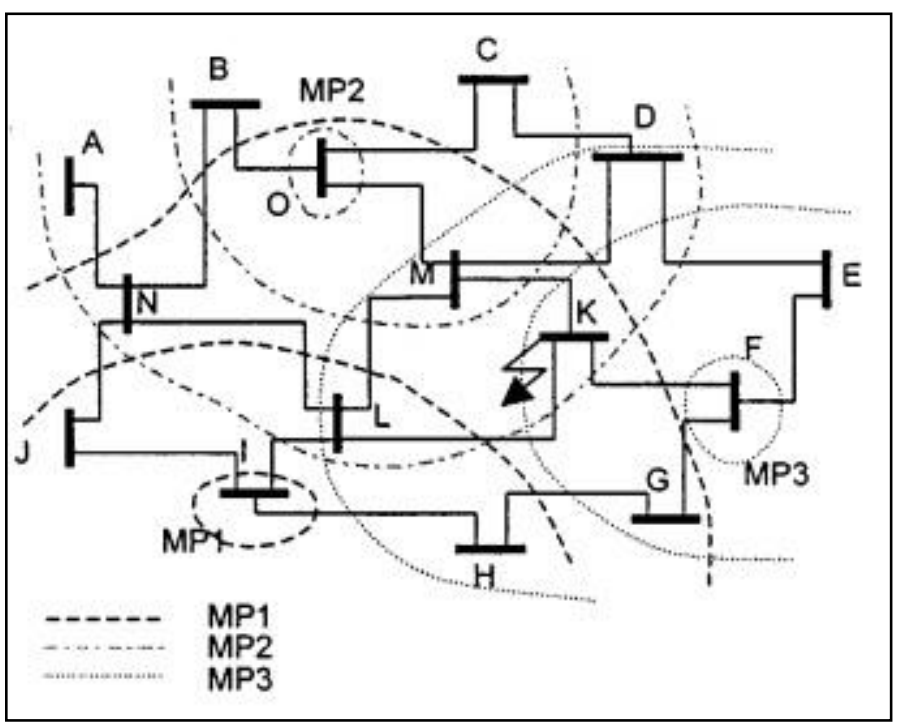

Fonte: (GALIJASEVIC, 2002).

O autor supracitado também considera que os contornos da redução de tensão são construídos através de uma série de simulações de curto-circuito. O contorno mais próximo de uma medição no ponto do local da falta que a circunda produz pelo menos $30 \%$ de afundamento em um determinado ponto.

Dois contornos exteriores circundam os locais que produzem $20 \%$ e $10 \%$ de quedas de tensão, respectivamente. Supondo que, após a falta ocorrer no local marcado com o símbolo da falta, os valores de "sag" de tensão seguintes são medidos em cada ponto de medição desta maneira:

MP1: 15\%.(Local de instalação do medidor de tensão 1)

MP2: 17\%.(Local de instalação do medidor de tensão 2)

MP3: 22\%.(Local de instalação do medidor de tensão 3)

A localização de faltas no ponto (K) é estimada por encontrar a interseção dos contornos que correspondem às medidas:

MP1: G, K, M, O, N.

MP2: A, N, L, K, D;

MP3: E, K, G. 
Para a estimativa da localização: assumir uma falta trifásica sólida no local. A tensão no local pode ser calculada utilizando a Equação 1.

$$
V_{i, k}^{c a l}=V_{f} \frac{Z_{i k}}{Z_{k k}}
$$

Onde:

$V_{f}=$ Tensão nominal do sistema.

$Z_{i k}=(i, k)$-ésimo elemento da matriz da impedância local.

$Z_{k k}=(k, k)$-ésimo.elemento da matriz da impedância local.

O cálculo de tensão acima é repetido para cada local de medição.

Um procedimento para encontrar a localização do defeito pode ser então descrito da seguinte forma:

Após ocorrer e detectar a falha, a queda de tensão é medida no local em cada ponto de medição $\left(i=0,1,2, \ldots, N_{m}\right)$.

Calcula-se a tensão para todos os locais medidos $\left(i=0,1,2, \ldots, N_{m}\right)$, assumindo que a falha ocorre em todos os outros locais $\left(k=0,1,2, \ldots, N_{b}\right)$, um local por vez.

Calcular a diferença entre magnitudes das tensões calculadas e medidas.para cada $(\mathrm{i}=0,1,2$, ..., $\mathrm{N}_{\mathrm{m}}$ ).

$$
\delta_{i, k}=\left|V_{i, k}^{c a l}\right|-\left|\bar{V}_{i}^{\text {meas }}\right|
$$

Estima-se o local com defeito, minimizando a diferença $\delta_{i 2}$ sobre todos os locais de falha possível "K" para cada ponto de medição "i".

$$
\left|I_{i}=k \ni \operatorname{Min}\left\{\delta_{i, k}\right\}\right|
$$

Aceita-se a estimativa mais frequentemente obtida " $l_{i}$ " como o local mais provável da localização do defeito.

Este método proposto pode ser empregado em sistemas de distribuição de energia. Uma desvantagem apresentada é de necessitar de vários equipamentos de medição 
de tensão e um sistema robusto de transmissão de dados desde os pontos de medição até uma central de armazenamento e tratamento dos dados.

O método não foi julgado viável, devido ao custo elevado de implantação, principalmente pelos valores de transformadores de potencial e medidores a serem instalados em cada ponto, no sistema de média tensão, por isso, não foi considerada a sua aplicação neste desenvolvimento.

O método proposto no artigo Senger (1998) descreve um sistema de localização de faltas em redes primárias de distribuição, que consiste na utilização de oscilógrafos digitais instalados na subestação, cujo sinal de disparo dos registros de oscilografia opera por sobre corrente, registrando tensões e correntes nas três fases medidas na subestação.

Com as medições dessas grandezas nos momentos de pré-falta e pós-falta, determinam-se os fasores correspondentes e o tipo de falta. Depois disso uma rotina de localização de faltas gera pontos de teste a cada 50 metros ao longo do alimentador.

Para cada um desses pontos, é calculada a corrente de falta que, injetada no ponto, produziria as tensões e correntes medidas na subestação, baseada nos princípios da superposição e das componentes simétricas. Para isso, utiliza-se uma base de dados com informações sobre a topologia e os parâmetros elétricos do alimentador.

Por fim, é feita a seleção do ponto de falta, observando o valor da corrente de falta em todos os pontos de teste. Se o defeito for assimétrico, este pode ser localizado ao observar o valor da corrente de falta nas outras fases, que deve ser zero.

Esse método apresenta boa aceitação apenas para redes radiais equilibradas, conectadas através de transformadores delta-estrela, sendo essa a principal desvantagem desse método. 
Como o objetivo inicial deste trabalho era atender alimentadores em delta no secundário dos transformadores de distribuição, este método não foi considerado aplicável.

Na dissertação de mestrado de Luiz (2012), a autora realiza uma análise que aborda a influência dos níveis de curto-circuito com a.inserção de geração distribuída em alimentadores de distribuição.

A contribuição para uma falta de uma pequena unidade GD não é grande, no entanto, ressalta a autora, que as contribuições agregadas de muitas unidades pequenas, ou poucas unidades grandes, podem alterar os níveis de curto-circuito de forma a causar descoordenações, afetando a confiabilidade e segurança do sistema de distribuição.

Como exemplo, mostra-se na Figura 5 a distribuição das correntes em um alimentador típico com derivações protegidas por fusíveis.

Figura 5 - Exemplo do aumento do nível de curto-circuito em função da contribuição da GD

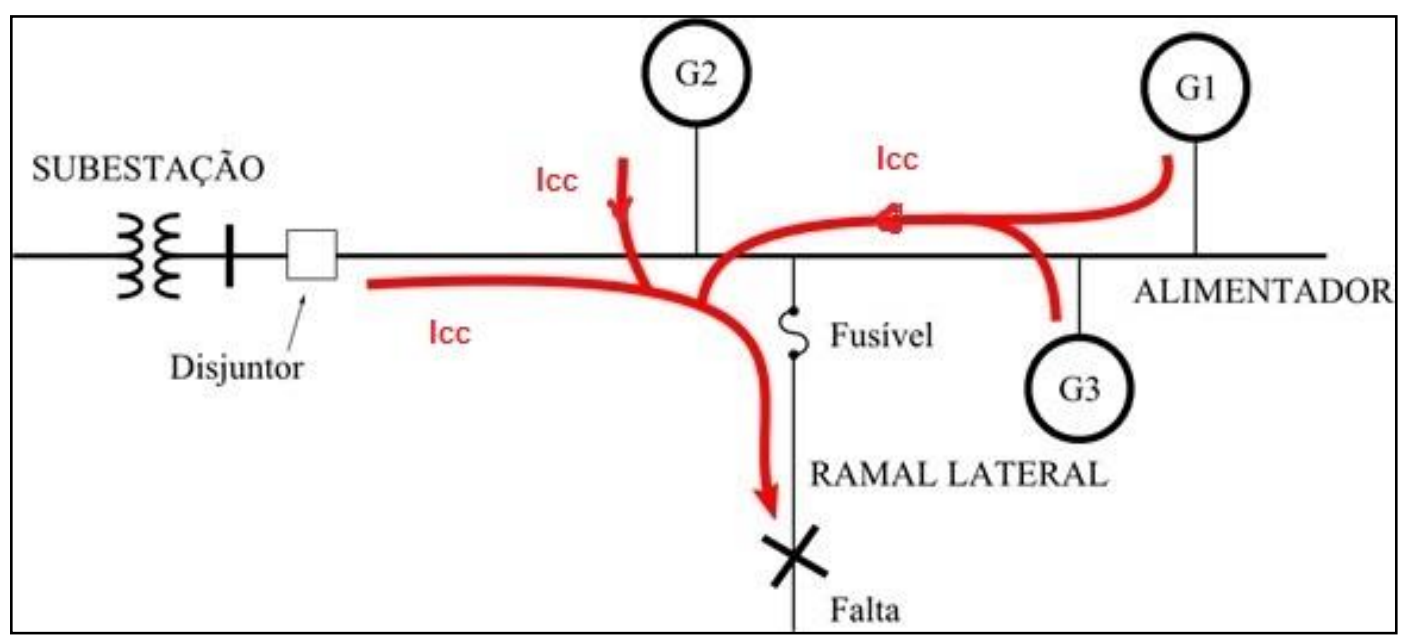

Fonte: Adaptado de (LUIZ , 2012).

$\mathrm{Na}$ dissertação ressalta-se que o incremento no nível de curto-circuito dependerá do tipo de máquina que compõe a unidade de Geração Distribuída (GD). Para geradores síncronos, a contribuição dependerá da tensão pré-falta, das reatâncias sub transitória e transitória da máquina e das características da excitatriz. 
Já geradores de indução contribuem para faltas enquanto permanecem girando em função da tensão residual no alimentador. Para esses geradores, a contribuição duraria apenas alguns ciclos e é determinada pela divisão da tensão pré-falta e a reatância transitória da máquina.

Uma observação importante levantada nessa dissertação é que a contribuição dos geradores para as correntes de falta também será mais significativa em redes urbanas, compostas por circuitos de baixa impedância, do que em redes rurais, caracterizadas por impedâncias altas, com níveis de curto-circuito menores.

A autora conclui, em seu trabalho, que em redes rurais a inserção da unidades de GD pode ser benéfica. Isso porque em circuitos com alta impedância, nos quais a corrente de falta é muito similar à condição de carga, uma elevação do nível do curto-circuito resulta na possibilidade de melhor diferenciação entre as duas situações.

\subsection{Técnica Heurística Construtiva (HC)}

Nesta seção é apresentado um estado da arte relacionado com a conceituação das técnicas heurísticas e suas aplicações:

Conforme a definição do livro Bazeman, 2004), heurísticas são estratégias simplificadoras ou regras práticas que as pessoas se utilizam ao tomar decisão.

Para Hammond, Keeney e Raiffa (2008) heurísticas são "rotinas inconscientes para lidar com a complexidade inerente da maioria das decisões".

Para os autores Zanakis e Evans (1981 apud Fritzen, 2012), a palavra heurística é derivada do grego "heuriskein" e significa descoberta ou aquilo que serve para descobrir.

$\mathrm{Na}$ análise deste mesmo trabalho, as heurísticas são algoritmos que apresentam bons desempenhos ou soluções factíveis de modo fácil e rápido para vários 
problemas. O que também é encontrado nos trabalhos de Goldbarg e Luna (2005 apud Fritzen, 2012), que descrevem que as heurísticas são capazes de garantir boas soluções ou até mesmo a solução ótima, especialmente nas ocasiões em que a busca se inicia a partir de uma solução viável próxima do ótimo.

$\mathrm{Na}$ tese de doutorado Fritzen (2012), para o autor, a heurística construtiva (HC) é um procedimento desenvolvido através de um modelo cognitivo, usualmente através de regras baseadas na experiência dos desenvolvedores.

Ao contrário dos métodos exatos, que buscam encontrar uma forma algorítmica na busca de uma solução ótima através da combinação ou busca de todas as soluções possíveis, as heurísticas normalmente tendem a apresentar certo grau de conhecimento acerca do comportamento do problema, gerando um número muito menor de soluções.

$\mathrm{O}$ autor desta tese enfatiza que, uma $\mathrm{HC}$, de modo geral, consiste em tentar encontrar uma boa resposta a um determinado problema, considerando a cada iteração somente o próximo passo, ou seja, o critério de escolha é basicamente local.

O ponto de partida é uma solução vazia e, a cada passo da construção, um conjunto de dados é considerado, inserindo sempre um dado de cada vez, até que a solução esteja completa.

Algoritmos construtivos não possuem nenhum esquema de backtracking, ou seja, após inserir um dado, não é possível retirá-lo da solução.

Os métodos heurísticos englobam estratégias, procedimentos e métodos aproximativos com o objetivo de encontrar uma boa solução, mesmo que não seja a ótima, em um tempo computacional razoável.

O autor também esclarece que se espera que uma heurística seja projetada de forma a almejar soluções que sejam próximas da solução ótima para o problema e que sejam solucionadas em curto espaço de tempo. 
A heurística "construtiva gulosa" é a forma mais simples e mais utilizada para se projetar uma heurística construtiva para um problema de otimização, pois parte-se de uma solução vazia e adiciona-se sequencialmente elementos à solução através de algum critério (função de avaliação) guloso. Ao final, é gerada uma solução viável.

Em sua conclusão sobre heurística construtiva Fritzen (2012 apud Diaz et al., 1996) descrevem 5 (cinco) fatores que relatam a utilização da HC na resolução de problemas do sistema elétrico de potência, com incertezas, dentre as quais os 2 (dois) que mais se empregam na solução dos problemas propostos para utilização da técnica de localização de faltas, alvo desta tese, são:

- quando não existe um método exato para a resolução deste problema ou o mesmo requer um tempo muito alto de processamento. Neste caso, oferecer uma solução boa é melhor do que não ter nenhuma solução;

- quando limitações de tempo e/ou custos obriguem a utilização de métodos de resposta rápida.

Estes fatores fazem parte das características que levaram a escolha desta técnica heurística para o desenvolvimento do sistema de localização de áreas com faltas desta tese.

Conforme a dissertação de mestrado Wirmond (2009), um algoritmo é considerado um método heurístico quando não há conhecimentos matemáticos completos sobre seu comportamento, ou seja, quando, sem oferecer garantias, o algoritmo procura resolver problemas complexos utilizando uma quantidade não muito grande de recursos, especialmente no que diz respeito ao consumo de tempo para encontrar soluções de boa qualidade.

Conforme Gerbex (2001 apud Wirmond, 2009), os métodos Heurísticos podem ser usados para resolver problemas de otimização combinatória. Os algoritmos heurísticos buscam a solução dentro de um subespaço de um espaço de busca total. Dão uma boa solução em um tempo computacional razoável podendo 
convergir para mínimos ou máximos locais. A maior vantagem está em não serem limitados por restrições no espaço de busca como continuidade ou existência da derivada da função custo (GERBEX, 2001).

Para Sucupira (2004 apud Wirmond, 2009), os métodos Heurísticos construtivos definem de forma meticulosa o valor de cada componente da solução. O método GRASP (em inglês, Greedy Randomized Adaptive Search Procedure) é o mais citado: cada interação é composta por uma fase construtiva e uma fase de busca por entornos.

A cada passo da fase construtiva selecionam-se os componentes que causam melhor efeito se adicionados à solução atual e em seguida acrescenta-se um desses elementos, selecionado aleatoriamente à solução.

Segundo Mendel (1992), para a maior parte dos problemas em sistemas de potência existem dois tipos de conhecimentos envolvidos: os objetivos que são facilmente modelados através de técnicas matemáticas e os subjetivos, impossíveis de serem modelados pelos métodos matemáticos tradicionais.

Através das análises anteriormente realizadas, verificou-se que a técnica da heurística construtiva $(\mathrm{HC})$ é uma boa técnica, dentre as quais, foi a escolhida para ser aplicada neste trabalho para a localização de defeitos nos alimentadores primários de distribuição, pois utiliza poucos recursos computacionais e converge para uma solução buscada como ótima em um tempo relativamente curto, quando comparada com outras técnicas de análises estudadas no sistema elétrico de potência.

\subsection{Tipos de faltas no sistema de distribuição}

Registros históricos obtidos na Companhia Paranaense de Energia. - COPEL e relatados em relatórios específicos trazem informações interessantes sobre os tipos de defeitos que ocorrem e a distribuição estatística de causas, em sistemas aéreos de distribuição, conforme mostram as Tabela 3 e Tabela 4 a seguir. 
Tabela 3 - Distribuição de faltas no sistema de distribuição

\begin{tabular}{llll}
\hline & Total & Permanentes & Transitórias \\
\hline Trifásicos & $2 \%$ & $95 \%$ & $5 \%$ \\
Bifásicos & $11 \%$ & $70 \%$ & $30 \%$ \\
Fase/terra & $79 \%$ & $20 \%$ & $80 \%$ \\
Outros & $8 \%$ & & \\
\hline
\end{tabular}

Fonte: Relatórios estatísticos da Copel (2010).

Nessas tabelas observa-se a elevada quantidade de defeitos transitórios, fase-terra e a grande incidência de defeito originários de "árvores e ventos".

Tabela 4 - Percentagem de faltas no sistema de distribuição

\begin{tabular}{ll}
\hline Causa & Percentagem \\
\hline Árvores e ventos & $46 \%$ \\
Descargas atmosféricas & $19 \%$ \\
Falhas de equipamentos & $11 \%$ \\
Erro humano & $9 \%$ \\
Falhas de isoladores & $6 \%$ \\
Objetos estranhos & $2 \%$ \\
Outras causas & $6 \%$ \\
\hline
\end{tabular}

Fonte: Relatórios estatísticos gerados na Copel (2010) e Kindermann (1992).

\subsection{Representação do sistema a montante da rede primária}

Para representação dos sistemas de geração, transmissão, subtransmissão e subestação, a montante da barra inicial do circuito primário (barra de média tensão da subestação de distribuição), são utilizados equivalentes de rede. Tais equivalentes de rede podem ser dados em termos das impedâncias equivalentes de sequência direta e de sequência zero ou, mais usualmente, através dos dados das 
potências de curto-circuito trifásico e curto-circuito fase-terra na barra de média tensão da subestação.

As impedâncias sequenciais em "pu" ( $z_{t}$-impedância equivalente de sequência positiva, $z_{2}=z_{1}$ - impedância equivalente de sequência negativa e $z_{0}$-impedância equivalente de sequência zero), podem ser obtidas diretamente dos dados de potência de curto-circuito trifásico $\left(S_{3 \phi}\right)$ e fase-terra $\left(S_{\phi T}\right)$, como estes:

$$
z_{1}=z_{2}=\frac{S_{\text {Base }}}{S_{3 \emptyset}^{*}} \quad \text { e } \quad z_{0}=3 \frac{S_{\text {Base }}}{S_{\emptyset T}{ }^{*}}-2 \frac{S_{\text {Base }}}{S_{3 \emptyset}{ }^{*}}
$$

Onde: $S_{\text {Base }}=$ valor adotado de potência de base.

Normalmente os cálculos tradicionais de curto circuitos consideram Z1 $=$ Z2, entretanto isto não é verdade, pois, com máquinas girantes X1 é diferente de X2.

A Figura 6 apresenta uma representação do sistema de distribuição a montante. Considerando que os sistemas a "montante" do defeito são sistemas de Alta Tensão - AT, Extra Alta Tensão - EAT e Ultra Alta Tensão - UAT, e que nestes sistemas as correntes de curto circuito são da ordem de alguns ampéres até 50/60 kA e, portanto, fica praticamente impossível prever qual corrente será injetada em cada caso, pois depende de parâmetros como: número de unidades despachadas, número de unidades de carga leve, média e pesada, entre outros fatores. 
Figura 6 - Representação do sistema de distribuição a montante

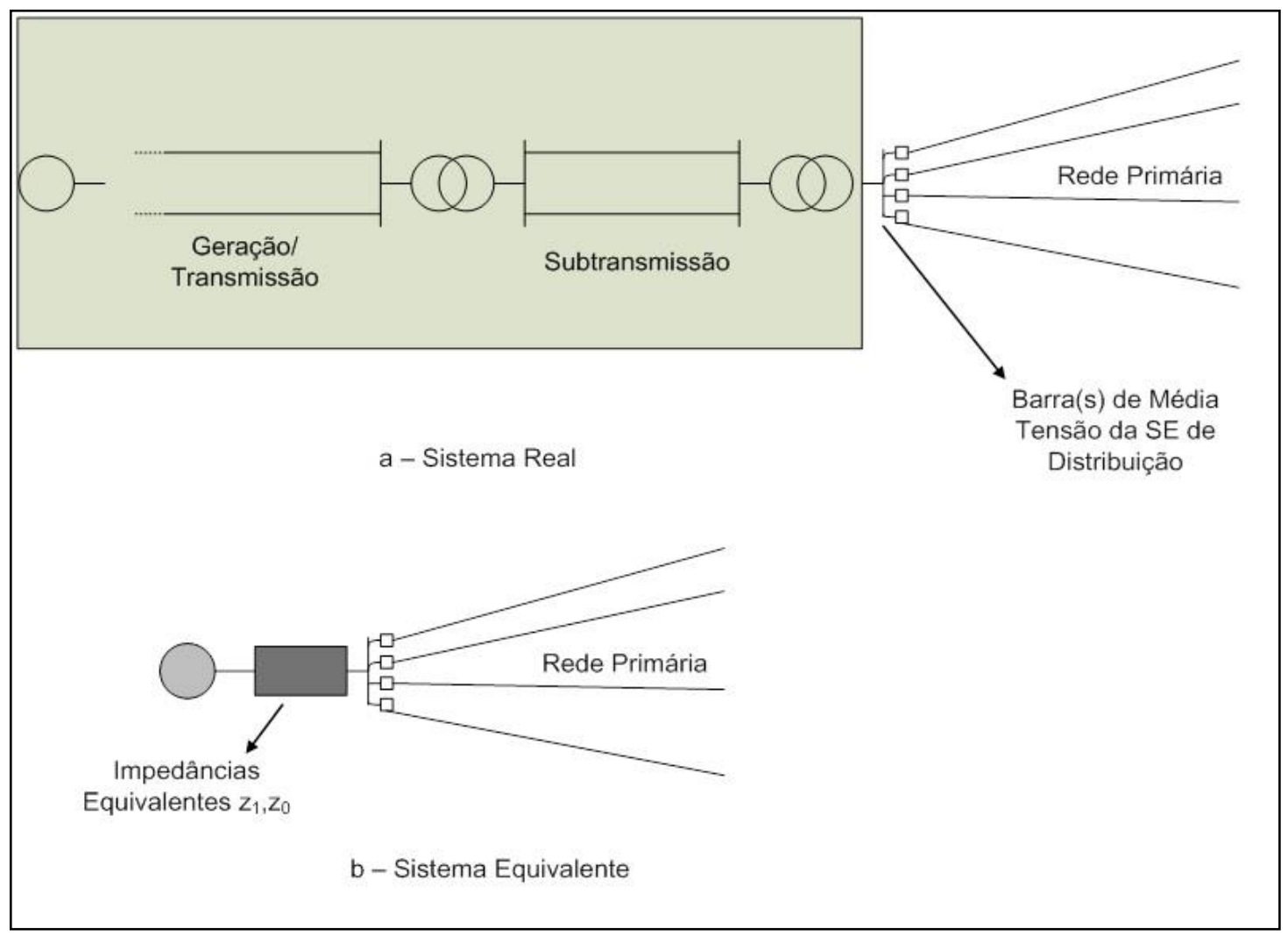

Fonte: Elaborada pelo autor. 


\section{METODOLOGIA PROPOSTA}

\subsection{Procedimentos heurísticos em problemas com incertezas}

A solução determinística $S$ de um problema que depende das variáveis a(i), $\mathrm{i}=1, \mathrm{n}$ pode ser representado por:

$$
\mathrm{S}=\mathrm{S}\{\mathrm{A}(\mathrm{i})\}, \quad \mathrm{i}=1, \mathrm{n}
$$

Se cada uma das variáveis a(i) apresentarem incertezas, então poderão ser representadas por enuplas de pares, onde.o primeiro elemento de cada par é um valor possível.de $A(i)$ e o segundo é o seu grau de pertinência. Assim:

$$
A(i)=A\{\text { ha }(i, j), \text { pa }(i, j)\}, \quad j=1, n(i)
$$

Onde;

ha $(i, j)$ - é o valor da variável $A$ (i).com grau de pertinência. pa ( $i, j$ ). $\}$.

.$n 1$ - é a quantidade de pares que definem a incerteza da variável $A(i)$

Graficamente isso pode ser ilustrado pela Figura 7.

Figura 7 - Grau de pertinência em função dos valores possíveis da variável

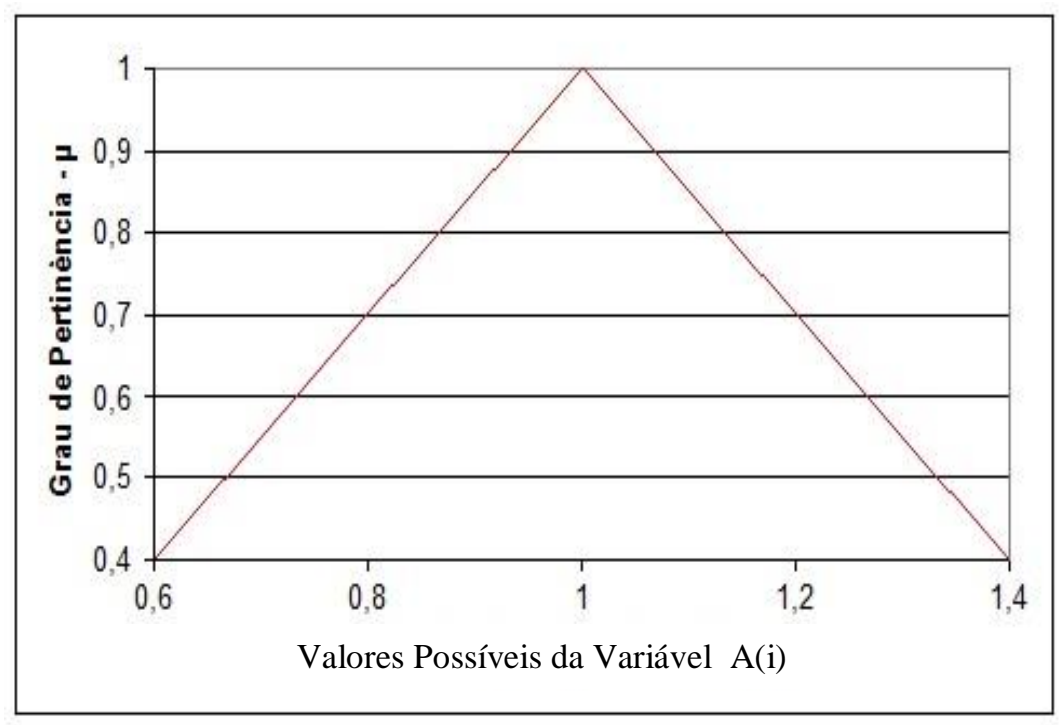


Fonte: Elaborada pelo autor.

Onde o valor 1 da variável corresponde ao grau de pertinência 1, valor 1,2 da variável corresponde ao grau de pertinência 0,7 e assim sucessivamente.

Portanto, enquanto havia apenas uma solução determinística $S$ para uma enupla da variáveis $\{\mathrm{A}(\mathrm{i})\}, \mathrm{i}=1, \mathrm{n}$ haverá $\mathrm{n}(1) \times \mathrm{n}(2) \times \ldots \ldots \ldots . . \times \mathrm{n}(\mathrm{n})$, soluções $\mathrm{S}(\mathrm{k})$ correspondendo às soluções resultantes de todas as possíveis combinações de valores. A cada solução assim obtida é associada a pertinência (ao conjunto de soluções) definida pelo produto das correspondentes pertinências de cada variável, conforme ilustrado na Figura 8.

Figura 8 - Grau de pertinência em função dos valores possíveis da solução

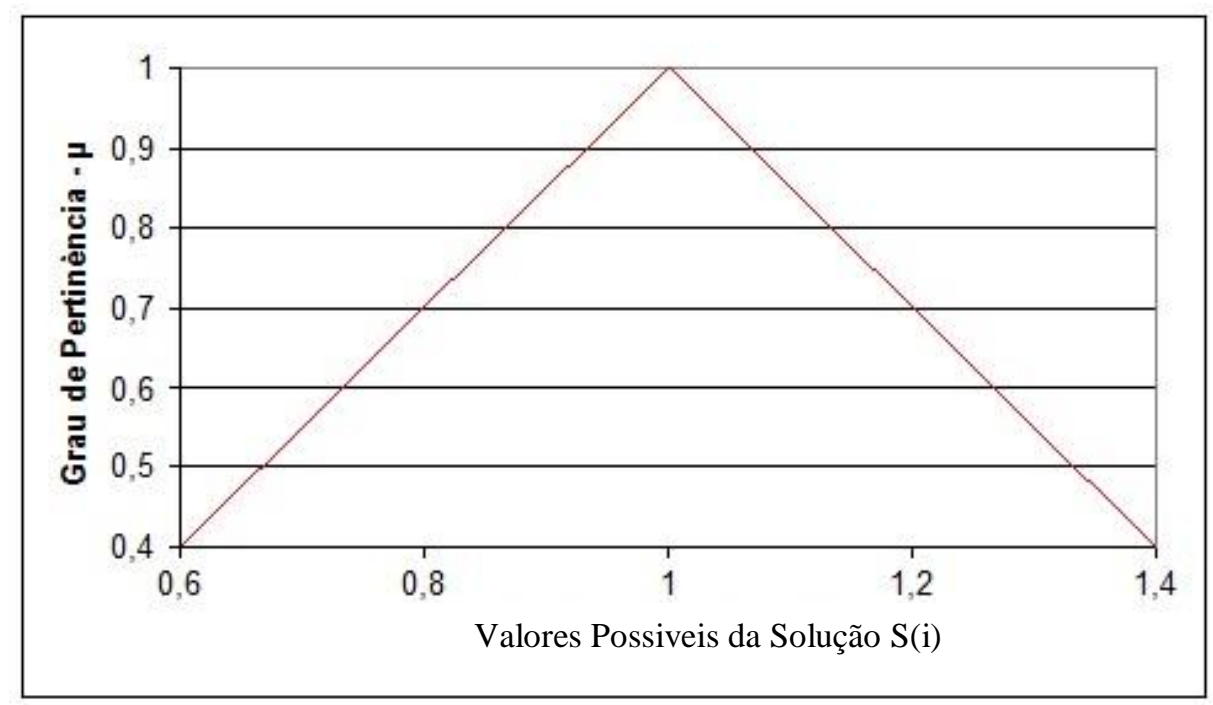

Fonte: Elaborada pelo autor.

Assim, se por exemplo, houver 3 variáveis com incertezas, com 5 possíveis valores e correspondentes pertinências para cada uma delas, haverá soluções $S(i)$, i =1,125 soluções heurísticas.

\subsection{Fontes de incertezas no cálculo de curto-circuito}

As modelagens utilizadas em cálculos de curto-circuito se fundamentam em vários parâmetros para representação da rede e das condições em que ocorrem as faltas 
que, por sua própria natureza encerram incertezas, ensejando, usualmente a adoção de valores típicos.

Por conseguinte, os resultados obtidos desse cálculo com esses valores determinísticos, negligenciando a incerteza são susceptíveis à erros, que variam de acordo com a importância do parâmetro no cálculo e com a imprecisão do parâmetro adotado, impactando diretamente no ajuste do sistema proteção da rede, podendo ocasionar tanto atuações indevidas como a não sensibilização desses dispositivos.

Considerando a formulação clássica para cálculo de curto-circuito, conforme apresentado a seguir:

Defeito trifásico:

$i_{3 \Phi}=\frac{V_{\text {pré-falta }}}{z_{1, \text { sistema }}+z_{1, \text { condutor }}}(\mathrm{pu})$

Defeito fase- fase:

$\left|i_{2 \Phi}\right|=\frac{\sqrt{3}}{2}\left|i_{3 \Phi}\right|(\mathrm{pu})$

Defeito fase-terra com impedância de defeito:

$$
i_{\Phi T}=\frac{3 x V_{\text {pré-falta }}}{2\left(z_{1, \text { sistema }}+z_{1, \text { condutor }}\right)+\left(z_{0, \text { sistema }}+z_{0, \text { condutor }}\right)+3 z_{\text {Def. }} \quad \text { (pu) }}
$$

No defeito dupla-fase-terra tem-se 2 valores de corrente, uma para a terra e outra entre as 2 fases em defeito.

Observa-se que as variáveis que trazem consigo incertezas e que, potencialmente, podem apresentar impacto importante nos resultados de curto circuito são: 
Resistências de defeito: o contato de condutor energizado com o solo ou outra superfície com diversos graus de aterramento resulta em diferentes valores de resistência de contato e consequentemente, de resistência de defeito. Esses valores dependem de vários fatores relacionados com o tipo de solo, quando o contato for com o solo, grau de umidade, depósitos e condição das superfície de contato, grau de umidade do ar, dentre outros. Assim, a resistência de defeito é um parâmetro de difícil avaliação, encerrando uma significativa incerteza em sua determinação e ensejando a atenção para a faixa de valores que pode assumir.. No âmbito desta pesquisa foram realizados alguns ensaios de campo para avaliar a resistência de defeito, conforme é apresentado em capitulo posterior. Vale lembrar que usualmente, utiliza-se alguns valores de referência situados entre $20 \Omega$ e $40 \Omega$ (Cebrian et al., 2007) e adota-se o valor típico de 40 ohms para resistência de defeito em simulação e estudos determinísticos para sistemas de proteção.

Equivalente elétrico (potência de curto-circuito) do sistema supridor : o cálculo de curtocircuito do sistema de distribuição suprido por uma subestação é diretamente influenciado pela impedância do sistema supridor à montante. As frequentes alterações topológicas desse sistema decorrentes de ações operativas, a disponibilidade de suas unidades geradoras, dentre outros fatores como a variação dos parâmetros elétricos das linhas em função das temperaturas e resistência de aterramento, trazem incertezas do valor de impedância equivalente do sistema supridor, utilizada para o cálculo de curto circuito do sistema de distribuição.

Parâmetros elétricos do componentes das redes primárias: a diversidade de condutores e arranjos das redes de distribuição, bem como a influencia da temperatura no valor da resistência dos condutores, ao lado de frequentes imprecisões de cadastro, resulta em significativa incerteza na determinação dos parâmetros elétricos a serem adotados em cálculo de curto circuito.

Resistência de aterramento: outro aspecto de incerteza na determinação das correntes de curto-circuito, notadamente naqueles que envolvem contato entre condutor e solo, refere-se à avaliação da resistência correspondente dos pontos de aterramento.

Basicamente, nos postes onde existem instalados equipamentos específicos da rede primária, como transformadores de distribuição, para-raios, reguladores de tensão, bancos de capacitores, entre outros, são feitos aterramentos basicamente dependentes dos arranjos (quantidade de hastes e disposição), resistividade do solo, entre outros.

Há uma nítida dificuldade de controle desta informação, uma vez que exigiria o conhecimento dos arranjos utilizados em cada aterramento, que podem abrigar diferentes formas (no que tange à dimensão, quantidade de hastes e respectivas disposições). 
Tensão pré-falta: em geral, no cálculo de curto-circuito admite-se um valor de tensão pré-falta igual a 1,0 pu, quando na realidade, devido à natureza das redes de distribuição de energia que são, muitas vezes, muito longas e com extensas ramificações, esse valor pode variar dentro dos limites estipulados pela resolução número 505/2001 da ANEEL (2001).

\subsection{Formulação do problema e encaminhamento da solução}

O problema formulado para esta pesquisa é:

a determinação da área provável de ocorrência de curto circuito em uma rede de distribuição primária, conhecendo-se as correntes e tensões pré e pós defeito na subestação, para orientar a busca do local do defeito por parte das equipes de manutenção.

O encaminhamento dado para a solução consiste em calcular, previamente, as correntes de curto circuito em cada final de tramo da rede, para todas as variáveis heurísticas envolvidas, e compará-los ao valor das correntes verificadas na subestação.

$\mathrm{O}(\mathrm{s})$ valor(es) de corrente(s) de defeito, previamente calculado(s), mais próximo(s) daquele verificado na subestação está(ão) associado(s) ao(s) tramo(s) com maior probabilidade de ser sede do defeito, com diferentes graus de pertinência.

Com isso são determinadas as áreas prováveis de ser sede do defeito, com os correspondentes pertinências e portanto prioridades de busca pelas equipes de manutenção.

\subsection{METODOLOGIA}

A metodologia proposta para a delimitação de trechos, de um alimentador primário onde ocorreu um curto circuito detectado por equipamentos de proteção instalados na subestação se fundamenta em regras heurísticas e consiste nas seguintes etapas, conforme ilustra o diagrama da Figura 9: 
Figura 9 - Fluxograma das etapas da metodologia desenvolvida

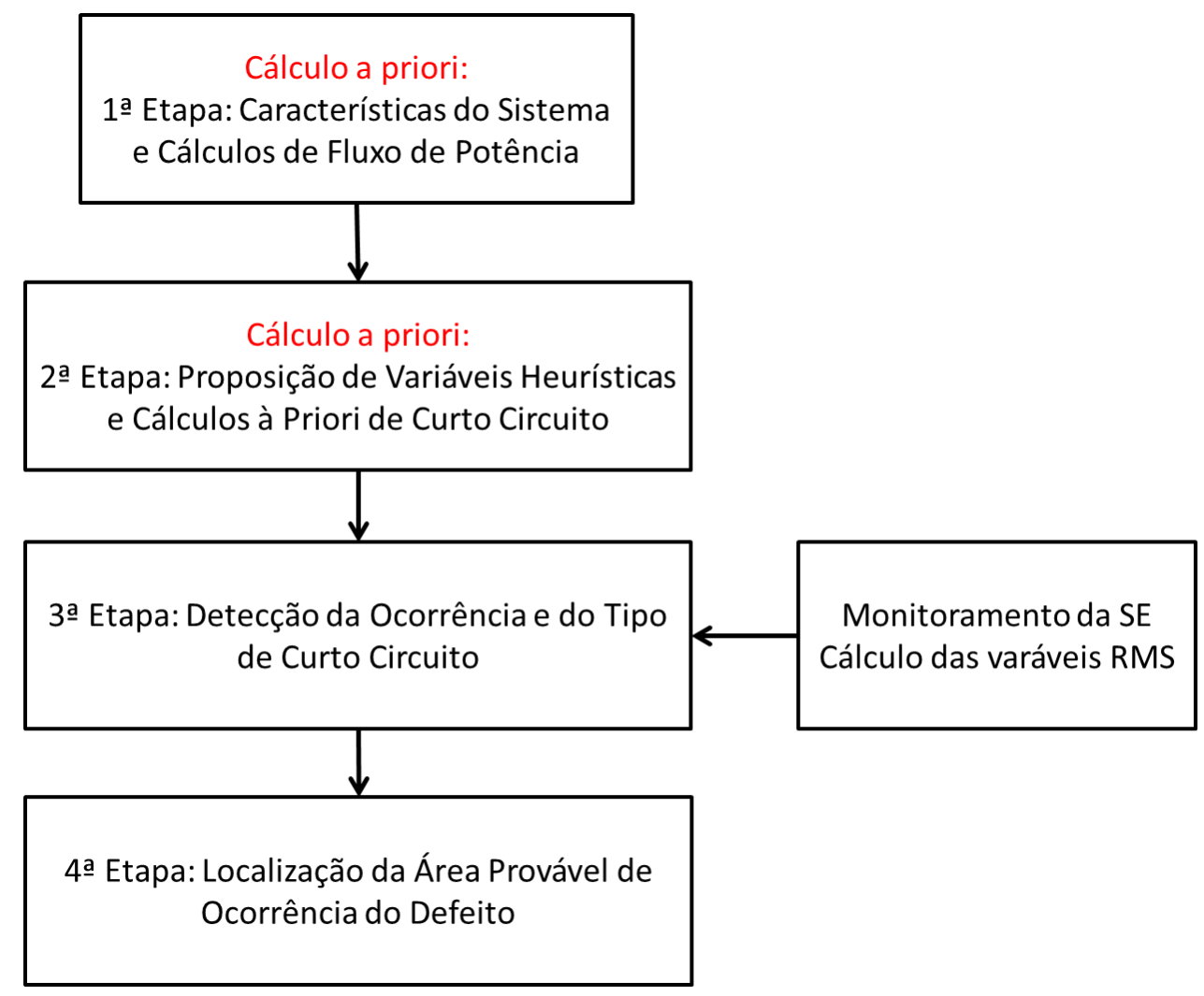

Fonte: Elaborada pelo autor.

Na sequência são apresentadas as etapas da metodologia:

1ª Etapa: Características do Sistema e Cálculos de Fluxo de Potência

O processo se inicia com a caracterização da rede objeto de análise, por meio do cadastramento adequado de seus parâmetros físicos e operacionais, como:

- equivalente elétrico mais provável do sistema supridor;

- topologia da rede de distribuição;

- características elétricas dos componentes das linhas do sistema distribuidor;

- localização e tipo dos equipamentos de manobra ou de proteção instalados na rede;

- ajustes de proteção dos disjuntores da subestação;

- diagrama diário das cargas, em patamares leve, médio e ponta; 
- "pontos notáveis", da rede, definidos como sendo aqueles onde há derivação de ramal ou final de linha ou imediatamente precedente de equipamento de proteção (chave-fusível ou religador) ou ainda, algum ponto de interesse para cálculo de curto circuito.

Nesta etapa são calculados o fluxo de potência na rede para cada patamar diário de carga.

2ª Etapa: Proposição de Variáveis Heurísticas e Cálculos à Priori de Curto Circuito

São propostas as variáveis heurísticas para cada um dos parâmetros que apresentam incertezas e os correspondentes graus de pertinência.

Vale lembrar que as variáveis Heurísticas, potencialmente, consideradas são:.resistência de defeito, equivalente elétrico do sistema supridor, resistência de aterramento do sistema, tensão pré-falta e para os parâmetros elétricos das linhas. Assim devem ser definidos :

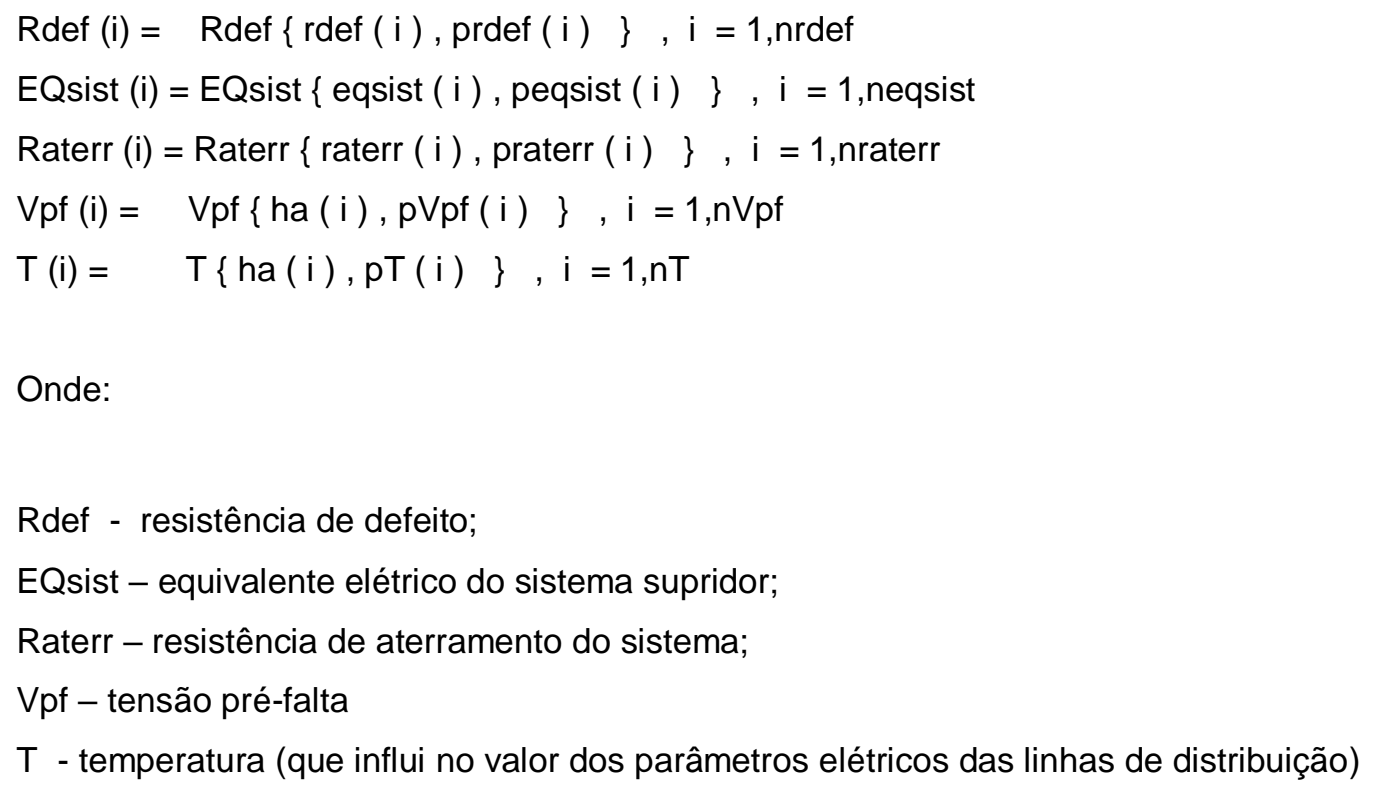

Posteriormente, são calculados os níveis de curto circuito trifásico e fase-terra nos pontos notáveis considerando, para todas as possíveis combinações das enuplas de valores "mi" das variáveis heurísticas e correspondentes pertinências: 


$$
\begin{aligned}
& \text { "mi" }(j)=\{[\text { Rdef }(i), i=1, \text { nrdef ] }, \quad[\text { EQsist }(i), i=1 \text {, neqsist }] \text {, } \\
& \text { [Raterr (i), i }=1, \text { nraterr ], } \quad \text { [ Vpf (i) }, i=1, n V p f \text { ], } \\
& \text { [ } \mathrm{T}(\mathrm{i}), \mathrm{i}=1, \mathrm{nT}]\}
\end{aligned}
$$

$\mathrm{j}=1$, nrdef $\times$ neqsist $\times$ nraterr $\times n V p f \times n T$ para curto que envolve a terra e;

$\mathrm{j}=1$, .neqsist $\times \mathrm{nVpf} \times \mathrm{nT}$. para curto que não envolve a terra

Assim, por exemplo, se forem consideradas apenas as 3 variáveis heurísticas mais relevantes $\{$ Rdef, EQsist, $T$ \} e ainda, houver 5 valores para cada uma dessas variáveis, haverá:

- 25 valores de correntes de curto circuito que não envolvem a terra (trifásico e dupla fase) para cada ponto notável, ou seja, 5 EQsist $\times 5 \mathrm{~T}=25$ e ;

- 125 valores de correntes de curto circuito que envolvem a terra ( monofásico e dupla fase terra ) para cada ponto notável, ou seja, 5 Rdef $\times 5$ EQsist $\times 5 T=125$;

Com os valores de curto circuito, são montadas Matrizes de Referência de corrente de defeito, uma para curto envolvendo a terra e outra para curto não envolvendo, para cada tramo (entendido como sendo trechos de alimentador entre 2 pontos notáveis), associadas a cada valor de pertinência. As correntes de curto circuito para cada uma dessas matrizes são:

Matriz de Referencia com corrente de curto que envolvem a terra :

Icterra $\{\mathrm{i}, \mathrm{j})$ onde;

i - caracteriza o tramo i

j - caracteriza a pertinência da solução $=\{\operatorname{Rdef}(k)$, EQsist $(I), T(m)\}$

Matriz de Referencia com corrente de curto que não envolvem a terra:

Ic $\{\mathrm{i}, \mathrm{j})$ onde;

i - caracteriza o tramo i

j -. caracteriza a pertinência da solução $=\{E Q s i s t ~(I), T(m)\}$

A Tabela 5.ilustra a estrutura da Matriz de Referência das Correntes de Curto Circuito Trifásico. 
O produto das pertinências resultaram em 5 valores superiores a 0,6 . Os valores das pertinências que resultaram foram os seguintes:

Tabela 5 - Valores de pertinências resultantes superiores a 0,6

\begin{tabular}{|l|l|}
\hline $\mathrm{i}=1 \mathrm{a} 25$ & $\mathrm{j}=1 \mathrm{a} 25$ \\
\hline Pertinência & Valor \\
\hline 0.70 & 0.80 \\
\hline 0.60 & 0.82 \\
\hline 0.80 & 0.90 \\
\hline 1.0 & 1.0 \\
\hline 0.7 & 1.2 \\
\hline
\end{tabular}

Fonte: Elaborada pelo autor.

$3^{\text {a }}$ Etapa: Detecção da Ocorrência e do Tipo de Curto Circuito

A metodologia prevê o monitoramento permanente da operação dos disjuntores da subestação e, imediatamente à abertura de um deles, por comando do sistema de proteção, são realizadas as seguintes ações;

- Captura de (8) pontos por ciclo de cada corrente registrada no oscilógrafo nos instantes seguintes ao evento de abertura do disjuntor;

- Calculo das correntes (de fase e de neutro) Rms de curto circuito, com base na amostra capturada no oscilógrafo do relé de proteção;

-.Determinação do tipo de curto circuito a partir dos valores das correntes e tensões registradas.

4ํㅡㄹ Etapa: Localização da Área Provável de Ocorrência do Defeito

De posse do tipo de defeito, dos valores das correntes de curto circuito calculadas a partir do oscilógrafo é realizada pesquisa ao longo da Matriz de Referência correspondente ao tipo de curto circuito detectado, para identificar qual (ais) tramo (s) que poderiam ser sede da ocorrência. 
A identificação desse(s) tramo(s) é realizada por meio de comparação da semelhança entre a corrente de defeito calculada e as correntes lc $\{i, j)$.ou Icterra \{ i , j) , conforme o defeito envolva a terra ou não. Nessa comparação é utilizado um parâmetro de "erro" "psi1".

Se o resultado dessa pesquisa for apenas um tramo, a Área Provável de Defeito estará localizada.

Se houver mais de um tramo, como resultado da pesquisa, é acionado um segundo recurso de filtragem, que consiste em verificar o tipo do equipamento de proteção de rede que operou, por meio dos registros do oscilógrafo. Vale lembrar que um religador provoca sucessivos blocos de registros de correntes sustentadas de falta no oscilógrafo e a operação de uma chave fusível, por sua vez, resulta em apenas um bloco. A Figura 10 ilustra a diferença desses registros.

Figura 10 - Resultados de oscilografia

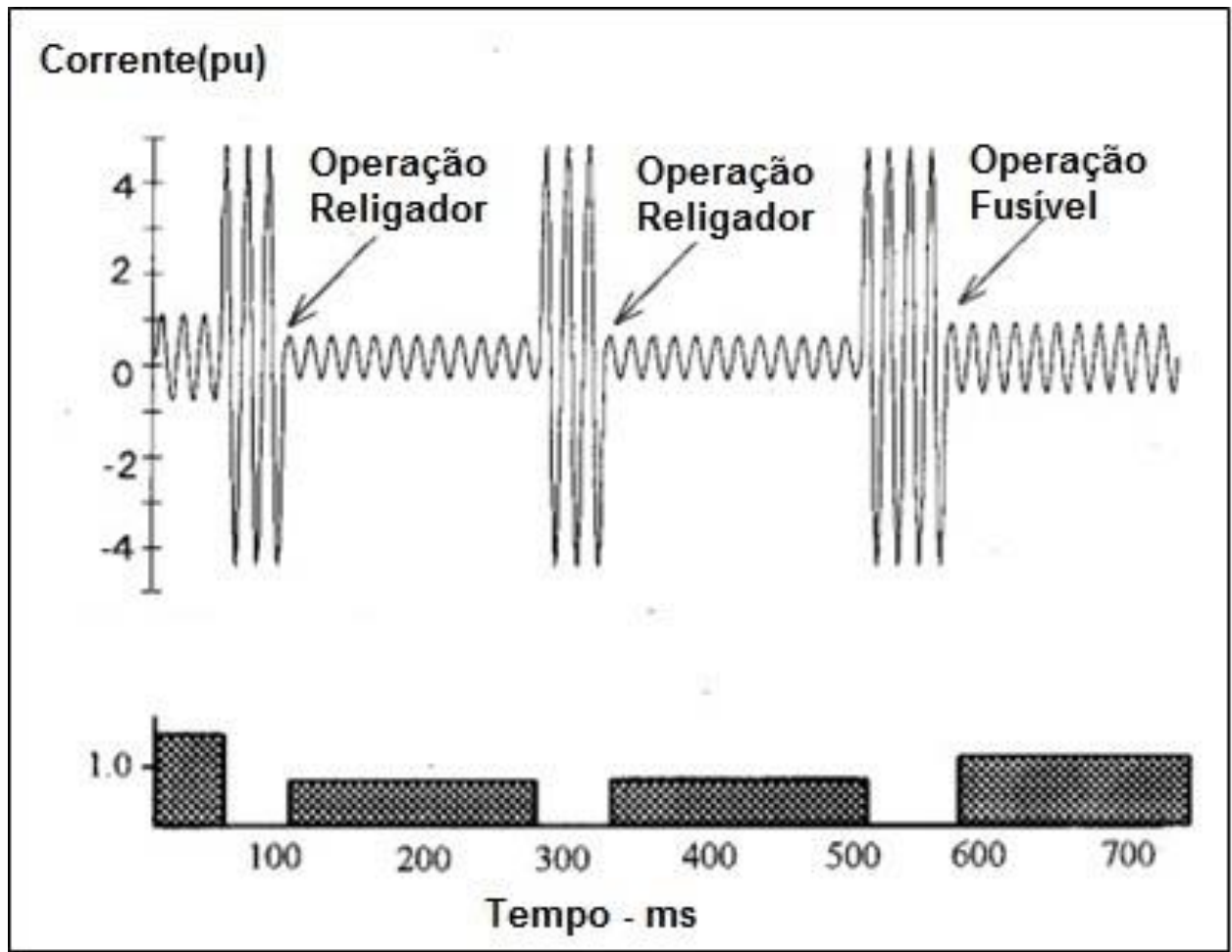

Fonte: Elaborada pelo autor.

Se esse critério de filtragem puder identificar o tramo com defeito, a Área Provável de Defeito estará localizada. 
Se ainda houver mais de um tramo após essa segunda filtragem, aplica-se o terceiro critério de seleção para restringir a Área Provável de Defeito, que consiste em comparar a diferença entre as correntes de carga pré e pós defeito, com a corrente de carga prevista para os tramos candidatos. Também nessa comparação se utiliza de um "erro" psi2" pré estabelecido. Ressalta-se que as correntes de carga esperadas para cada período do dia (carga leve, média e pesada) de cada tramo foi pré-calculada na primeira etapa e devidamente armazenada.

Todos os tramos que atenderam a esse terceiro critério integram a Área Provável de Defeito.

O Anexo B apresenta um exemplo ilustrativo. 


\section{AVALIAÇÃO EXPERIMENTAL DE RESISTÊNCIA DE DEFEITO}

\subsection{Ensaios de campo realizados}

Diante do elevado nível de incerteza presente na variável heurística Rdef, resistência de defeito, foram realizados ensaios em campo para avaliar esse parâmetro em diversas situações de defeito em alimentador de 13,8 kV, com o objetivo de subsidiar a aplicação da metodologia proposta nesta pesquisa, com valores heurísticos fundamentados.

Também foi realizado um ensaio de condutor de alimentador $13,8 \mathrm{kV}$ ao solo, com a presença de um geração distribuída (GD) conectada na rede primária, para avaliar seu impacto na aplicação da metodologia proposta, numa situação particularmente frequente.

Os ensaios foram registrados em vídeo, disponíveis no CD - ROM em anexo e também em Internet.

"Testes de curto-circuito com RF" https://youtu.be/vL3msk-34fE

"Testes de curto-circuito com GD" https://youtu.be/Gm2qXYiAHP4

\subsection{Avaliação da Resistência de defeito}

Os ensaios de curto-circuito foram realizados em ambiente conhecido, em rede 13,8 kV com cabo de alumínio nu convencional ou alumínio coberto em arranjo "spacer", considerando várias situações de contato do cabo com vários tipos de solo e com árvore.

Os ensaios consistem em provocar curto circuitos levando condutores a solos e, por meio das medições de correntes e de tensões, são calculadas as Rdef correspondentes ao tipo de solo.

Conhecidos as Rdef associadas a cada tipo de solo é possível determinar a 
pertinência de cada valor dessa variável heurística por meio da incidência de cada um desses tipos de solo ao longo da trajetória de determinado alimentador.

Foram realizados os seguintes ensaios:

- Curto circuito fase terra em solo de "terra fértil" (normalmente com baixa Rdef)

Conforme mostra a Figura 11, o cabo da fase A foi levado até o solo, provocando o curto circuito, cujo valor monitorado da corrente é de $1800 \mathrm{~A}$, o que provocou a atuação, de imediato, após a temporização pela curva de atuação, do relé de proteção. A Rdef desse caso resultou em valor $<20$ ohms.

Figura 11 - Curto circuito fase terra - terra, baixa RF

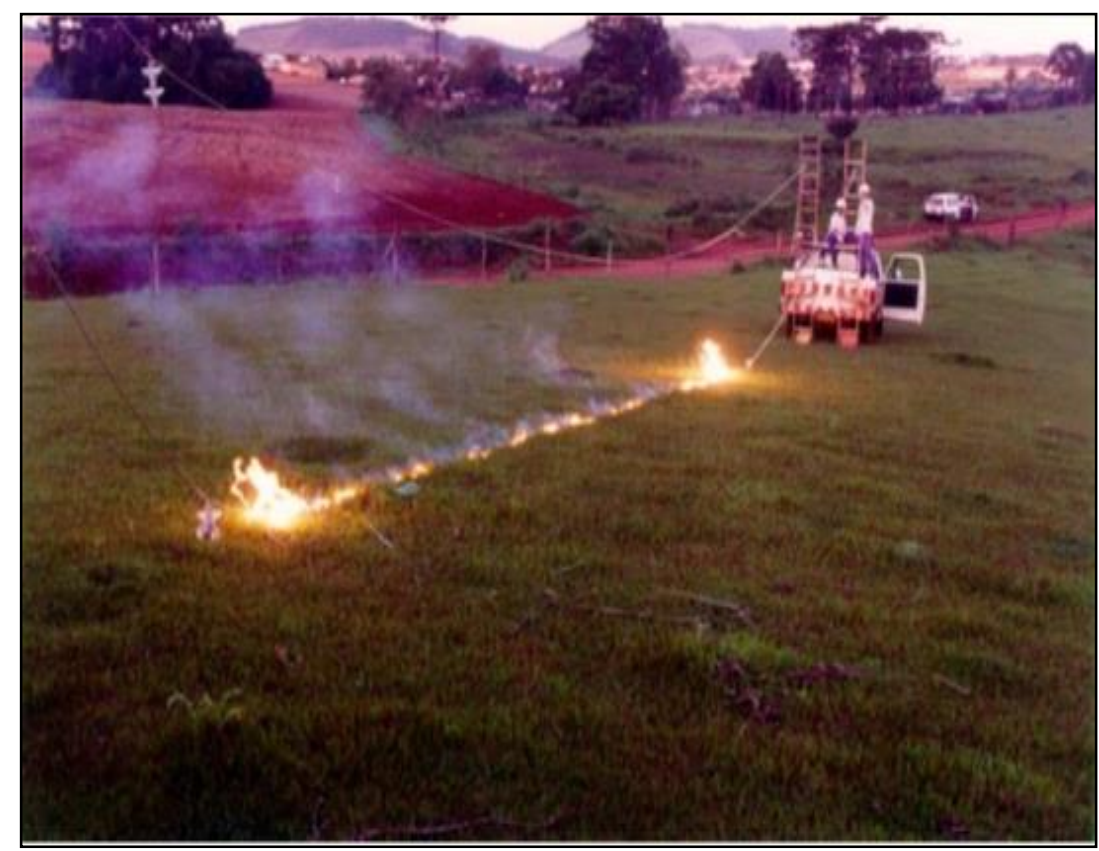

Fonte: Elaborada pelo autor.

- Curto circuito fase terra sobre grama molhada

No caso apresentado na Figura 12, houve a atuação do elemento de neutro, ajustado em.25 A, do relé proteção. A corrente de curto circuito é da ordem de 1200 A resultando em. 20 ohms $\leq$ Rdef $\leq 40$ ohms. 
Figura 12 - Curto circuito fase terra - grama úmida

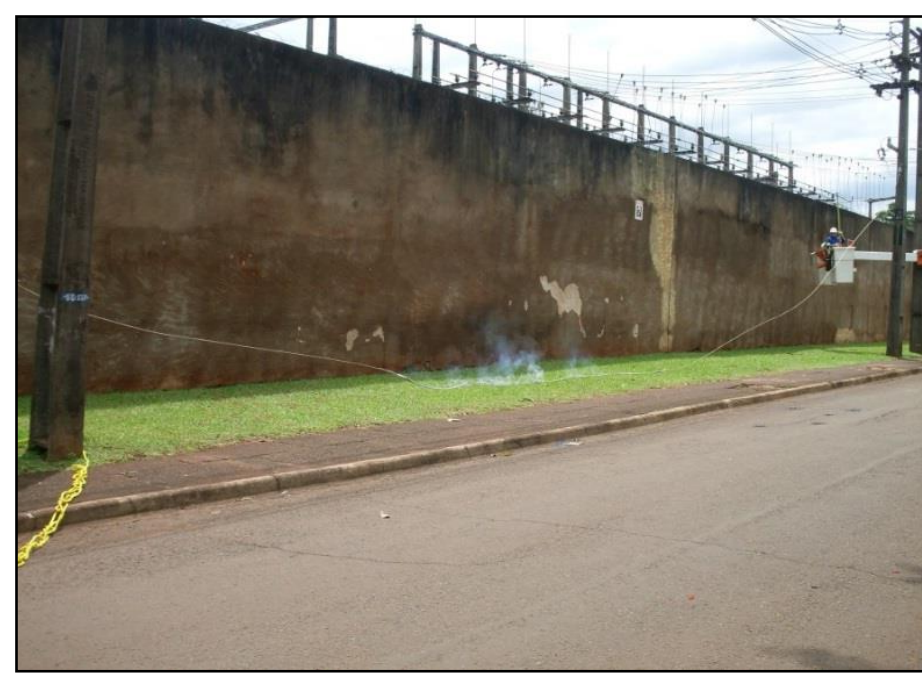

Fonte: Elaborada pelo autor.

- Curto circuito fase terra - pedra brita e cabo de alumínio coberto.

Este ensaio foi realizado levando um condutor do tipo "coberto" de rede compacta, ao solo de pedra britada, no interior da subestação Jusante, conforme mostrado na Figura 13.

Figura 13 - Curto circuito fase terra - pedra brita e cabo coberto

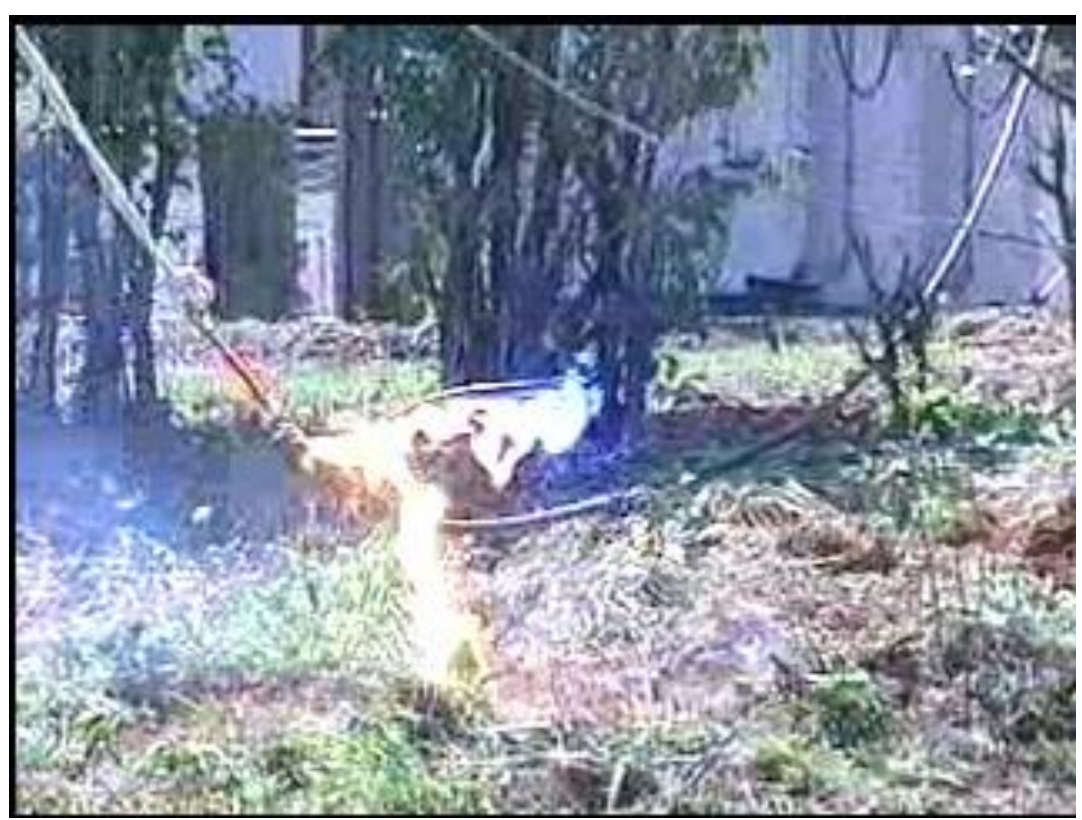

Fonte: Elaborada pelo autor. 
Embora o defeito ocorra junto a fonte, praticamente com impedância de rede primária nula, observa-se que a Rdef é maior do que 1000 ohms devido ao isolamento propiciado pela cobertura do cabo.

O defeito apenas gerou arco elétrico, sendo que a corrente oscilografada é da ordem de mili-ampéres.

Como a unidade de neutro dos relés de proteção estão ajustados em $25 \mathrm{~A}$, não houve a atuação desta proteção. Este defeito é considerado como uma falta de alta impedância e, portanto a metodologia heurística desenvolvida nesta tese não se aplica.

- Curto circuito fase terra - cabo sobre árvore

Este ensaio consiste na queda do condutor nu sobre uma árvore, à semelhança de frequentes ocorrências em áreas rurais com densa arborização ou urbanas arborizadas, conforme mostrado na Figura 14.

Figura 14 - Curto circuito fase terra - cabo sobre árvore

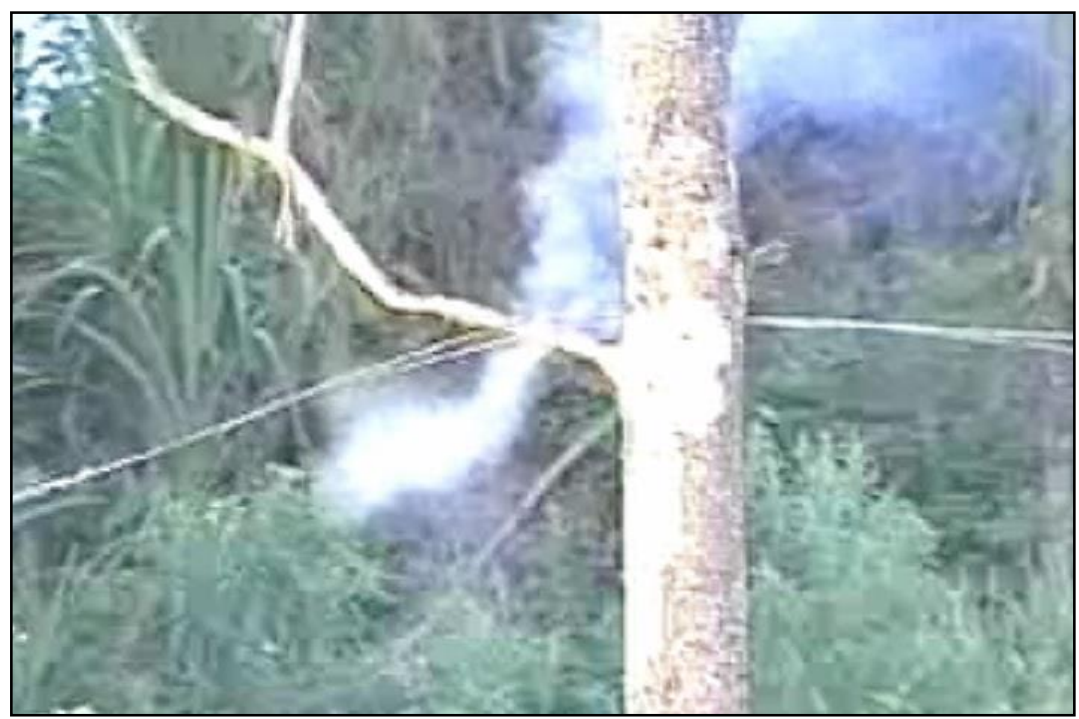

Fonte: Elaborada pelo autor.

Inicialmente, quando o cabo cai sobre uma árvore, a resistência de defeito é elevada, alcançando valor maior do que 1.000 ohms.

Após algum tempo, com a passagem da corrente pelo interior do caule da árvore, ocorre a carbonização dos galhos, fazendo com que a resistência de defeito diminua 
para valores de 40 ohms $\leq$ Rdef $\leq 100$ ohms. Assim, a corrente aumenta, atingindo nesse caso cerca de 540 A.e, portanto detectada pelo relé de proteção de fase do alimentador primário.

O defeito, inicialmente de alta impedância, passa posteriormente ser detectado pela metodologia heurística desenvolvida.

\section{- Curto circuito fase terra - cabo sobre o asfalto}

A manta asfáltica, frequentemente presente sob o percurso de alimentadores urbanos, se caracteriza por ser um material de alta resistência elétrica. Um exemplo deste caso é apresentado na Figura 15.

Figura 15 - Curto circuito fase terra - cabo sobre asfalto

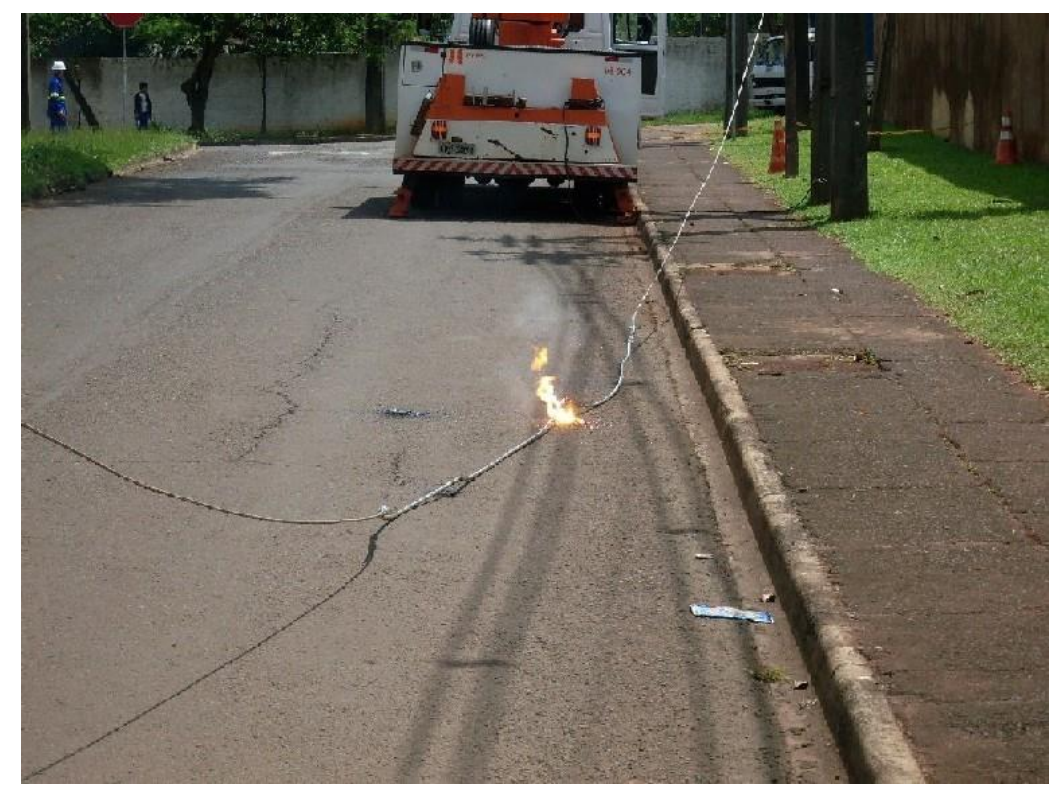

Fonte: Elaborada pelo autor.

As correntes registradas neste ensaio de curto circuitos são da ordem de apenas 3,0 A a 8,0 A, caracterizando Rdef > 1.000 ohms, sem sensibilizar a proteção de sobre corrente. Portanto o método heurístico desenvolvido nesta tese não se aplica a este tipo de defeito. 


\subsection{Resultados}

Concluindo, observa-se que, por meio da realização de ensaios de curto circuitos em campo, utilizando um alimentador em 13,8 kV.levado a diversos tipos de solo, se obteve valores heurísticos de Rdef, a serem utilizados na metodologia proposta nesta pesquisa. A pertinência de cada valor heurístico deve ser adequada aos tipos de terreno percorrido pelo alimentador em análise. 


\section{FERRAMENTA PARA APLICAÇÃO DA METODOLOGIA}

Foi desenvolvida, no âmbito desta pesquisa, uma ferramenta computacional para a aplicação da metodologia proposta para de localização da área de ocorrência de defeito em redes primárias de distribuição. Para tanto foi utilizado o ambiente, disponível no mercado, de análise de redes Interplan (RUFATO, 2012), ao qual foi agregado um módulo que contem as funcionalidades necessárias para a aplicação objeto desta pesquisa.

Citado ambiente de análise de redes dispõe de várias facilidades (Figura 16), dentre as quais destaca-se:

Representação georeferenciada da rede de distribuição, que permite a visualização da área onde houve a ocorrência e por consequência, para onde deve ser despachada a equipe de manutenção.

Interface gráfica amigável. Por meio de menu, o usuário pode selecionar equipamentos previamente cadastrados a ser apresentados nos diagramas da rede, selecionar cores utilizadas no display, selecionar a forma de apresentação dos resultados de tensão, dentre outras facilidades.

Figura 16 - Representação gráfica de um alimentador e do menu

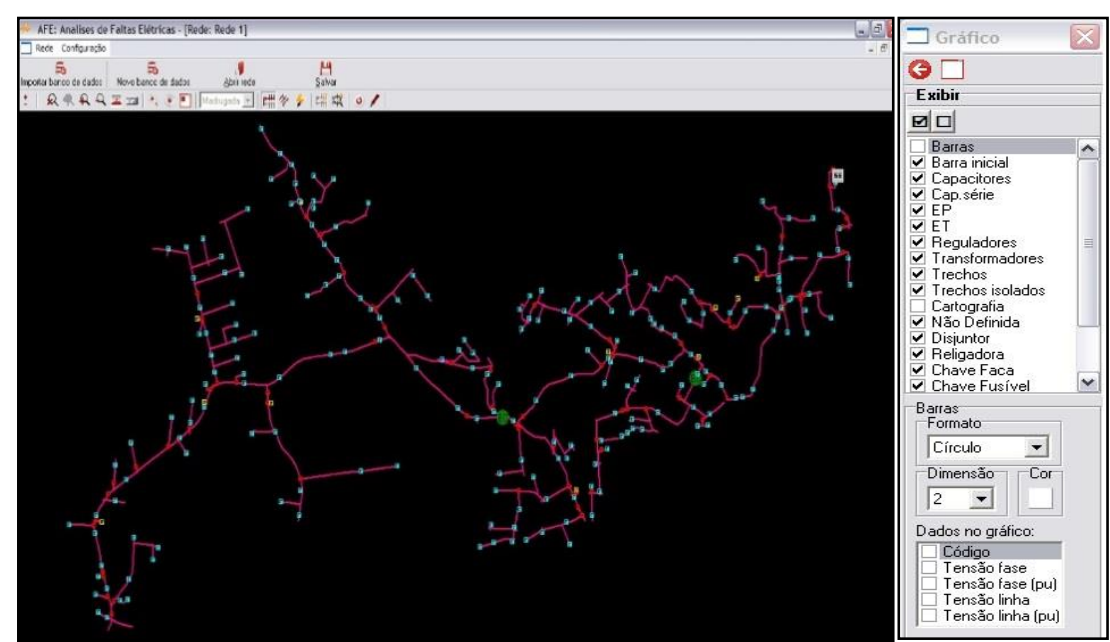

Fonte: Elaborada pelo autor. 
O módulo de localização da área onde ocorreu o curto circuito, em um dado alimentador, oferece resultados tanto utilizando o método convencional determinístico, como para o método heurístico desenvolvido nesta pesquisa. Esse módulo é processado em 3 etapas sequenciais, a saber:

Entrada de dados da corrente de curto circuito no barramento da subestação, que pode ser realizada por meio de conexão direta com oscilógrafo ou por inserção manual (Figura 17);

A partir dos dados do item a) são calculadas as correntes rms de curto circuito, pelo método trapezoidal;

Finalmente, é processada a etapa para a determinação das áreas prováveis onde houve a ocorrência pelo método determinístico ou pelo método heurístico, conforme escolha do usuário.

Figura 17 - Dados de entrada e cálculo de correntes rms

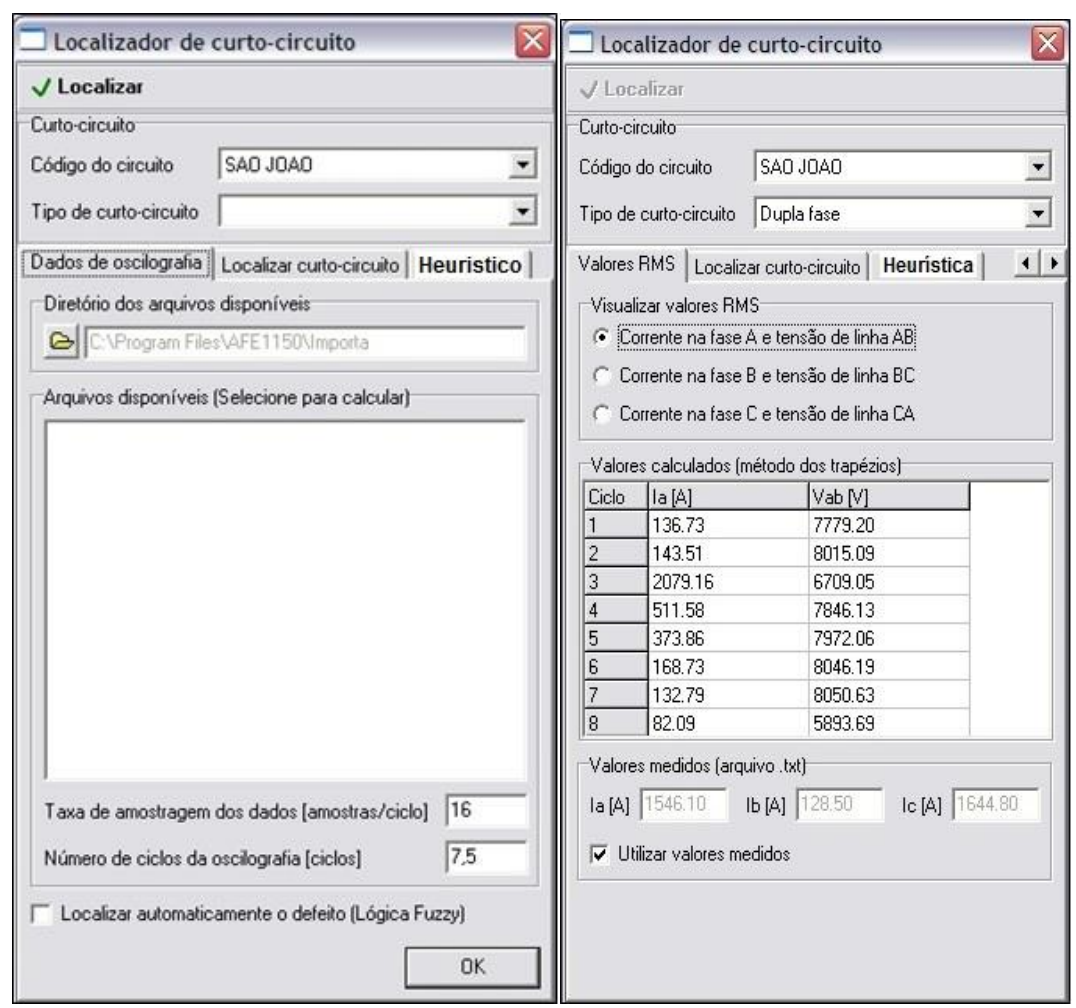

Fonte: Elaborada pelo autor. 
A Figura 18 e Figura 19 a seguir apresentam as telas referente ao cálculo da metodologia determinística e os resultados obtidos sobre a indicação das áreas prováveis onde ocorreu o curto circuito.

Figura 18 - Tela para o cálculo do método determinístico

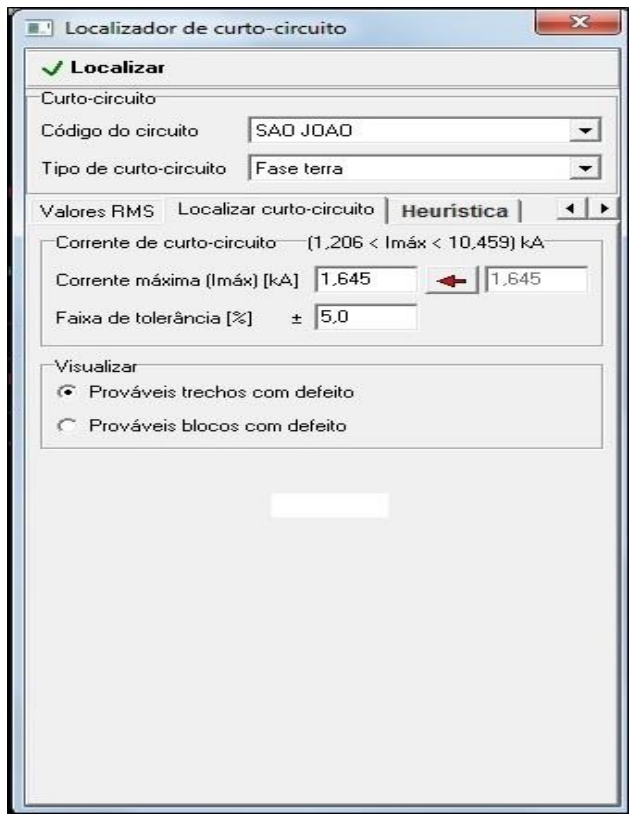

Fonte: Elaborada pelo autor.

Figura 19 - Resultados obtidos sobre a indicação das áreas prováveis

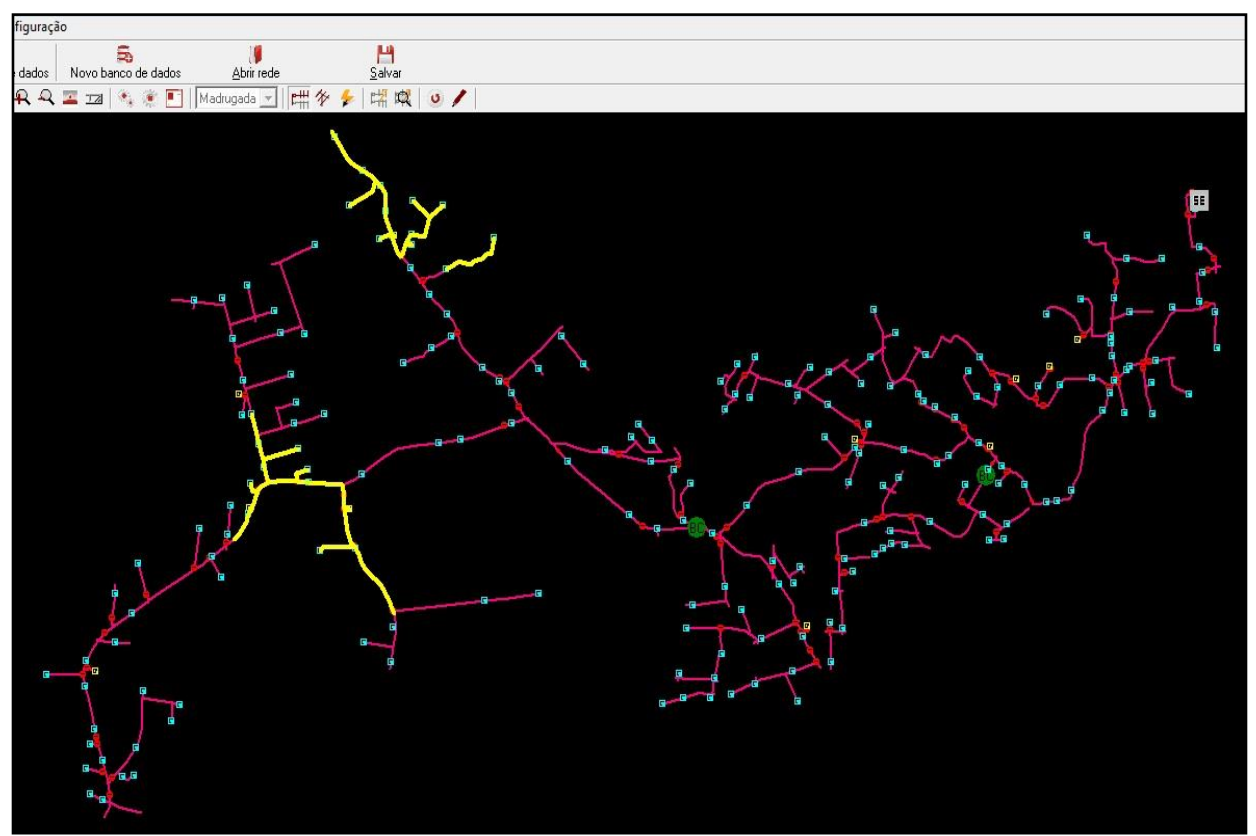

Fonte: Elaborada pelo autor. 
A Figura 20 apresenta os resultados obtidos pela aplicação da metodologia heurística onde vale a pena ressaltar que é possível selecionar cores das áreas onde há diferentes pertinências da ocorrência de curto circuito.

Figura 20 - Localizador de defeito (curto-circuito) com método Heurístico

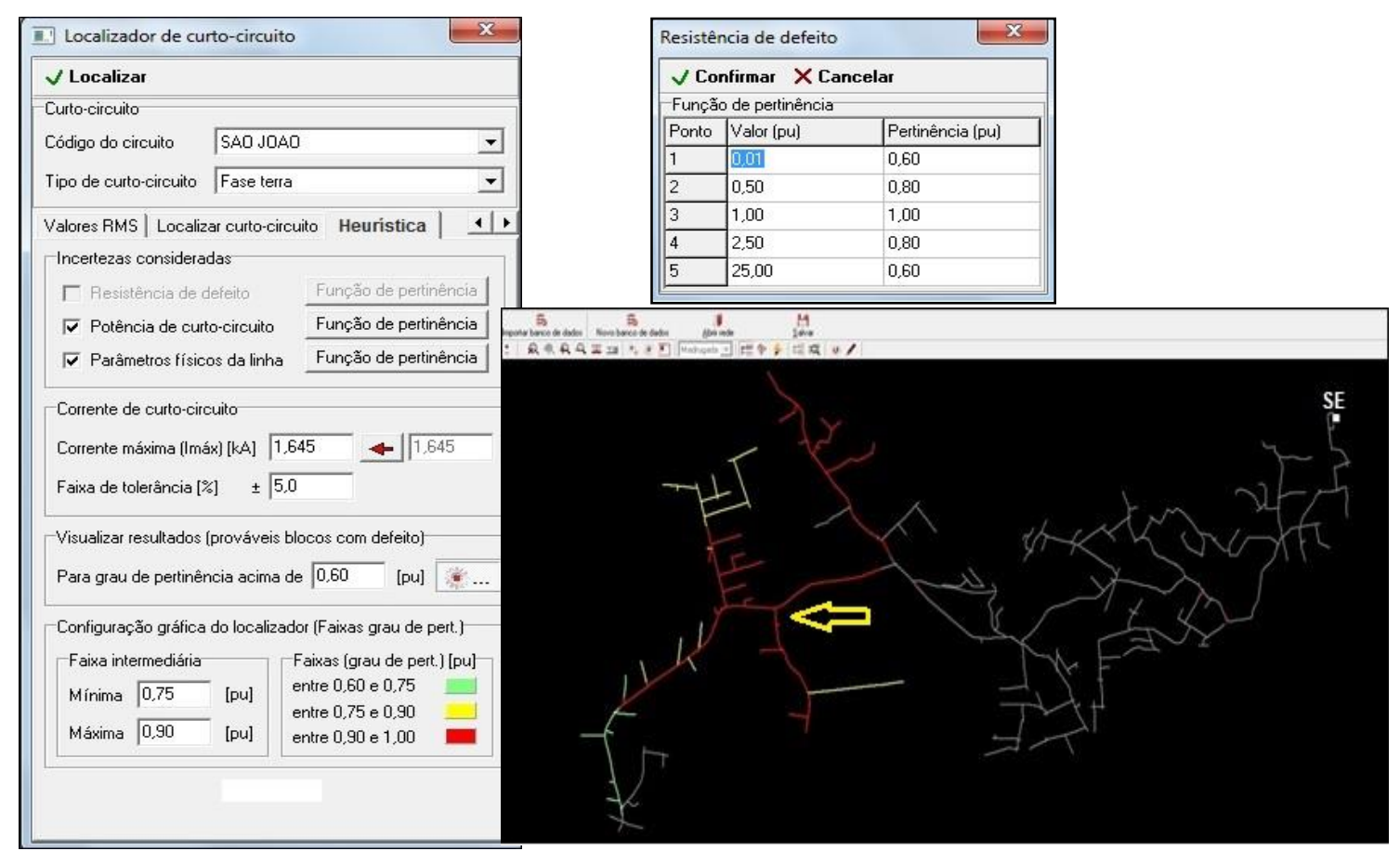

Fonte: Elaborada pelo autor.

Conforme a configuração gráfica dada, a área com defeito é;

- a vermelha, com $90 \%$ a $100 \%$ de pertinência,

- a amarela, com $75 \%$ a $90 \%$ de pertinência ou,

- a verde, com $60 \%$ a $75 \%$ de pertinência.

Assim, a equipe de manutenção será inicialmente encaminhada para a área vermelha. Se não houver sucesso, se encaminhará para a área amarela e finalmente, para a verde.

Realizando-se uma análise dos dados calculados, empregando-se o método de localização proposto nesta tese, mostrados no diagrama do alimentador estudado, Figura 20, pode-se concluir que: 
O defeito tem probabilidade entre $90 \%$ e $100 \%$ de ter ocorrido nos trechos pintados em vermelho, no alimentador estudado.

O defeito tem probabilidade entre $75 \%$ e $90 \%$ de ter ocorrido nos trechos pintados em amarelo, no alimentador estudado.

O defeito tem probabilidade entre $60 \%$ e $75 \%$ de ter ocorrido nos trechos pintados em verde, no alimentador estudado.

Neste caso, o defeito realmente ocorreu no ramal de derivação do alimentador primário, indicado pela seta amarela, na Figura 20, mostrando que, conforme indicado pela ferramenta de localização empregada, o defeito foi localizado com a probabilidade entre $90 \%$ e $100 \%$, dentro da área vermelha.

Logo, para o operador do centro de distribuição do sistema, fica claro que primeiramente ele deverá direcionar as equipes de manutenção de redes para os locais com a maior probabilidade de ocorrência dos defeitos, que são os trechos pintados em vermelho no alimentador.

Isto propicia aos clientes que estão sendo alimentados por este circuito um menor tempo para a reparação do defeito, diminuindo os tempos de não fornecimento de energia e os custos com a movimentação das equipes de manutenção das concessionárias de energia. 


\section{ESTUDO DE CASO}

\subsection{Localização de Defeitos Registrados em Alimentadores}

A metodologia proposta para indicação da área de ocorrência de defeitos em alimentadores primários foi aplicada em casos reais, para avaliação de seu desempenho.

A aplicação foi realizada, fundamentando-se em registros de históricos de ocorrências, que indicam a localização do curto circuito e contém os registros oscilográficos extraídos de equipamentos de proteção instalados na Subestação Cidade Industrial de Curitiba - SE- CIC e na Subestação Pilarzinho - SE - PIL.

A rede foi representada pelas suas impedâncias (conforme Anexo C) a $30^{\circ} \mathrm{C}$, a resistência de defeito de referência foi adotada como sendo de 40 ohms e os equivalentes elétricos de sequência positiva e zero foram calculados por meio dos métodos convencionais resultando em :

As variáveis heurísticas consideradas são:

- Resistência de Defeito:

0 ohms => pertinência 0,6

20 ohms $=>$ pertinência 0,8

40 ohms $\Rightarrow$ pertinência 1,0

100 ohms $=>$ pertinência 0,8

1000 ohms => pertinência 0,6
- Equivalente elétrico da rede supridora:

0,6 p.u. $=>$ pertinência 0,4

0,8 p.u $=>$ pertinência 0,7

1,0 p.u $=>$ pertinência 1,0

1,2 p.u $=>$ pertinência 0,7

1,4 p.u => pertinência 0,4

- Temperatura do condutor :

$60{ }^{\circ} \mathrm{C}$ (fator de correção $\left.=0,71\right)=>$ pertinência 0,4

$50^{\circ} \mathrm{C}$ (fator de correção $=0,82$ ) $=>$ pertinência 0,6 
$40{ }^{\circ} \mathrm{C}$ (fator de correção $\left.=0,91\right)=>$ pertinência 0,8

$30^{\circ} \mathrm{C}$ (fator de correção $\left.=1,00\right)=>$ pertinência 1,0

$20^{\circ} \mathrm{C}$ (fator de correção $\left.=1,08\right)=>$ pertinência 0,4

Foram estudados os seguintes defeitos em alimentadores com a indicação das características do defeito e a comparação dos resultados obtidos pela aplicação da metodologia e a localização constatada em campo:

Alimentador Anita Garibaldi da SE Pilarzinho 230/13,8 kV,

Corrente de curto-circuito oscilografada - 5.644 A.

Tipo de defeito: fase-fase.

Endereço do defeito : Rua Dr. Alberto Piekarz x Rua José Milek Filho.

Figura 21 - Alimentador Anita Garibaldi. Local do defeito (seta) e resultado da aplicação da metodologia heurística (tramos em vermelho $>90 \%$ de pertinência)

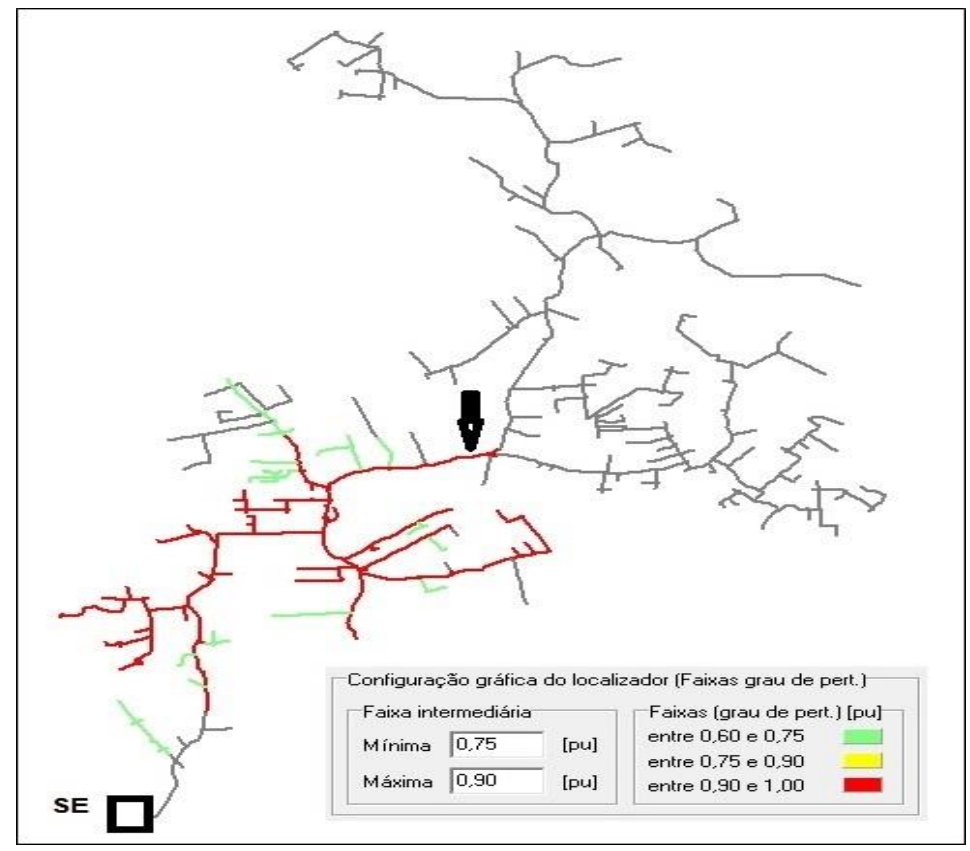

Fonte: Elaborada pelo autor. 
Alimentador Barreirinha da SE Pilarzinho 230/13,8 kV,

Corrente de curto-circuito oscilografada - $980 \mathrm{~A}$.

Tipo de defeito: fase-terra com impedância.

Endereço: Rua Alberto Otto x Rua Theodoro Makiolka.

Figura 22 - Alimentador Barreirinha Local do defeito (seta).e resultado da aplicação da metodologia heurística (tramos em vermelho $>90 \%$ de pertinência)

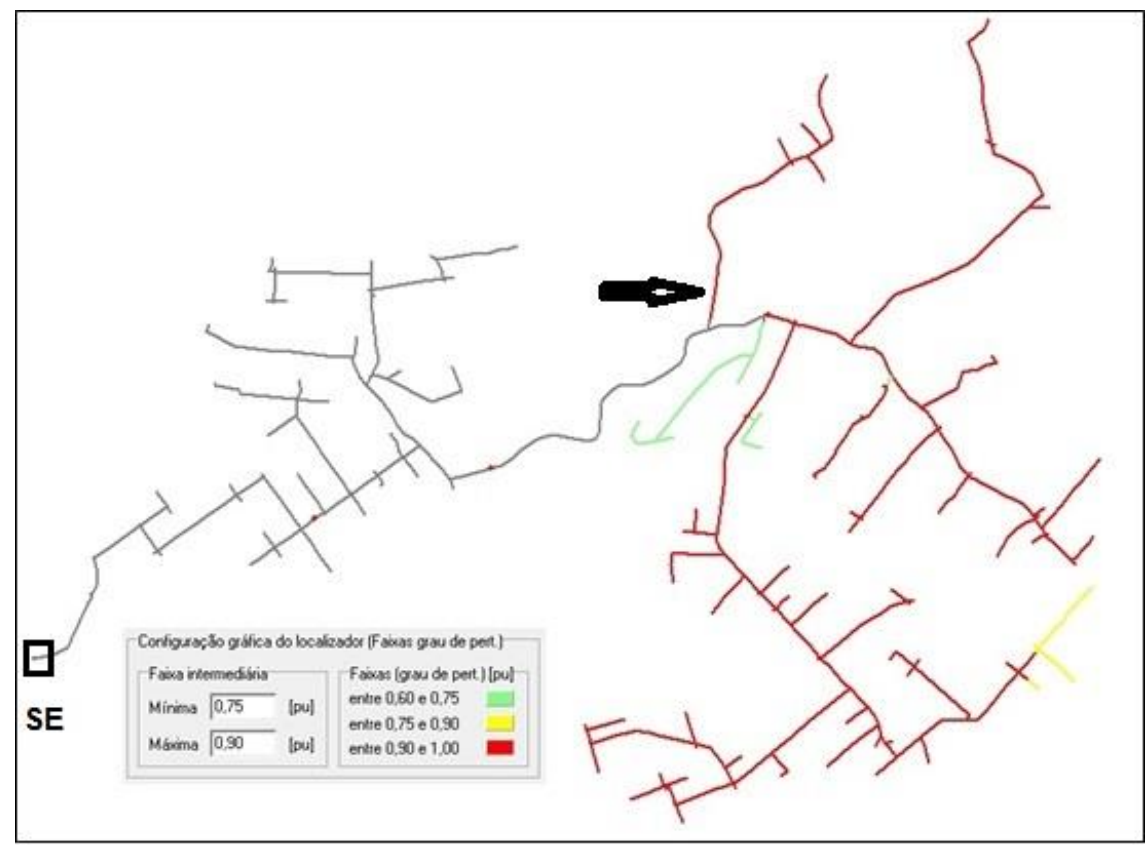

Fonte: Elaborada pelo autor.

Alimentador Tangua da SE Pilarzinho 230/13,8 kV,

Corrente de curto-circuito oscilografada - $300 \mathrm{~A}$.

Tipo de defeito: fase-terra com impedância.

Endereço: Rua das Laranjeiras. 
Figura 23 - Alimentador Tanguá. Local do defeito (seta).e resultado da aplicação da metodologia heurística (tramos em vermelho $>90 \%$ de pertinência)

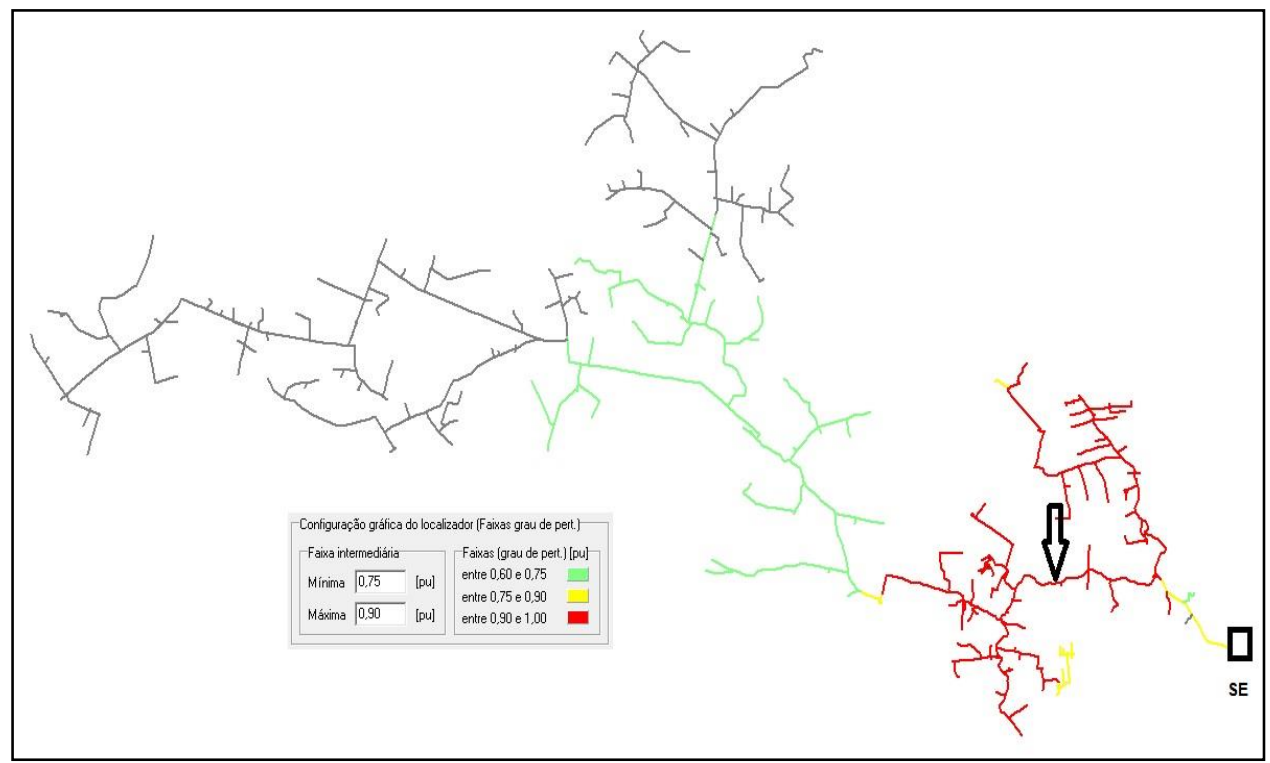

Fonte: Elaborada pelo autor.

Alimentador Tanguá da SE Pilarzinho 230/13,8 kV

Corrente de curto-circuito oscilografada: 966,0 A.

Tipo de defeito: fase-terra com impedância.

Endereço da falta: interno à subestação Pilarzinho.

Figura 24 - Alimentador São João Local do defeito (seta) e resultado da aplicação da metodologia heurística (tramos em vermelho $>90 \%$ de pertinência)

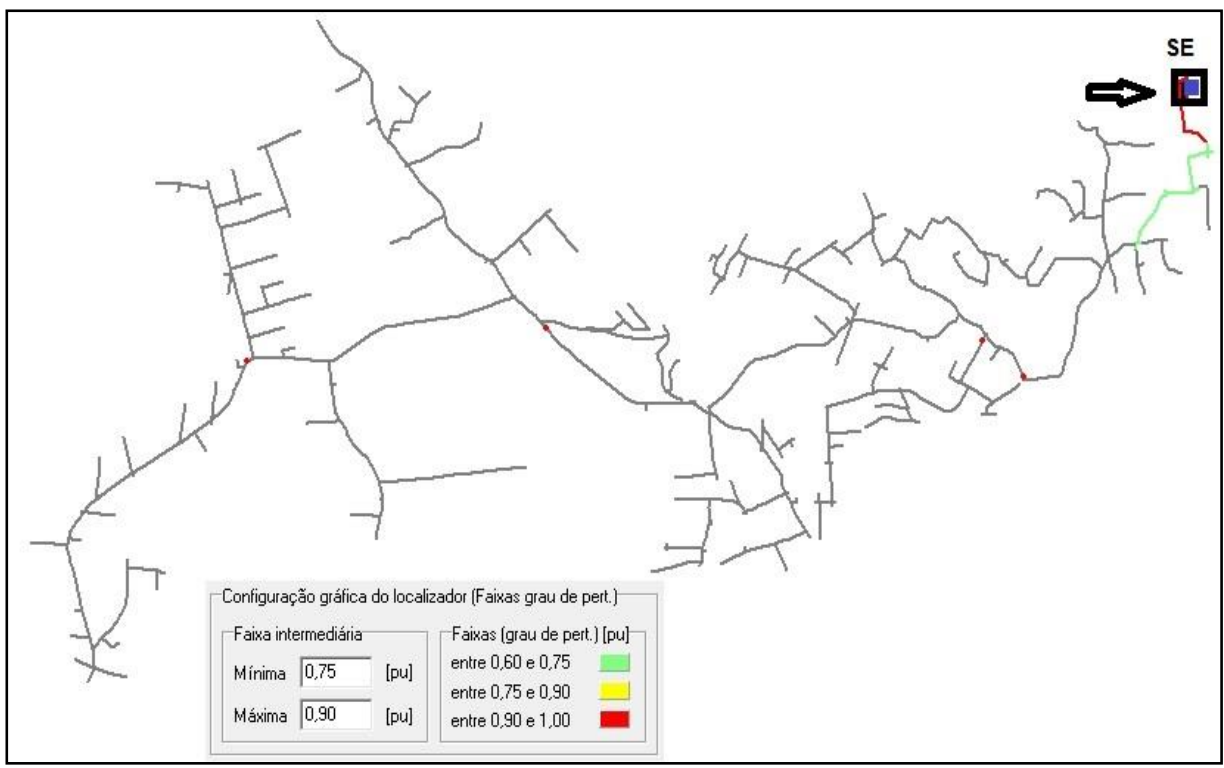

Fonte: Elaborada pelo autor. 
Alimentador Oswaldo Cruz.- SE Cidade Industrial de Curitiba 230/13.8 kV

Corrente de curto-circuito oscilografada: $1.830 \mathrm{~A}$.

Tipo de defeito: fase-terra com impedância.

Endereço da falta: Rua Desembargador Cid Campelo x Rua Pedro Gusso

Alimentador Eletrofrio.- SE Cidade Industrial de Curitiba 230/13.8 kV

Corrente de curto-circuito oscilografada: $1.440 \mathrm{~A}$.

Tipo de defeito: fase-terra com impedância.

Endereço da falta Endereço: Rua João Bettega x Rua Senador Acioly Filho

Observa-se que a localização real da falta nos casos estudados está contida na área mais provável (> 90\%) da localização da ocorrência, resultante da aplicação da metodologia heurística proposta, evidenciando a sua assertividade, embora em alguns casos a área indicada é razoavelmente extensa.

Figura 25 - Alimentador Oswaldo Cruz Local do defeito (seta) e resultado da aplicação da metodologia heurística (tramos em vermelho $>90 \%$ de pertinência)

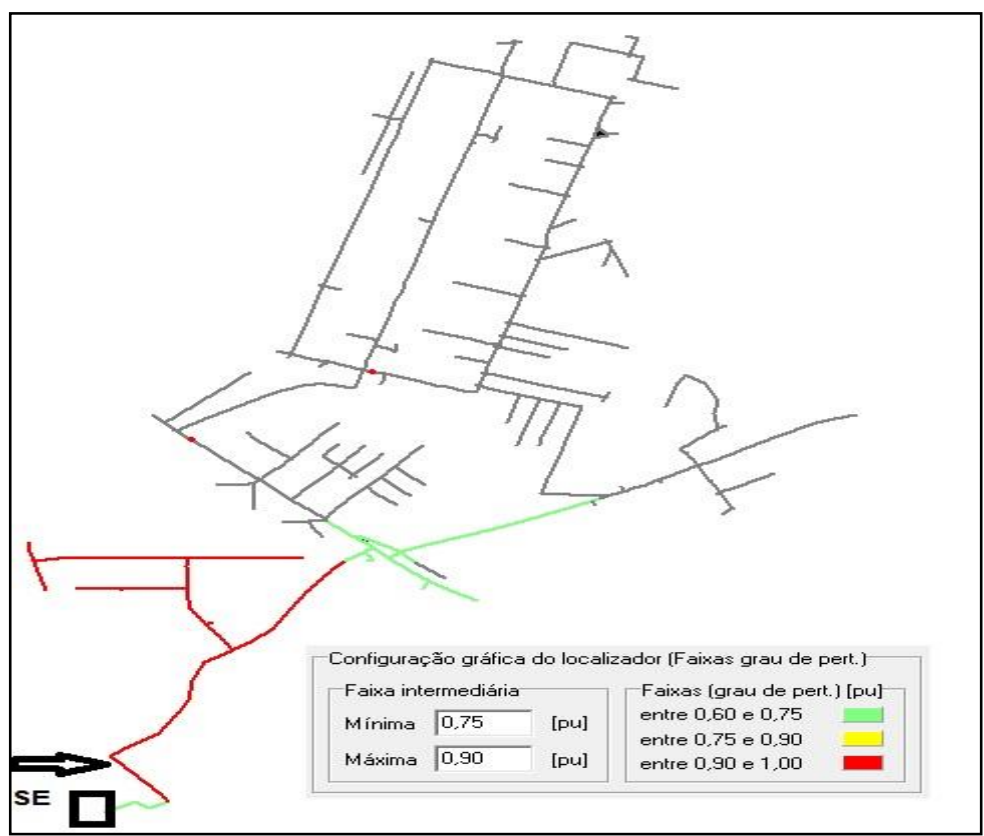

Fonte: Elaborada pelo autor. 
Figura 26 - Alimentador Eletrofrio Local do defeito (seta) e resultado da aplicação da metodologia heurística (tramos em vermelho $>90 \%$ de pertinência)

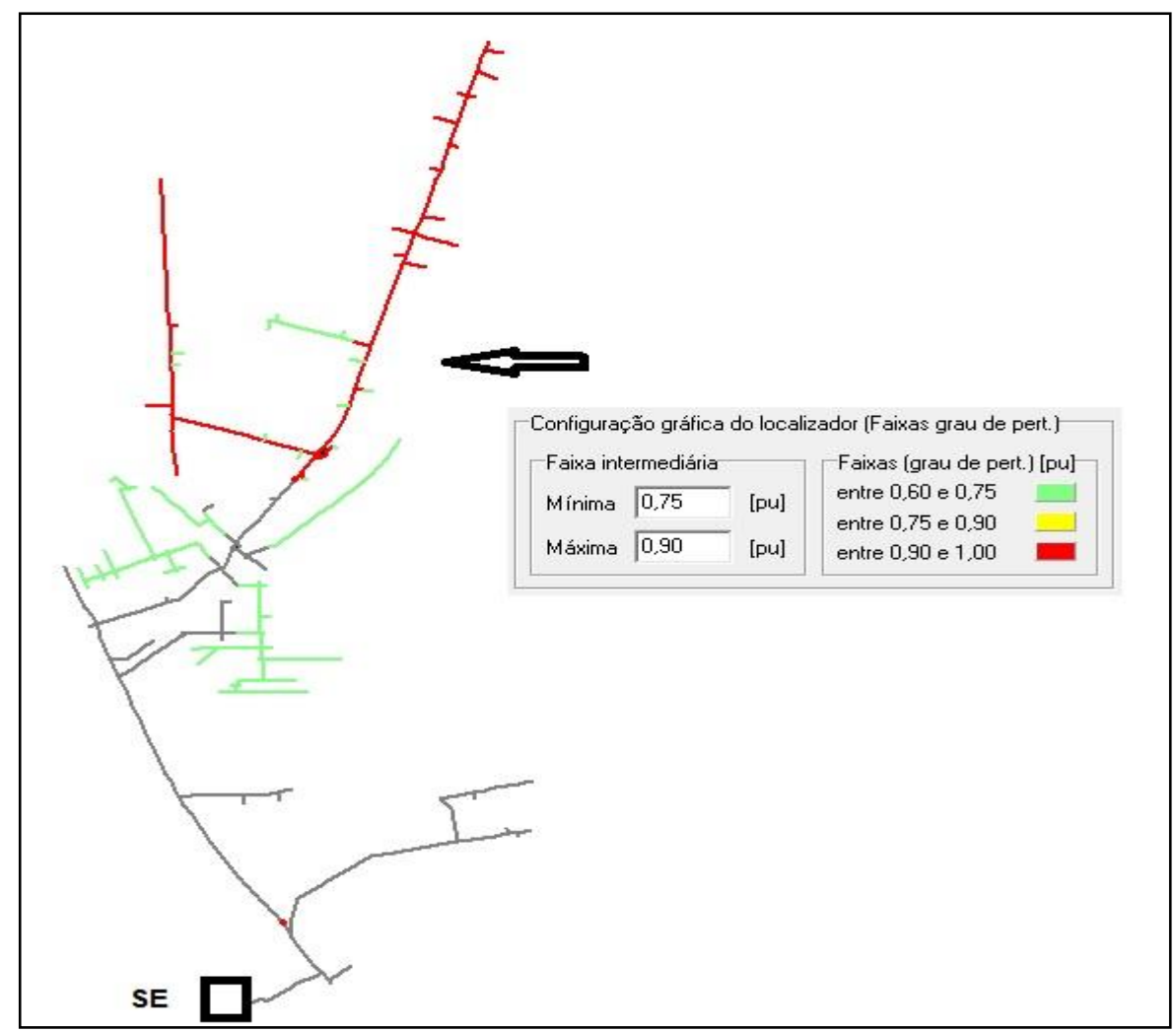

Fonte: Elaborada pelo autor.

\subsection{Estudo Paramétricos de Variáveis Heurísticas}

Focando o defeito ocorrido no alimentador Eletrofrio objeto de estudo anteriormente, foi realizado estudo paramétrico que consistiu no cálculo determinístico das correntes resultantes considerando, separadamente, cada um dos valores das variáveis heurísticas.

Assim, foram calculadas as correntes para cada um dos valores heurísticos de potência de curto circuito (equivalente elétrico) na subestação, considerando os valores de resistência de defeito e de resistência do condutor fixos. Analogamente para os valores heurísticos de resistência de defeito e de resistência do condutor, foram realizados os cálculos mantendo os demais valores heurísticos fixos.

Os valores de referência adotados foram: 
- Impedância da curto circuito da subestação, que resulta na corrente de curto de 1.440 A quando da ocorrência do defeito ocorrido na Rua João Bettega x Rua Senador Acioly Filho :

$\mathrm{Z1}=0,0120+\mathrm{j} 0,4164 \mathrm{pu}$.

$\mathrm{Z0}=0,3231+\mathrm{j} 3,5263 \mathrm{pu}$.

- Temperatura de operação dos condutores: $30 \stackrel{\circ}{ } \mathrm{C}$.

- Resistência de defeito: 40 ohms

Os resultados obtidos estão apresentados nos 3 gráficos de corrente de curto circuito em função de variações, respectivamente, de potência de curto circuito, de resistência do condutor (temperatura) e de resistência de defeito, mantendo-se em cada um, os outros dois parâmetros fixos.

Figura 27 - Corrente de c. c. versus potência de c.c. da subestação

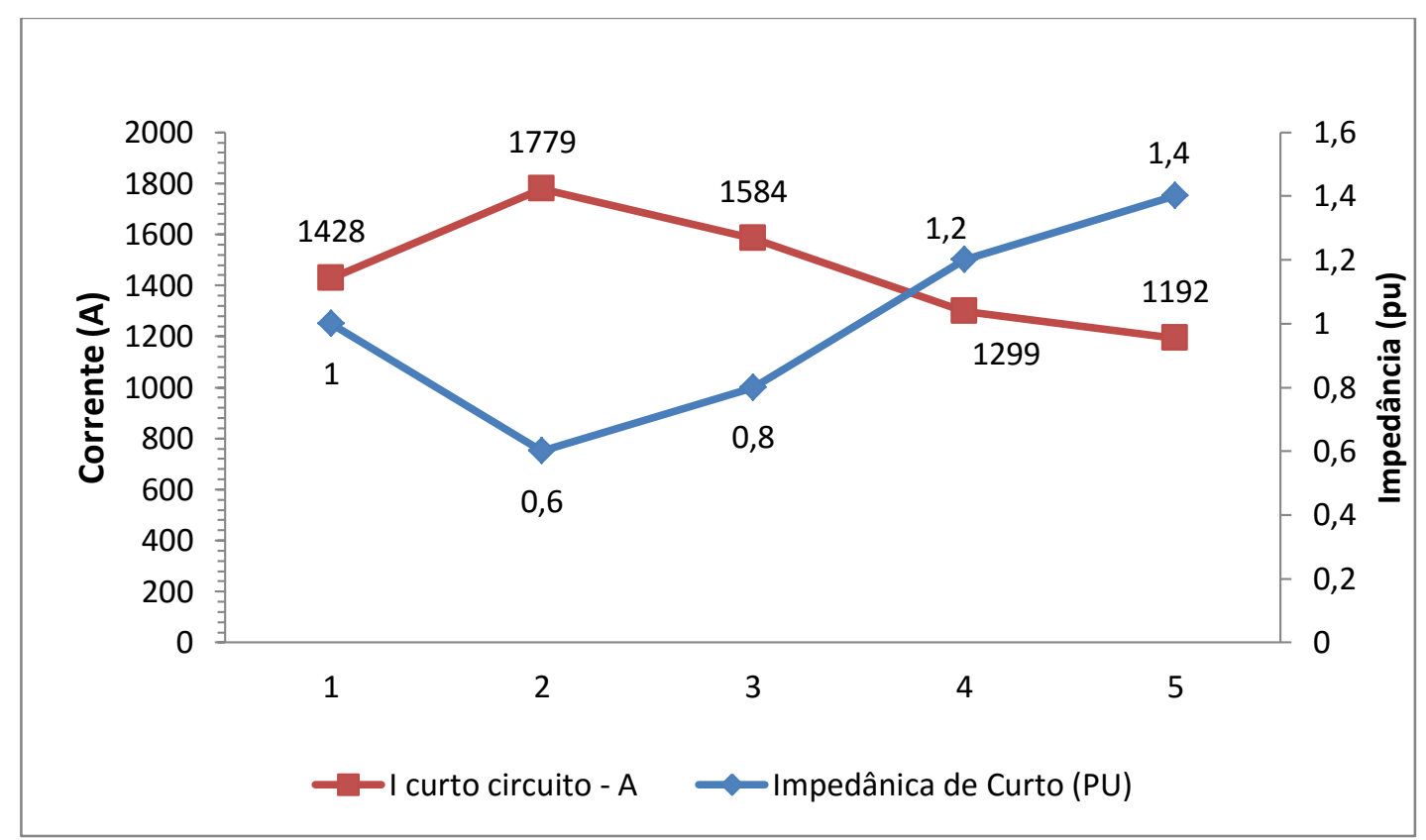

Fonte: Elaborada pelo autor.

Na Figura 27 observa-se que há variação de $83 \%$ a $125 \%$ da corrente de c.c. para as variações das possíveis potências de c.c. da subestação, o que resulta, pelo método determinístico, diferentes indicações de locais de c.c., que se situariam fora da área (vermelha) preconizada pela aplicação do método heurístico. 
Figura 28 - Corrente de c.c. versus temperatura de operação dos condutores

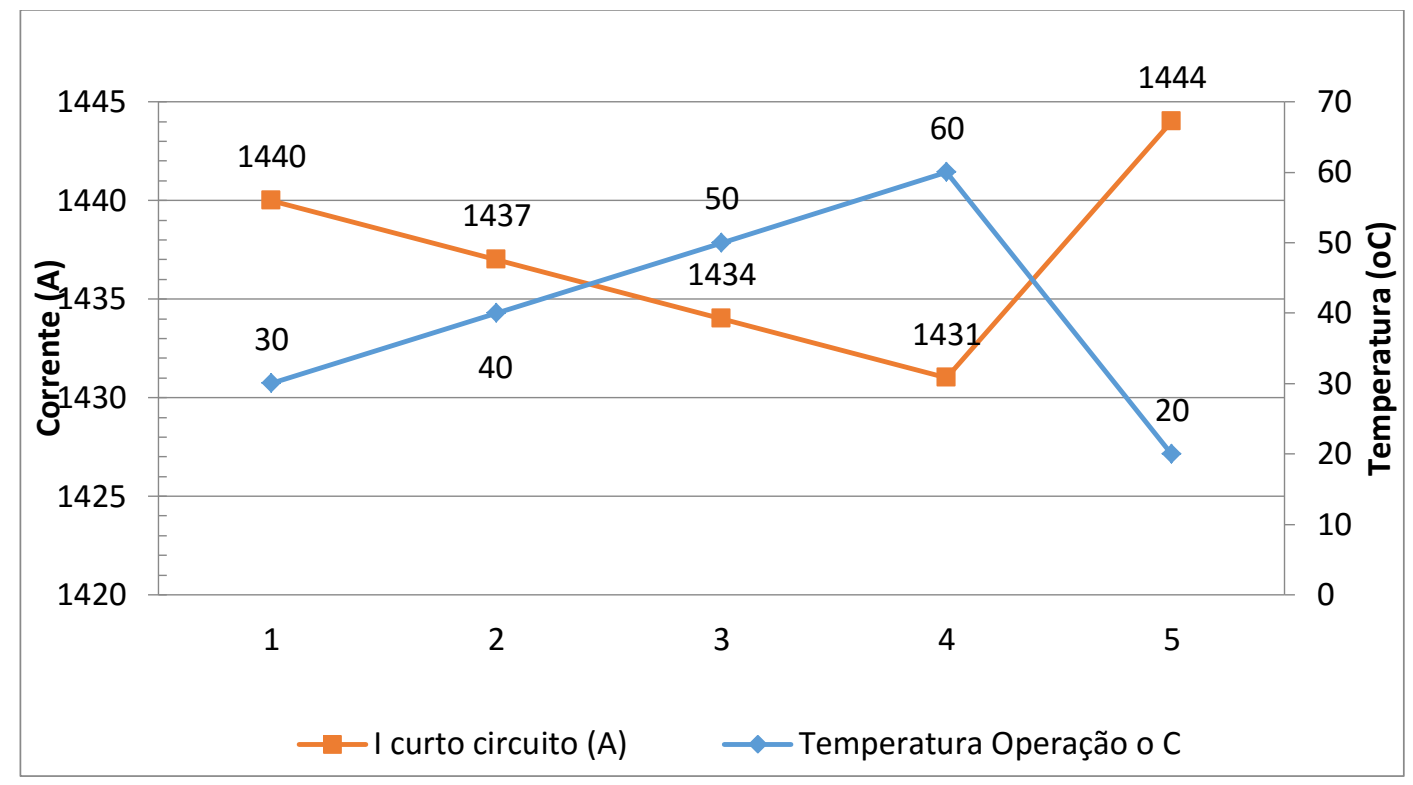

Fonte: Elaborada pelo autor.

$\mathrm{Na}$ Figura 28 observa-se que as variações de temperatura consideradas, que impactam na resistência dos condutores, não provocam valores significativamente diferentes nas correntes de c.c., apresentando, portanto, resultados semelhante aos que se obteriam com a aplicação do método heurístico.

Figura 29 - Corrente de c.c. versus resistência de defeito

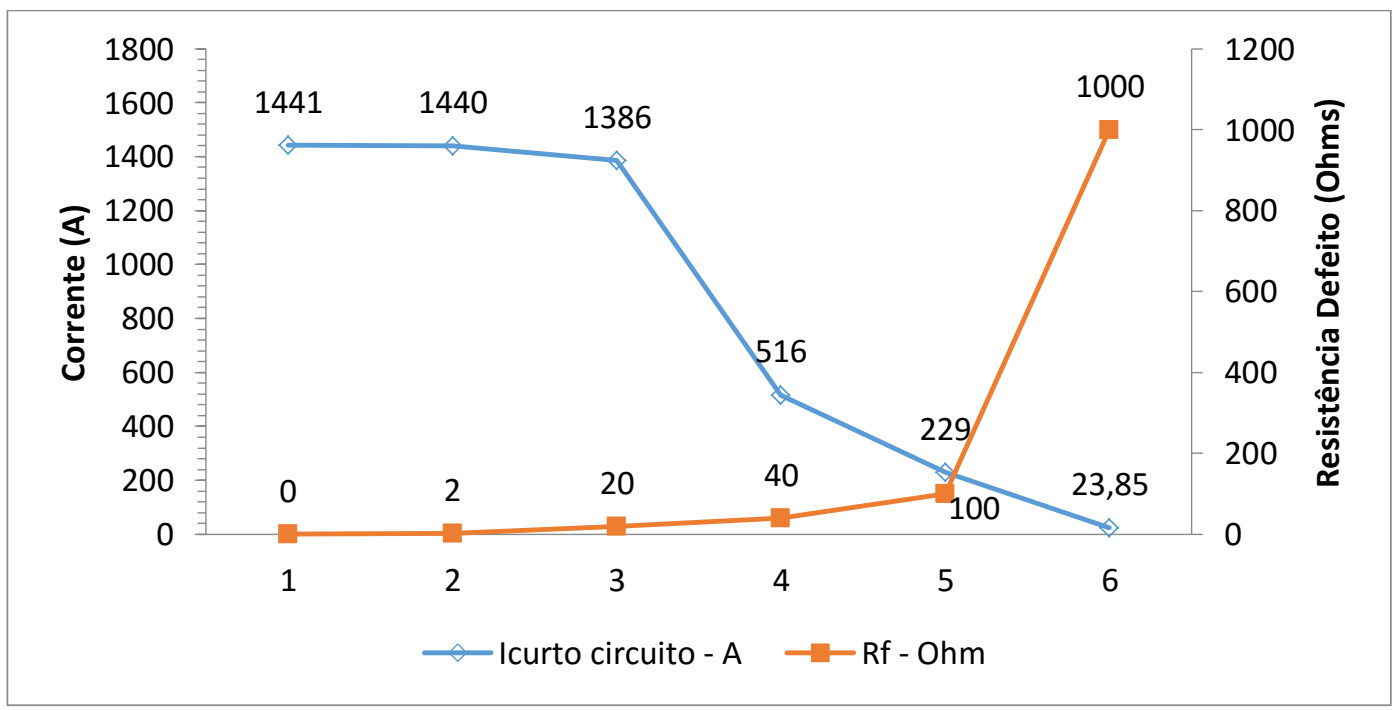

Fonte: Elaborada pelo autor.

Finalmente, verifica-se significativas variações na c.c. quando há variação da resistência de defeito, conforme mostra a Figura 29. 
Nota-se que, para valores elevados de resistência de defeito (por exemplo: 1000 ohms, a corrente de curto circuito ( 23 A) é menor que a corrente de carga (usualmente de 100 a $300 \mathrm{~A}$ ), o que significa que o defeito não é detectado pelo sistema de proteção (usualmente ativado por corrente maiores que $350 \mathrm{~A}$ ). Observase que apenas resistências de defeito.da ordem de 40 ohms (ou mais), que resultam em corrente de curto circuito maiores que $500 \mathrm{~A}$, nesse caso, seriam detectada pelo sistema de proteção, com razoável fator de segurança ( 1,4 ou seja $350 \mathrm{~A} / 500 \mathrm{~A}$ ).

É interessante notar que os relés de proteção de neutro, normalmente, operam para valores de corrente superior a $25 \mathrm{~A}$, o que ocorre, neste caso, para resistências de defeito menores que 100 ohms, com elevado fator de segurança.

Evidencia-se então, que a aplicação simples e direta da metodologia determinística pode levar a resultados incorretos de localização de defeito quando não se conhece o valor da resistência de defeito. 


\section{CONCLUSÕES E TRABALHOS FUTUROS}

Este trabalho propõe o desenvolvimento de metodologia com variáveis heurísticas para localização de regiões de ocorrência de curto-circuito em alimentadores primários de sistemas de distribuição, a partir de:

- conhecimento da correspondente corrente de falta na subestação, por meio de registros de oscilografia presentes, usualmente, nos sistemas de proteção da subestação;

- das características físicas e operacionais da rede;

- variáveis heurísticas referentes a parâmetros mais influentes nos valores de curtocircuito.

Este trabalho identificou diversas variáveis heurísticas, dentre as quais, as principais foram;

- resistência de defeito, que varia em função do contato condutor-solo;

- resistência dos condutores, que podem variar de acordo com a temperatura de operação e também impactam na impedância da rede;

- equivalente elétrico do sistema supridor (subestação) e tensão pré-falta;

Vale ressaltar que a variável heurística "resistência de defeito" apresenta o maior grau de incerteza e pode produzir resultados incorretos se aplicado método determinístico para o cálculo de curto circuito. Este fato ensejou a realização de ensaios em campo para avaliação desse parâmetro em diversas situações reais, a saber: 
- condutor sobre brita

- condutor sobre árvore

- condutor sobre grama

- condutor sobre terra

- condutor sobre asfalto

Nota-se que os testes indicaram resistência de defeito abaixo de 100 ohms em todas as situações, exceto as de condutor ao solo de asfalto e de brita. Este fato permite a aplicação da metodologia proposta, recomendando que as pertinências dos valores das variáveis heurísticas envolvidas sejam determinadas pelo solo percorrido pelo alimentador.

A metodologia proposta resulta em:

- a melhoria da qualidade de fornecimento pela redução dos tempos de atendimento de ocorrências em redes primárias contribuindo para o alcance das crescentes metas de continuidade exigida pelo Órgão Regulador, como a melhoria da imagem da Concessionária e;

- a redução dos custos operacionais resultantes da eficiência das equipes de campo, que usualmente dispendem significativos esforços para localização de defeitos, sobretudo em condições climáticas adversas, quando frequentemente ocorrem defeitos.

Finalmente, ressalta-se que foi desenvolvida uma ferramenta para operacionalizar a metodologia proposta, a qual foi aplicada em vários alimentadores reais de uma grande distribuidora brasileira, havendo a comprovação da sua eficácia.

Dentre os temas abordados nesta pesquisa, alguns não pertencem ao foco deste trabalho, porém poderiam ser objeto de outras pesquisas futuras, destacando-se:

- aprofundamento da metodologia envolvendo outras heurísticas; pesquisa dos melhores valores padrões para as pertinências, os erros, etc.

- sistema de mapeamento de resistência de defeitos em função do tipo de solo e de 
pertinências;

- extensão da metodologia para detecção e localização de defeitos de alta impedância (>100 ohms),

- análise do impacto de geração distribuída na localização de defeitos em redes primárias de distribuição. 


\section{REFERÊNCIAS}

AGGARWAL, R.K., ASLAN, Y., JOHNS, A.T. An interactive approach to fault location on overhead distribution lines with load taps. IEEE Developments in Power System Protection. (Conference Publication No. 434), 1997, p. 184-187.

ALSTOM T\&D ENERGY. Network protection - automation guide. First Edition. Levallois-Perret. France, July, 2002.

ANEEL. Agência Nacional de Energia Elétrica. Resolução №505, Brasília, nov 2001, $14 \mathrm{p}$.

ANSI/IEEE STANDARD. ANSI/IEEE Standard C37-2 - Standard Electrical Power System Device Function Numbers ANSI number. IEEE Sevice Center, 1979.

ANTUNES, A. U.; OLIVEIRA C. C. B; GUARALDO J. C.; CUNHA, A. P.; DUARTE, D. P.; SCHMIDT, H. P.; PIOLI, D.; QUEIROGA, R., SOUZA, H. G. B. Avaliação de desempenho e possíveis ajustes do sistema de proteção para sistema desequilibrado com neutro multi-aterrado. IV CITENEL - Congresso de Inovação Tecnológica em Energia Elétrica, Araxá - MG, Brasil, 2007.

ASSOCIAÇÃO BRASILEIRA DE NORMAS TÉCNICAS. NBR-14039: Instalações elétricas de média tensão de $1 \mathrm{kVa}$ 36,2kV. Rio de Janeiro, 2005, 87p.

BAZERMAN, M.H. Processo Decisório: para cursos de Administração, Economia e MBAs. Rio de Janeiro: Elsevier Editora, 2004.

BÍSCARO, A. A. P. Proposta de algoritmos inteligentes para localizar faltas e monitorar a qualidade da energia em redes de distribuição de energia elétrica. Tese de Doutorado. UNESP. Ilha Solteira, São Paulo, 2013.

BLACKBURN, J. L. Applied protective relaying. 2 edição. Coral Springs. Flórida: Westinghouse Electric Corporation Editora,1979.

CEBRIAN, J. C. A.; MATSUO, N.; FONTANA, C.; VASCONCELOS, G.; KAGAN, N.; SUEMATSU, A. Sistema de gerenciamento inteligente e suporte a operação de redes de energia. CBQEE, Santos - São Paulo, ago. 2007.

CHOI, M. S., LEE, S., LEE, D., JIN, B. A new fault location algorithm using direct circuit analysis for distribution systems. IEEE Transactions on. Power Systems. $p$ 35-41, 2004. 
COOPER POWER SYSTEM. Controle de religador microprocessado Form 6. São Paulo, 2002.

COPEL - COMPANHIA PARANAENSE DE ENERGIA. Manuais de instruções técnicas de proteção de redes de distribuição contra sobre correntes - MIT's 162501, 162502 e 162503. Curitiba, 2004.

Critérios de proteção para os sistemas de distribuição $13,8 \mathrm{kV}$ e 34,5kV..Diretoria de Distribuição, SED/DPPR, Curitiba, 2009.

DAS, R. Determining the locations of faults in distribution systems. Tese de Doutorado. University of Saskatchewan, Saskatoon, Canada, 206p, 1998.

DAS, R., SHADEV, M., SHIDU, T. A technique for estimating locations on shunt faults on distribution lines. Conference Proceedings. IEEE WESCANEX, v. 1, p 611, 1995.

E. O. SCHWEITZER III, SCHEER, GARY W., FELTIS, MARK W. A fresh look at distribution protection. Second International Symposium on Distribution Automation and Demand side Management. Florida, 1992.

ERIKSSON, L.; SAHA, M. M.; ROCKFELLER, G. D. An accurate fault locator with compensation for apparent reactance in the fault resistance resulting from remote-end infeed. IEEE Transactions on Power Apparatus and Systems, v. 104, n. 2, p. 424-436, February 1985.

FALCÃO, D. M. Técnicas inteligentes aplicadas a sistemas de potência: Conjuntos, Lógica e Sistemas Fuzzy. UFRJ, Rio de Janeiro, ago 2002.

FRITZEN, P. C.. Estimação da seção em falta e processamento de alarmes em sistemas de potência utilizando um sistema híbrido fundamentado na heurística construtiva e na programação inteira. Tese de Doutorado. UFSM. Santa Maria - RS, 2012.

GALIJASEVIC, Zijad.; ABUR, Ali. Fault location using voltage measurements. IEEE Transactions On Power Delivery, V. 17, no. 2, pp.441,445, Apr. 2002. doi: 10.1109/61.997915.

GE PUBLICATION. GET- 6450. Distribution system feeder overcurrent protection. General Electric, USA, 1998.

GIRGIS, A., FALLON, C., LUBKERMAN, D. A fault location technique for rural distribution feeders. IEEE Transactions. Ind. Applications. 26 (6). p 1170-1175, 1993.

GOLE, A., MARTINEZ-VELASCO, J.A., KEN, A.J.F. Modelling and analysis of system transients using digital programs. IEEE PES Special Publication, TP-1330, jan.1999. 
J.S. HAMMOND, R.L. KEENEY, H. RAIFFA The hidden traps in decision making (HBR OnPoint enhanced edition) Harvard Business Review. Outbro de 2008.

HE Y., SODER L., ALLAN R. N. Distribution automation: impact of communication system on reliability of automatic control. IEEE Porto Power Tech Conference, Porto - Portugal, set, 2001.

HEISING, CHARLES R., PATTERSON, RONALD C, WEINTRAUB, ELAINE Y. Digital relay software quality. General Electric - Protection \& Control. Malvern. PA. USA, 1997.

JARDINI, JOSÉ ANTONIO. Sistemas elétricos de potência - automação. São Paulo: EPUSP, 1999.

KAGAN, N.; OLIVEIRA, C. C. B. O. reconfiguração de redes de distribuição de energia elétrica através de ferramentas para solução de problemas de decisão com múltiplos objetivos e incertezas. SBA Controle \& Automação. V. 9 no. $1 /$ jan., fev., mar. e abr. 1998.

KINDERMANN, GERALDO. Curto circuito. 1 ed. Porto Alegre: Editora Sagra-DC Luzzato, 1992.

LUIZ, Cicéli M. Avaliação dos impactos da geração distribuída para proteção do sistema elétrico. Dissertação de Mestrado. UFMG. Belo Horizonte, 2012.

MANASSERO, GIOVANNI J. Sistema para localização de faltas em linhas de transmissão com subestações conectadas em derivação. Tese de Doutorado. Escola Politécnica da USP. São Paulo, 2006.

MARQUEZ, DIOGENES C., KRAUSS, CARLOS C. et ALLI. A Experiência da COPEL na integração de proteções digitais ao sistema de automação de subestações. XVII SNPTEE. Uberlândia, Minas Gerais, 2003.

MENDEL, J.M. Fuzzy logic systems for engineering: a tutorial. Proceedings of IEEE, vol.83, Califórnia, USA, 1992.

MEZA, E. B. M.; DE SOUZA, J. C. S.; SCHILLING, M. TH.; COUTTO FILHO, M. B. Utilização de um modelo neuro-fuzzy para a localização de defeitos em sistemas de potência. XVIII Seminário Nacional de Produção e Transmissão de Energia Elétrica. Curitiba - PR, Brasil, 2005.

MOONEY, JOE. Microprocessor-based transmission line relay applications. Schweitzer Engineering Laboratories, Inc, Pullman, WA, USA, 1998.

MORA-FLÔREZ,J; MELÊNDEZ,J; CARRILLO-CAICEDO,G. Comparison of impedance based fault location methods for power distribution systems. Electric Power Systems Research, Elseiver B.V 78., p 657-666, 2008. 
NOVOSEL, D., HART, D., MYLLYMAKI,D. System for locating faults and estimating fault resistance in distribution networks with tapped loads. US Patent number 5,839,093, 1998.

RUFATO JÚNIOR, E. Viabilidade técnica e econômica da modernização do sistema de proteção da distribuição. Dissertação de mestrado, Escola Politécnica da USP, São Paulo, Brasil, 2006.

RUFATO, E.,J.;LANGE,F.L.; ANTUNES, A. U.;DUARTE, D. P.;TAHAN, C.M.V., Utilização de lógica fuzzy em cálculo de curto-circuito para localização de faltas em redes de distribuição. São Paulo: IEE PES,.2012.

RUFATO, ELOI J. Relatórios de Ensaios de curto circuito na SE de Francisco Beltrão e Marmeleiro. COPEL - CNDS - Relatório 01/98, Curitiba, 02/2002.

RUFATO, Eloi J.; OLIVEIRA, Carlos C. B.; OMORI, Júlio et alli. Análise da influência de componentes harmônicos de corrente em relés de proteção nos sistemas monofásicos com retorno pela terra. VIII Simposio lberoamericano sobre Protección de Sistemas Electricos de Potencia - SIPSEP. Monterrey. México, 05/2006.

RUFATO, ELOI JR.. Relatórios de ensaios de curto circuito na SE de Francisco Beltrão e Marmeleiro. COPEL - CNDS - Relatório 01/98, Curitiba, 02/2002.

RUFATO, ELOI JR; KOEHLER, MARCOS. Avanços tecnológicos sob o aspecto de funções da proteção de sobre corrente do sistema de distribuição. Universidade de São Paulo. São Paulo, 2002.

SAHA, M., ROSOLOWSKI, E. Method and device of fault location for distribution networks. US Patent number 6,483,435, 2002.

SENGER, E. C, MANASSERO, G. J., PELLINI, E.L...Automated fault location system for primary distribution networks, IEEE Transactions on Power Delivery, $v$ 20, n 2, p 1332-1340, 2005.

SENGER, E. C. Localizador de faltas para redes de distribuição. III Conladis, set. 1998.

SENGER, E. C. Proteção digital de sobre corrente. Tese de Doutorado. Escola Politécnica da USP. São Paulo, 1991.

SENGER, EDUARDO C.. Proteção digital. Escola Politécnica - USP - Universidade de São Paulo. São Paulo, jun. 2001.

SHADEV, M, AGARWAL, R. A technique for estimating transmission line fault locations from digital impedance relay measurements. IEEE Transactions on Power Delivery. 3 (1). p 121-129, 1998.

SILVA, J. C. R. Priorização de áreas para a Instalação de chaves telecomandadas no sistema de distribuição. Dissertação (Mestrado) - Escola 
Politécnica da Universidade de São Paulo. Departamento de Energia e Automação Elétricas, São Paulo, 2005.

SILVA, MURILO. Implementação de um localizador de faltas híbrido para linhas de transmissão de três terminais baseados na transformada wavelet. Tese de Doutorado. Escola de Engenharia de São Carlos, Universidade de São Paulo, São Carlos, São Paulo, 2008.

SRINIVASAN, K , A. St-JACQUES, A.. A new fault location algorithm for radial transmission lines with loads. IEEE Transactions on Power Delivery, p 1676-1682, 1989.

STEVESON, Willian. Elementos de análise de sistemas de potência. Mc Graw Hill, 1986.

TAKAGI, T.; YAMAKOSHI, Y.; YAMAURA, M.; KONDOW, R.; MATSUSHIMA, T. Development of a new type fault locator using the one-terminal voltage and current data. IEEE Transactions on Power Apparatus and Systems, PAS-101, n. 6, p. 2892-2898, Aug. 1982.

TEAM ARTECHE - Disponível em: http://www.teamarteche.com. Acesso em: 20 maio 2012.

WARRINGTON, A. Protective relays, their theory and practice. Chapman and Hall, V2, London, 1968.

WESTINGHOUSE ELECTRIC CORPORATION. Electrical transmission and distribuition reference book. 4 ed. Westinghouse Electric Corporation, East Pittsburgh, PA, 1964.

WHIPP\&BOURNE. GVR recloser and panacea control instruction manual. Castleton. England, 1997.

WIRMOND, V. E.. Alocação de TCPST em sistema de transmissão usando algoritmos genéticos e fluxo de potência ótimo. Dissertação de Mestrado. UFPR. Curitiba , 2009.

YANG, L., SPRINGS, C. One terminal fault location system that corrects for fault resistance effects. US Patent number 5,773,980, 1998.

ZHU, J, LUBKEMAN, D., GIRGIS, A. Automated fault location and diagnosis on electric power distribution feeders. IEEE Transactions on Power Delivery, $p$ 801809, 1997.

ZHU, J.; LUBKEMAN, D. L.; GIRGIS, A. A. Automated fault location and diagnosis on electrical power distribution feeders IEEE Transactions on Power Delivery. V. 12, № 2, Apr. 1997. 
ZIMMERMAN, K. Aplicações de relés micro processados na distribuição. Schweitzer Engineering Laboratories, Inc., Belleville, IL USA, 2008.

ZIMMERMANN, H.J.. Fuzzy set theory and its applications. Third edition, Kluwer, 1996. 
ANEXOS 


\section{ANEXO A: PUBLICAÇÕES ORIUNDAS DESTA PESQUISA}

A seguir são apresentados duas publicações oriundas desta tese e algumas outras publicações do autor relacionadas com o tema.

RUFATO, E.,J.;LANGE,F.L.; ANTUNES, A. U.;DUARTE, D. P.;TAHAN, C.M.V., Fault Location System for Primary Feeders on Short Circuit Model Considering the Uncertaintes of Parameters Involved. São Paulo: Revista IEEE-AL, 2015.

RUFATO, E.,J.;TAHAN, C.M.V., Energy Production Using the Co-Generation of Methane Gas Connected to Copel's Distribution Grid - Tests and Procedures. São Paulo: Revista IEEE-AL, 2015.

Copel, E.R.; Daimon, F.L.L.; Daimon, A.U.A.; Duarte, D.P.; Tahan, C.M.V. Use of Fuzzy logic in calculation of short-circuit for locating faults in distribution networks. Innovative Smart Grid Technologies Latin America (ISGT LA), 2013 IEEE PES Conference. 2013, Pp. 1 - 7, DOI: 10.1109/ISGT-LA.2013.6554428

RUFATO, E.,J.;LANGE,F.L.; ANTUNES, A. U.;DUARTE, D. P.;TAHAN, C.M.V., Utilização de lógica fuzzy em cálculo de curto-circuito para localização de faltas em redes de distribuição. São Paulo: IEE PES, 2012.

RUFATO, E.,J.;LANGE,F.L.; ANTUNES, A. U.;DUARTE, D. P.;TAHAN, C.M.V., Fault Location System for Primary Feeders on Short Circuit Model Considering the Uncertaintes of Parameters Involved. São Paulo: IEE PES, 2012.

RUFATO, E.,J.;TAHAN, C.M.V., Energy Production Using the Co-Generation of Methane Gas Connected to Copel's Distribution Grid - Tests and Procedures. Hong Kong, CHINA: International Conference on Earth Sciences and Engineering - ICESE, 2011.

PELLINI, E.L.; SENGER, E.C.; MANASSERO, G.; REIS FILHO, F.; RUFATO, E. Custom distribution feeder recloser IED with high impedance protection function. Electricity Distribution (CIRED 2013), 22nd International Conference and Exhibition on,.2013, Pp. 1 - 4, DOI: 10.1049/cp.2013.1010 
RUFATO, E.; SAKURAI, C.A.; PEREIRA, V.H.; RIBEIRO, J.R.; MIGUEL, D.S. Power line communication for monitoring small electricity generating plant Innovative Smart Grid Technologies Latin America (ISGT LA), 2013 IEEE PES Conference, 2013, Pp. 1 - 6, DOI: 10.1109/ISGT-LA.2013.6554485

RUFATO JUNIOR, E.; ANTUNES, A.; LANCE, F.; DUARTE, D.; TAHAN, C. Fault location system for primary feeders based on short circuit model considering the uncertainties of parameters involved, Electricity Distribution (CIRED 2013), 22nd International Conference and Exhibition,.2013, Pp. 1 4, DOI: 10.1049/cp.2013.0994. 


\section{ANEXO B: CASO EXEMPLO}

A rede da Figura 30 foi analisada para possibilitar o melhor entendimento da metodologia e da ferramenta desenvolvida.

Figura 30 - Diagrama unifilar do caso exemplo

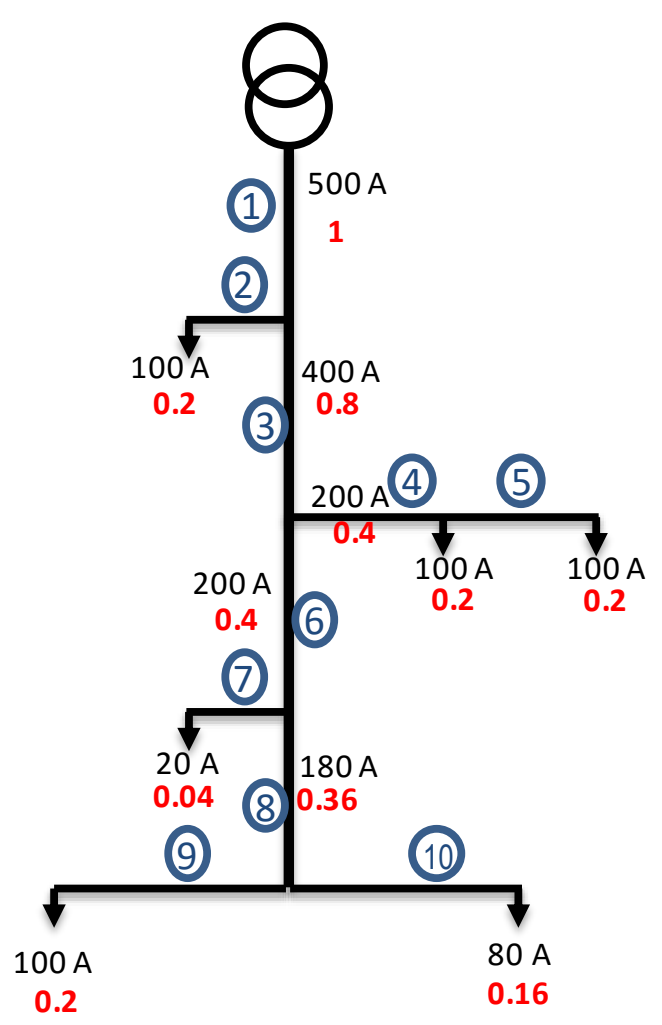

Nota: Eleborada pelo autor.

Cálculo do fluxo de potência a priori.

Considera-se que os trechos 2, 4 e 7 são trechos muito curtos e por estarem próximos ao tronco não são protegidos por chaves fusíveis. Esta rede é composta por 10 trechos (tramos) onde há um ponto notável ao final de cada trecho.

A Tabela 6 que apresenta os resultados do fluxo de potência, o qual foi ajustado previamente considerando a leitura de 500A pelo relé na subestação, ou seja, todos os blocos de carga foram reavaliados considerando que o valor lido é de 500A préfalta. Na simulação de carga máxima o trecho 9 tinha.um valor de $90 \mathrm{~A}$ para 490A na 
saída da subestação. Deste modo, elevou-se a corrente calculada a priori na subestação até o valor lido. Então, todos os demais trechos "pais" (trechos que alimentam as cargas foram corrigidos, ou seja, somando 0.02 "pu". a todos os demais trechos).

Tabela 6 - Valores de corrente em pu para os trechos em diferentes condições (A base é corrente na saída da SE)

\begin{tabular}{lllllllllll}
\hline Trechos & $\mathbf{1}$ & $\mathbf{2}$ & $\mathbf{3}$ & $\mathbf{4}$ & $\mathbf{5}$ & $\mathbf{6}$ & $\mathbf{7}$ & $\mathbf{8}$ & $\mathbf{9}$ & $\mathbf{1 0}$ \\
\hline $\begin{array}{l}\text { Valores não } \\
\text { ajustados (A) }\end{array}$ & 490 & 100 & 390 & 200 & 100 & 390 & 190 & 170 & 90 & 80 \\
Pré-Falta (A) & 500 & 100 & 400 & 200 & 100 & 200 & 20 & 180 & 100 & 80 \\
Pré-Falta (p.u.) & 1 & 0,2 & 0,8 & 0,4 & 0,2 & 0,4 & 0,04 & 0,36 & 0,2 & 0,16 \\
Defeito (A) & 2020 & - & - & - & - & - & - & - & - & - \\
Pós-Falta 1 (A) & 400 & 100 & 300 & 200 & 100 & 100 & 20 & 80 & 0 & 80 \\
Pós-Falta 2 (p.u.) & 0,8 & 0,2 & 0,6 & 0,4 & 0,2 & 0,2 & 0,04 & 0,16 & 0 & 0,16 \\
\hline
\end{tabular}

Os oscilogramas mostram que este defeito é um defeito trifásico. Os defeitos trifásicos ao final dos trechos 5, 9 e 10 possuem valores próximos para as correntes de curto-circuito. Os valores de correntes para estes 3 defeitos, previamente calculados, são 2020A, 2030A e 2050A respectivamente. Tais valores são considerados pelo programa como iguais, pois estão todos dentro de uma precisão $\varepsilon 1=50 \mathrm{~A}$. Os cálculos de curto-circuito destes 3 trechos mostram que os 3 são candidatos a terem o defeito. Ressalta-se que o valor da corrente de defeito é de 2020 A na SE.

O valor da corrente de carga do bloco que foi interrompido pelo fusível é da ordem de 100A. Esse valor é o valor das cargas atendidas pelos trechos 5, 9 e 10 dentro da precisão $\varepsilon 2=20 \mathrm{~A}$.

Aplicação das heurísticas.

As tabelas a seguir apresentam como foram obtidos os 25 casos de curto-circuito, os valores resultantes e a pertinência total (Tabela 7 e Tabela 8). 
Tabela 7 - Informação da pertinência e valores para i e j

\begin{tabular}{lllll}
\hline & i = 1 a 5 & j = 1 a 5 \\
\hline & u1 $(\mathrm{pu})$ & $\mathrm{v} 1(\mathrm{pu})$ & $\mathrm{u} 2(\mathrm{pu})$ & $\mathrm{v} 2(\mathrm{pu})$ \\
$\mathbf{1}$ & 0.4 & 0.6 & 0.4 & 0.71 \\
$\mathbf{2}$ & 0.7 & 0.8 & 0.6 & 0.82 \\
$\mathbf{3}$ & 1.0 & 1.0 & 0.8 & 0.9 \\
$\mathbf{4}$ & 0.7 & 1.2 & 1.0 & 1.0 \\
$\mathbf{5}$ & 0.4 & 1.4 & 0.4 & 1.08 \\
\hline
\end{tabular}

Tabela 8 - Valores finais da pertinência total e dos valores resultantes

\begin{tabular}{|c|c|}
\hline $\mathrm{u}$ total $=\mathrm{u} 1{ }^{*} \mathrm{u} 2$ & $v$ total $=v 1{ }^{*} v 2$ \\
\hline$(0.16)$ & 0.426 \\
\hline$(0.24)$ & 0.492 \\
\hline$(0.32)$ & 0.54 \\
\hline$(0.4)$ & 0.6 \\
\hline$(0,16)$ & 0.648 \\
\hline$(0.28)$ & 0.568 \\
\hline$(0.42)$ & 0.656 \\
\hline$(0.56)$ & 0.72 \\
\hline 0.7 & 0.8 \\
\hline$(0.28)$ & 0.864 \\
\hline$(0.4)$ & 0.71 \\
\hline 0.6 & 0.82 \\
\hline 0.8 & 0.9 \\
\hline 1.0 & 1.0 \\
\hline$(0.4)$ & 1.08 \\
\hline$(0.28)$ & 0.852 \\
\hline$(0.42)$ & 0.984 \\
\hline$(0.56)$ & 1.08 \\
\hline 0.7 & 1.2 \\
\hline$(0.28)$ & 0.756 \\
\hline$(0.16)$ & 0.994 \\
\hline$(0.24)$ & 1.148 \\
\hline$(0.32)$ & 1.26 \\
\hline$(0.4)$ & 1.4 \\
\hline$(0.16)$ & 1.512 \\
\hline
\end{tabular}

Observação (casos onde a pertinência é inferior a 0,6): 
Observa-se que apenas 5 casos apresentam a pertinência total superior (ou igual) a 0,6 .

Observa-se que inicialmente foi definido que o programa computacional não precisa realizar os cálculos a priori com variáveis heurísticas que resultam em pertinências menores do que $\mu=0.6$ pu.. A Tabela 9 mostra quais são as pertinências totais e os respectivos multiplicadores da corrente dos 5 casos de curto de circuito, apenas as que necessitam cálculos a priori apresentadas na tabela abaixo.

Tabela 9 - Pertinências totais e multiplicadores da corrente para os 5 curto circuitos

\begin{tabular}{ll}
\hline $\mathbf{i}=\mathbf{1}$ a $\mathbf{5}$ valores de pertinência & $\mathbf{j}=\mathbf{1}$ a $\mathbf{5}$. Valor \\
maiores que $\mathbf{0 , 6}$ & \\
\hline $\mathbf{0 . 7}$ & 0.8 \\
$\mathbf{0 . 6}$ & 0.82 \\
$\mathbf{0 . 8}$ & 0.9 \\
$\mathbf{1 . 0}$ & 1.0 \\
$\mathbf{0 . 7}$ & 1.2 \\
\hline
\end{tabular}

Deste modo tem-se apenas 5 valores de curto circuito para cada situação de carregamento e defeitos que não envolvem a terra para cada um dos 7 (10 - 3 trechos) pontos notáveis, ou seja 35 valores de curto circuito. Alguns dos valores calculados estão na Tabela 9.

A seguir identificam-se alguns valores candidatos da Matriz de Referência (Tabela 10) de corrente de curto circuito nos tramos. Há correntes de valores desde $1200 \mathrm{~A}$ até $2440 \mathrm{~A}$, com valores de pertinência de 0.6 a 1.2. O valor de pertinência 1 é muito próximo dos valores encontrados para defeitos ao fim dos trechos. 5, 9 e 10.

Entretanto como as correntes dos blocos são muito próximas, será preciso detalhar melhor toda a informação. Dos 35 valores de pertinência igual ou superior a 0.6 apenas os defeitos nos trechos 5, 7 e 9 são analisados com mais detalhes. 
No caso que alguma das magnitudes das correntes de curto circuito fosse obtida por variáveis heurísticas cujas pertinências sejam iguais a 1, esse tramo pode ser considerado o mais provável, desde que o bloco de carga também resultasse num bloco possível, isto é, em torno de 100A neste exemplo. Analisando-se os blocos de corrente carga percebe-se que $o$ trecho 9 e o trecho 5 são os que tem cargas iguais a $100 \mathrm{~A}$ e o bloco $10 \mathrm{com}$ carga de $80 \mathrm{~A}$ também se candidata em virtude da pequena diferença desde valor da carga (80A) com os demais blocos. Por outro lado, para os demais trechos os graus de pertinência são bem diversos.

Neste exemplo a pertinência 1 é compatível com a perda de 100A porém existem 3 regiões candidatas a serem o bloco com defeito, caso contrário, dentro das pertinências próximas ou iguais ter-se-ia que buscar outro bloco mais provável, para isso usa-se um delta pertinência. Ou seja, em função das incertezas dos cálculos de curto circuito as pertinências $\left|\mu_{2}-\mu_{3}\right|=0.03$ muito próximas são consideradas iguais.

Os valores de pertinência e de suas possíveis variações e dos erros de corrente são definidos pelo usuário. Este usuário pode a seu critério introduzir outras heurísticas, por exemplo, caso apenas um dos trechos candidatos percorra uma rua arborizada ou com defeitos frequentes, ele pode defini-la como a mais provável e enviar a equipe de manutenção.

A Tabela 10 apresenta parte dos 35 valores de corrente curto-circuito, a maioria com pertinência unitária. Os demais valores que não são apresentados são os valores de pertinência menores do que 1. Por exemplo, para defeitos no final do tramo 10 valor com pertinência 1 resultou com 3900A, com pertinência 0.8 , a segunda maior, o valor seria $3350 \mathrm{~A}$. 
Tabela 10 - Parte dos 35 valores de corrente de curto-circuito

\begin{tabular}{llll}
\hline $\begin{array}{l}\text { Trecho com defeito } \\
\mathbf{k}=\mathbf{1} \text { a } 35\end{array}$ & Curto-circuito & Valores a priori & $\begin{array}{l}\text { Pertinências totais } \\
\text { (A) }\end{array}$ \\
\hline $\mathbf{1}$ & & 3900 & 1 \\
$\mathbf{3}$ & 4000 & 3800 & 0,8 \\
$\mathbf{5}$ & 3350 & 2020 & 1 \\
$\mathbf{6}$ & 2020 & 3060 & 0,82 \\
$\mathbf{8}$ & 3100 & 2750 & 0,7 \\
$\mathbf{9}$ & 2545 & 2030 & 1 \\
$\mathbf{1 0}$ & 2020 & 2050 & 1 \\
\hline
\end{tabular}

Os valores de cálculo a priori mostram valores muito próximos entre si para os trechos 5, 9 e 10 respetivamente 2020A, 2030A e 2050A com pertinência unitária. Neste caso, pela proximidade das diferenças das correntes de curto-circuito dos tramos 5, 9 e 10 e pertinência 1, torna-se difícil distinguir qual é a área prioritária para o envio da equipe de manutenção. Entretanto a região provável de ter defeito já está definida, sendo constituída pelos tramos 5, 9 e 10. 


\title{
ANEXO C: DADOS UTILIZADOS NOS CASOS DE APLICAÇÃO DA FERRAMENTA
}

Para a realização destes estudos foram utilizados os seguintes valores de base:

\author{
Resistência de defeito: 40 ohms \\ Potência de curto-circuito trifásico: 238,7 MVAr \\ Potência de curto-circuito fase-terra: 68,5 MVAr
}

Os parâmetros dos cabos utilizados no alimentador primário de distribuição são mostrados na Tabela 11.

Obs. - Os valores de impedâncias R0, X0, R1, X1 estão em "pu", na base 100MVA. 
Tabela 11 - Parâmetros dos cabos utilizados no alimentador estudado

\begin{tabular}{|c|c|c|c|c|c|}
\hline CABO_ID & CODIGO & Ro & $\mathrm{XO}$ & $\mathbf{R 1}$ & $\mathrm{X} 1$ \\
\hline 1 & 1/0CA1 & 0,78250 & 1,91150 & 0,60470 & 0,44830 \\
\hline 2 & 1/0CA2 & 0,78250 & 1,91150 & 0,60470 & 0,44830 \\
\hline 3 & 1/0CA3 & 0,78250 & 1,91150 & 0,60470 & 0,44830 \\
\hline 4 & 1/0CA4 & 0,78250 & 1,91150 & 0,60470 & 0,44830 \\
\hline 5 & 1/0CAA1 & 0,86860 & 1,98150 & 0,69080 & 0,51830 \\
\hline 6 & 1/0CAA2 & 0,86860 & 1,98150 & 0,69080 & 0,51830 \\
\hline 7 & 1/0CAA3 & 0,86860 & 1,98150 & 0,69080 & 0,51830 \\
\hline 8 & 1/0CAA4 & 0,86860 & 1,98150 & 0,69080 & 0,51830 \\
\hline 9 & 1/0CAA5 & 0,86860 & 1,98150 & 0,69080 & 0,51830 \\
\hline 10 & 1/0CAA6 & 0,86860 & 1,98150 & 0,69080 & 0,51830 \\
\hline 11 & 1/0CAA7 & 0,86860 & 1,98150 & 0,69080 & 0,51830 \\
\hline 12 & $1 / 0 \mathrm{CC} 1$ & 0,55500 & 1,91310 & 0,37730 & 0,44990 \\
\hline 13 & 1/0CC2 & 0,55500 & 1,91310 & 0,37730 & 0,44990 \\
\hline 14 & 1/0CC3 & 0,55500 & 1,91310 & 0,37730 & 0,44990 \\
\hline 15 & $1 \mathrm{CA} 1$ & 0,94000 & 1,92000 & 0,76000 & 0,45000 \\
\hline 16 & $1 \mathrm{CA} 2$ & 0,94000 & 1,92000 & 0,76000 & 0,45000 \\
\hline 17 & $1 \mathrm{CA} 3$ & 0,94000 & 1,92000 & 0,76000 & 0,45000 \\
\hline 18 & 1CAA1 & 1,03000 & 1,98000 & 0,85000 & 0,52000 \\
\hline 19 & 1CAA2 & 1,03000 & 1,98000 & 0,85000 & 0,52000 \\
\hline 20 & $1 \mathrm{CC} 1$ & 0,65000 & 1,91000 & 0,47000 & 0,45000 \\
\hline 21 & 1323 & 1,38000 & 1,50000 & 0,25000 & 0,31000 \\
\hline 22 & 150CA_COMPACT153 & 0,38570 & 1,86890 & 0,20810 & 0,21570 \\
\hline 23 & 150CA_COMPACT253 & 0,38570 & 1,80070 & 0,20810 & 0,24980 \\
\hline 24 & $2 / 0 \mathrm{CA} 1$ & 0,65690 & 2,42420 & 0,47920 & 0,96100 \\
\hline 25 & $2 / 0 \mathrm{CA} 2$ & 0,65690 & 1,90420 & 0,47920 & 0,44100 \\
\hline 26 & $2 / 0 \mathrm{CA} 3$ & 0,65690 & 1,90420 & 0,47920 & 0,44100 \\
\hline 27 & 2/0CA4 & 0,65690 & 1,90420 & 0,47920 & 0,44100 \\
\hline 28 & 2/0CA5 & 0,65690 & 1,90420 & 0,47920 & 0,44100 \\
\hline 29 & 2/0CA6 & 0,65690 & 1,90420 & 0,47920 & 0,44100 \\
\hline 30 & 2/0CA7 & 0,65690 & 1,90420 & 0,47920 & 0,44100 \\
\hline
\end{tabular}

Fonte: Extraída do banco de dados da Copel (2010). 


\section{ANEXO D: dados oscilográficos contidos nos relés de proteção.}

Os dados oscilográficos registrados pelos dispositivos de proteção instalados em subestações ou em alimentadores são obtidos de forma manual, quando da necessidade de análise de tais dados pelo departamento de engenharia de proteção da concessionária.

Essa aquisição se processa da seguinte maneira: quando surge a necessidade da realização de algum estudo do desempenho da proteção em determinado alimentador, o departamento de engenharia de proteção envia uma solicitação ao departamento de manutenção para que seja efetuada a coleta destes manualmente, com o emprego de micro computadores, na subestação elencada para estudo de curto-circuito e de posterior localização de defeitos.

Porém, os dispositivos digitais de proteção (relés) possuem uma capacidade limitada de armazenamento desse tipo de dados. Esta limitação é circunscrita a um determinado número de eventos, sendo que, uma vez excedido o referido limite, o dispositivo inicia um processo de sobreposição de registros oscilográficos, apagando aqueles mais antigos.

Este critério acarreta a perda de quantidade considerável de dados oscilográficos que, se analisados, poderiam, além de otimizar os critérios de ajustes de proteção empregados atualmente nas concessionárias de energia elétrica, também permitir um ajuste particular visando atender às condições de redes específicas.

Desta forma é proposta uma solução que permita adquirir estes registros oscilográficos de forma automática, no momento logo após a ocorrência de um evento (curto-circuito) na rede de distribuição.

Após, estas oscilografias são transmitidas para um servidor de informática, remoto, de forma a evitar a perda dos dados oscilografados pela sobreposição de registros. Estes dados oscilográficos são utilizados no método desenvolvido, nesta tese, para localização de defeitos - método "a priori". 
Registro de eventos em relés digitais

Conforme descrevem Heising, Patterson e Weintraub (1997), os relés digitais registram as condições do sistema quando os elementos de proteção operam ou quando da ocorrência de condições definidas pelo usuário.

São normalmente registrados os valores das correntes e tensões durante uma préfalta e durante a falta que ocorrer no sistema elétrico.

Figura 31 - Relatório de eventos de um relé digital 351P - Whipp\&Bourne

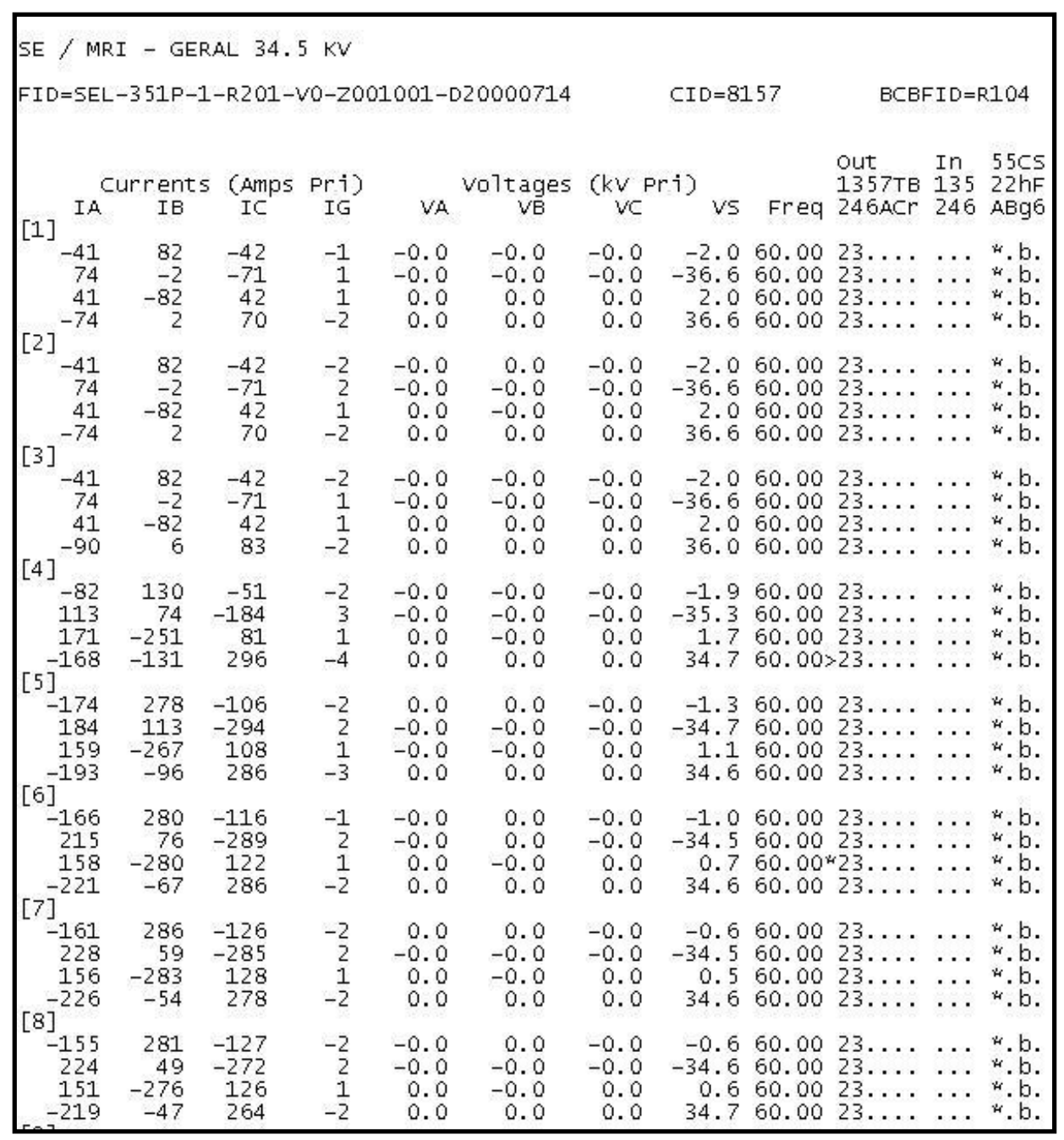

Fonte: Heising, Patterson e Weintraub (1997).

Na Figura 31 pode ser visualizado um relatório de eventos de um relé digital da SEL, modelo 351P, fornecido juntamente com um religador para proteção de 
alimentadores primários de distribuição, no qual se verificam as correntes, tensões, frequência e condições das saídas e entradas do relé.

Estes dados são de grande valia para análises das atuações das proteções, quais unidades atuaram, quais contatos fecharam e tempo de atuação das unidades ajustadas no relé.

O estudo realizado por Mooney (1998) informa que os registradores de sequência de eventos e oscilogramas geralmente são considerados como muito caros para aplicações na distribuição. Mas um operador do sistema de distribuição experiente deve também interpretar a saída dos oscilogramas gerados pelos relés de proteção para poder localizar as faltas nos alimentadores.

Na Figura 32 pode-se visualizar a sequência de eventos gerada por um relé digital de proteção instalado em circuitos de distribuição. Pode-se perceber que são registradas todas as operações realizadas pelo relé ou externas a ele, desde que sejam previamente programadas na lógica do sequenciador de eventos.

Esse tipo de relatório oferece ao analista de proteção muitas informações importantes para que se descubra que tipo de defeito ocorreu no sistema elétrico de distribuição e se o relé operou corretamente, assim como também o relé pode mostrar as operações realizadas em nível local ou remotamente, que posteriormente poderão ser analisadas pelo sistema especialista de análise e localização de defeitos. 
Figura 32 - Registro de sequência de eventos relé 351P Whipp\&Bourne

\begin{tabular}{|c|c|c|c|}
\hline $\begin{array}{l}308 \\
307 \\
306 \\
305 \\
304 \\
303 \\
302 \\
301 \\
300 \\
299 \\
298 \\
297 \\
296 \\
295 \\
294 \\
293 \\
292 \\
291 \\
290 \\
289 \\
288 \\
287 \\
286 \\
285 \\
284 \\
283 \\
282 \\
281 \\
280 \\
279 \\
278 \\
277 \\
276 \\
275 \\
274 \\
273 \\
272 \\
271 \\
270 \\
269 \\
268 \\
267 \\
266 \\
265 \\
264 \\
263 \\
262 \\
261 \\
260 \\
259 \\
258 \\
\end{array}$ & $\begin{array}{l}12 / 17 / 01 \\
12 / 17 / 01 \\
12 / 17 / 01 \\
12 / 17 / 01 \\
12 / 17 / 01 \\
12 / 17 / 01 \\
12 / 17 / 01 \\
12 / 17 / 01 \\
12 / 17 / 01 \\
12 / 17 / 01 \\
12 / 17 / 01 \\
12 / 17 / 01 \\
12 / 17 / 01 \\
12 / 17 / 01 \\
12 / 17 / 01 \\
12 / 17 / 01 \\
12 / 17 / 01 \\
12 / 17 / 01 \\
12 / 17 / 01 \\
12 / 17 / 01 \\
12 / 17 / 01 \\
12 / 17 / 01 \\
12 / 17 / 01 \\
12 / 17 / 01 \\
12 / 17 / 01 \\
12 / 17 / 01 \\
12 / 17 / 01 \\
12 / 17 / 01 \\
12 / 17 / 01 \\
12 / 17 / 01 \\
12 / 17 / 01 \\
12 / 17 / 01 \\
12 / 17 / 01 \\
12 / 17 / 01 \\
12 / 17 / 01 \\
12 / 17 / 01 \\
12 / 17 / 01 \\
12 / 17 / 01 \\
12 / 17 / 01 \\
12 / 17 / 01 \\
12 / 17 / 01 \\
12 / 17 / 01 \\
12 / 17 / 01 \\
12 / 17 / 01 \\
12 / 17 / 001 \\
12 / 17 / 01 \\
12 / 17 / 01 \\
12 / 17 / 01 \\
12 / 17 / 01 \\
12 / 17 / 01 \\
12 / 17 / 01 \\
\end{array}$ & $\begin{array}{l}12: 59: 38.840 \\
12: 59: 38.957 \\
12: 59: 38.957 \\
13: 00: 32.788 \\
13: 00: 32.821 \\
13: 00: 32.855 \\
13: 10: 31.847 \\
13: 10: 31.960 \\
13: 10: 31.960 \\
13: 10: 46.253 \\
13: 10: 46.286 \\
13: 10: 46.320 \\
13: 20: 09.991 \\
13: 20: 10.099 \\
13: 20: 10.099 \\
16: 30: 07.633 \\
16: 30: 07.666 \\
16: 30: 07.699 \\
16: 32: 32.283 \\
16: 32: 32.392 \\
16: 32: 32.392 \\
16: 36: 18.285 \\
16: 36: 18.319 \\
16: 36: 18.352 \\
16: 41: 20.246 \\
16: 41: 20.359 \\
16: 41: 20.359 \\
16: 41: 26.805 \\
16: 41: 26.839 \\
16: 41: 26.872 \\
16: 42: 49.607 \\
16: 42: 49.715 \\
16: 42: 49.715 \\
16: 44: 21.305 \\
16: 44: 21.339 \\
16: 44: 21.372 \\
16: 45: 33.335 \\
16: 45: 33.443 \\
16: 45: 33.443 \\
17: 02: 19.867 \\
17: 02: 19.901 \\
17: 02: 19.934 \\
17: 02: 51.183 \\
17: 02: 51.250 \\
17: 02: 59.155 \\
17: 02: 59.222 \\
17: 03: 41.127 \\
17: 03: 41.194 \\
17: 04: 21.457 \\
17: 04: 21.523 \\
17: 05: 18.276\end{array}$ & $\begin{array}{l}\text { CLOSE } \\
\text { CLOSE } \\
\text { 52A } \\
\text { TRIP } \\
\text { 52A } \\
\text { TRIP } \\
\text { CLOSE } \\
\text { CLOSE } \\
\text { 52A } \\
\text { TRIP } \\
\text { 52A } \\
\text { TRIP } \\
\text { CLOSE } \\
\text { CLOSE } \\
52 \mathrm{~A} \\
\text { TRIP } \\
\text { 52A } \\
\text { TRIP } \\
\text { CLOSE } \\
\text { CLOSE } \\
52 \mathrm{~A} \\
\text { TRIP } \\
\text { 52A } \\
\text { TRIP } \\
\text { CLOSE } \\
\text { CLOSE } \\
52 \mathrm{~A} \\
\text { TRIP } \\
52 \mathrm{~A} \\
\text { TRIP } \\
\text { CLOSE } \\
\text { CLOSE } \\
52 \mathrm{~A} \\
\text { TRIP } \\
52 \mathrm{~A} \\
\text { TRIP } \\
\text { CLOSE } \\
\text { CLOSE } \\
52 \mathrm{~A} \\
\text { TRIP } \\
\text { TRA } \\
\text { TRIP } \\
\text { TRIP } \\
\text { TRIP } \\
\text { TRIP } \\
\text { TRIP } \\
\text { TRIP } \\
\text { TRE }\end{array}$ \\
\hline
\end{tabular}

Fonte: Heising, Patterson e Weintraub (1997).

Oscilografia digital incorporada aos relés de proteção

Conforme enfatizam Heising, Patterson e Weintraub (1997), a função que merece destaque nos relés digitais de proteção é a oscilografia digital incorporada. Essa oscilografia anteriormente era realizada apenas pelos equipamentos chamados de oscilo perturbografos, os quais eram instalados em pontos estratégicos do sistema elétrico de potência, funcionavam com fitas magnéticas, onde eram registrados os sinais provenientes dos relés de proteção e de outros dispositivos do sistema elétrico.

Os dados gerados pelas oscilografias dos relés digitais são utilizados nas análises de atuações do sistema de proteção após a ocorrência dos defeitos. 
Essa função tem por objetivo o registro de ciclos de grandezas analógicas em caso de falta, armazenando alguns ciclos em condição de pré-falta e outros ciclos em condição de pós-falta.

O relé microprocessado registra os últimos eventos e atuações ocorridos, os quais são armazenados em memória não volátil, permitem ser acessados pelo operador através do painel frontal e também por dispositivos externos.

A maioria dos relés micro processados registra as condições do sistema quando os elementos de proteção operam ou quando da ocorrência de condições definidas pelo usuário.

Os dados dos eventos devem ser utilizados para avaliar a performance do relé. Rever os dados dos eventos é uma ferramenta valiosa para a manutenção. $O$ registro de eventos mostra os sinais $A C$ e $D C$ que o relé mede durante a perturbação, e também mostra quando o relé fecha o contato de disparo do circuito de comando do disjuntor.

Na Figura 33 e na Figura 34 podem ser visualizadas duas oscilografias geradas por relés digitais, nas quais são mostrados sinais analógicos (tensões e correntes) e sinais digitais (entradas e saídas de relés). 
Figura 33 - Oscilografia de relé digital - falta fase-terra

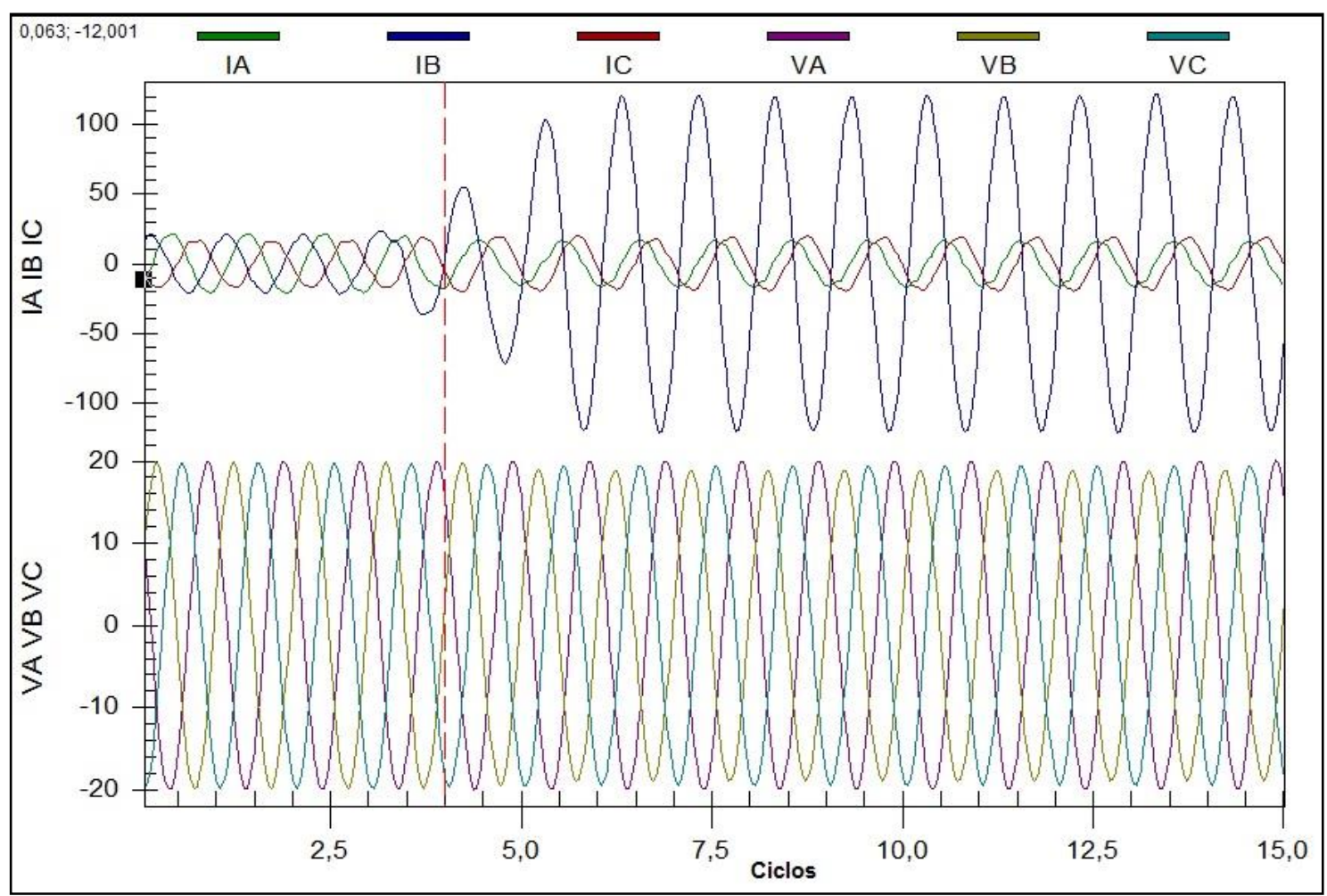

Fonte: Elaborada pelo Autor.

Figura 34 - Oscilografia de tensões, correntes e digitais

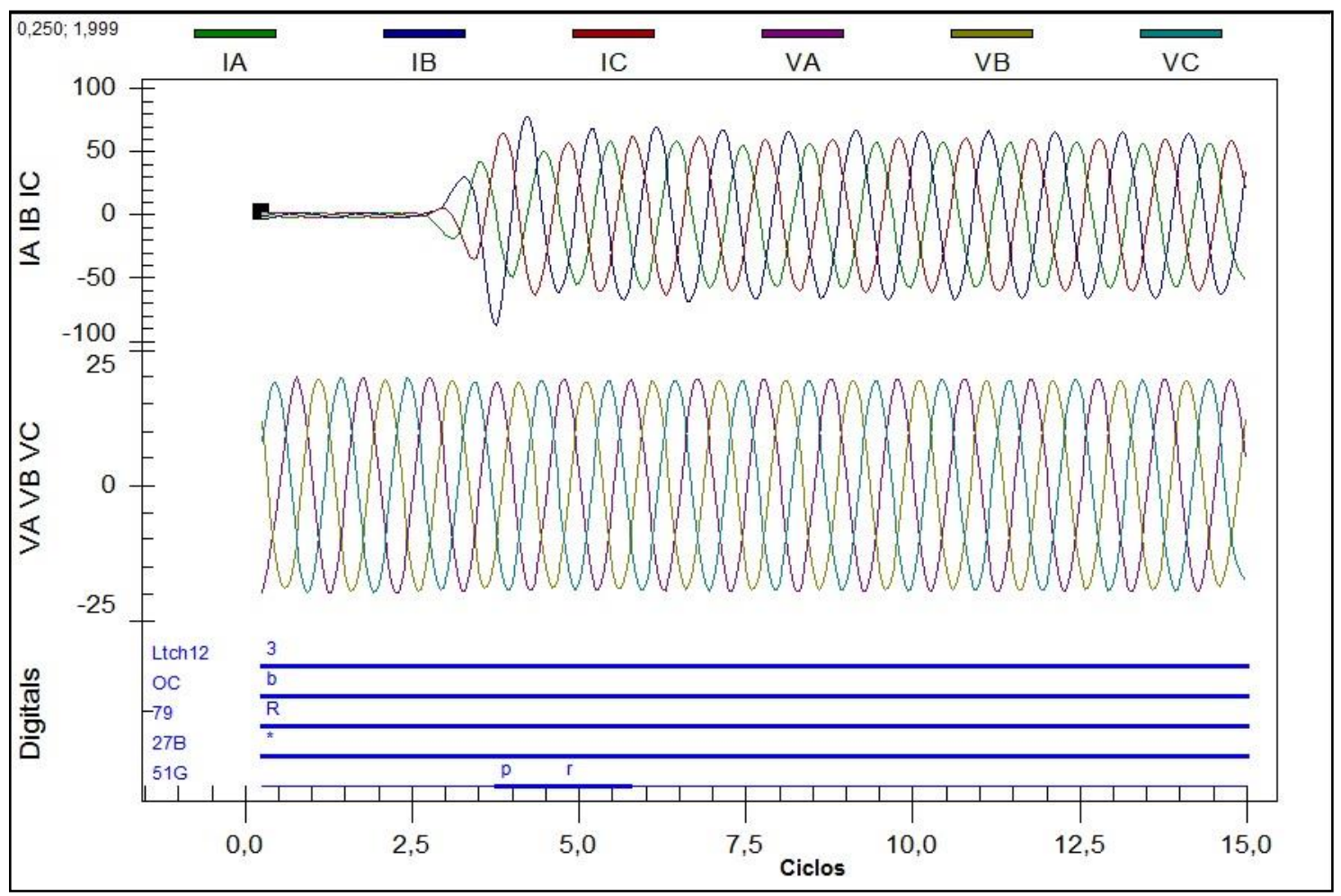

Fonte: Elaborada pelo Autor. 
Conforme RUFATO et al. (2012), a Figura 35 apresenta a oscilografia de um defeito entre fases, a partir da qual é possível observar a elevação dos valores das correntes IA, IB, IC e IN. Verifica-se também a elevação do potencial das tensões.

Figura 35 - Oscilografia de uma falta entre fases

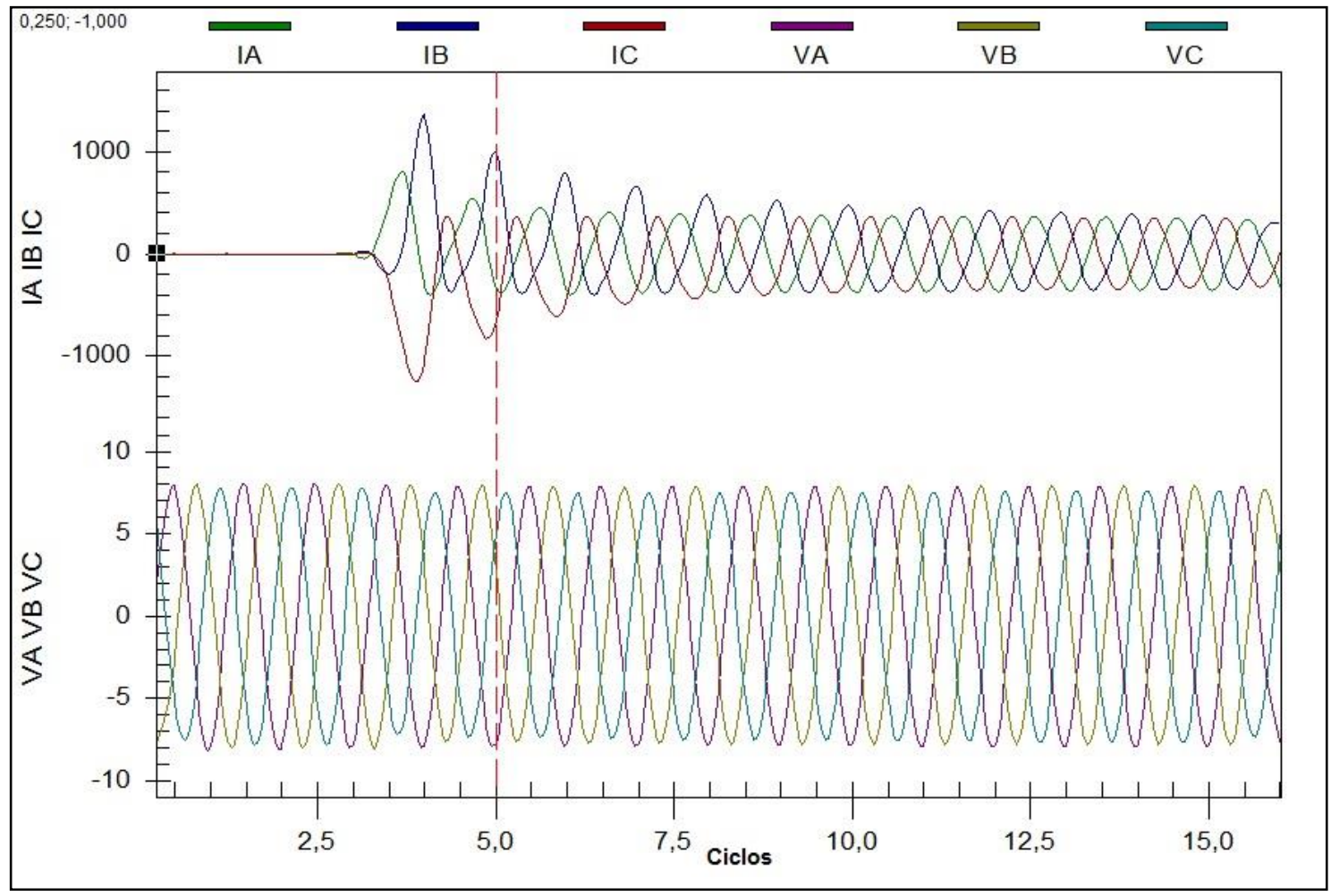

Fonte: Elaborada pelo Autor.

\section{Localização de faltas incorporada aos relés digitais de proteção}

Heising, Patterson e Weintraub (1997) descrevem uma função importante que pode ser implementada em relés digitais como sendo a de localização de faltas. Essa função tem a finalidade, de quando ocorrer uma falta no circuito alimentador ao qual o relé digital está instalado, como proteção, localizar o ponto onde o defeito ocorreu no alimentador.

Cabe aqui lembrar que este é um assunto muito estudado por diversas instituições de pesquisa e por fabricantes de equipamentos de proteção, sendo que esta função oferece uma localização boa para linhas de transmissão. 
Para circuitos de distribuição a sua aplicação não é tão determinística a ponto de dizer em que local dos vários ramais de um circuito de distribuição ocorreu a falta devido às várias variáveis deste tipo do sistema, como: impedâncias diferentes de condutores; impedâncias de falta diferentes ao longo dos circuitos.

Mesmo com todas estas restrições, é uma função importante para os engenheiros de proteção da distribuição se aliada a outras técnicas de localização de faltas, as quais poderão beneficiar os índices de qualidade e continuidade dos sistemas elétricos de distribuição. 


\section{ANEXO E - ENSAIOS EXPERIMENTAIS COM GERAÇÃO DISTRIBUIDA}

Através desses testes reais, validaram-se os parâmetros considerados nas funções heurísticas, para os valores de resistência de defeito e influência da GD sobre as impedâncias equivalentes do sistema. Através da monitoração das correntes de curto-circuito monofásicos com resistência de defeito e, com a atuação dos relés de proteção nas subestações fonte.

As pesquisas bibliográficas apresentadas no Capítulo 3 desta tese mostram que, nos estudos realizados pelos autores consultados, ocorrem variações nos valores das correntes de curto-circuito com a inserção de geração distribuída em alimentadores de distribuição, as quais poderão provocar, ou não, influências na aplicação do método proposto de localização de defeitos.

A fim de comprovar e validar o método, realizou-se testes de curto-circuito, reais, em alimentadores de distribuição, com e sem a presença de geração distribuída. Comprovando-se assim que a variação na corrente de curto-circuito, provocada pela geração distribuída, para os casos testados, não traz variação expressiva na localização dos defeitos no alimentador.

Isso se deu devido ao fato de que na maioria das vezes as gerações distribuídas estão localizadas nos finais dos alimentadores de distribuição, e o efeito da impedância acumulada dos condutores minimiza a influência daquelas correntes de curto-circuito fase-terra para a utilização do método proposto de localização de defeitos, apresentado nesta tese.

Os defeitos considerados de alta impedância, que não fazem parte do desenvolvimento desta tese (resistências de defeitos maiores que 100 ohms), devem ser estudados para serem localizados por técnicas e equipamentos específicos para estes eventos, por exemplo, os relés de detecção de defeitos de alta impedância. 


\section{Configuração do alimentador primário de testes}

O diagrama unifilar da Figura 36 apresenta o sistema de distribuição primário utilizado nos ensaios com geração distribuída, constituída de uma $\mathrm{PCH}$ conectada no trecho final do alimentador.

Figura 36 - Configuração do sistema de testes

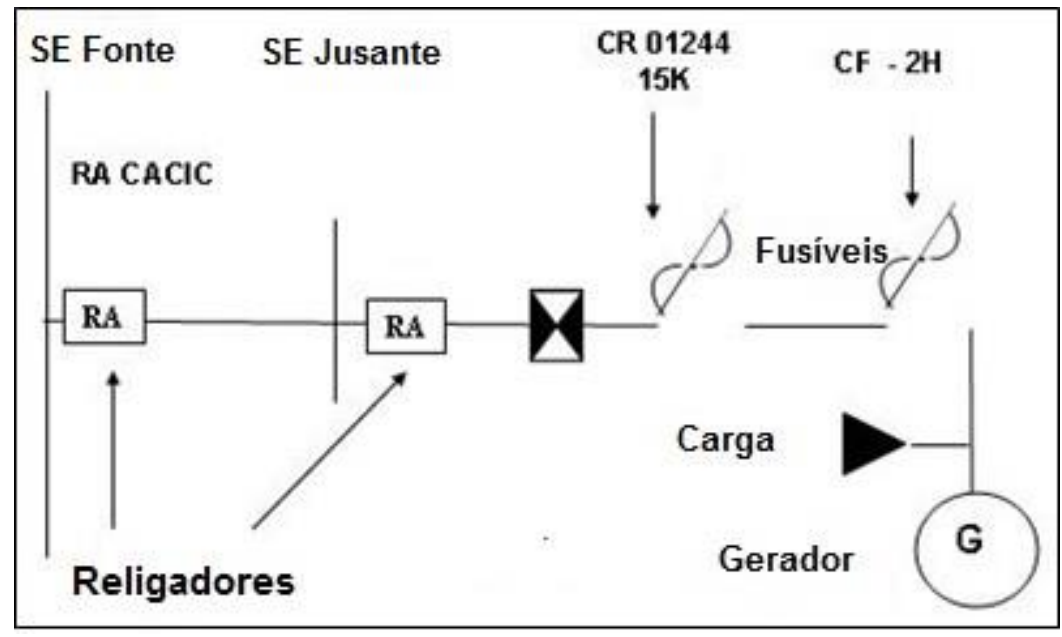

A PCH, ilustrada na Figura 37 tem capacidade instalada de 1,48 MVA.

Figura 37 - Pequena Central Hidroelétrica - PCH

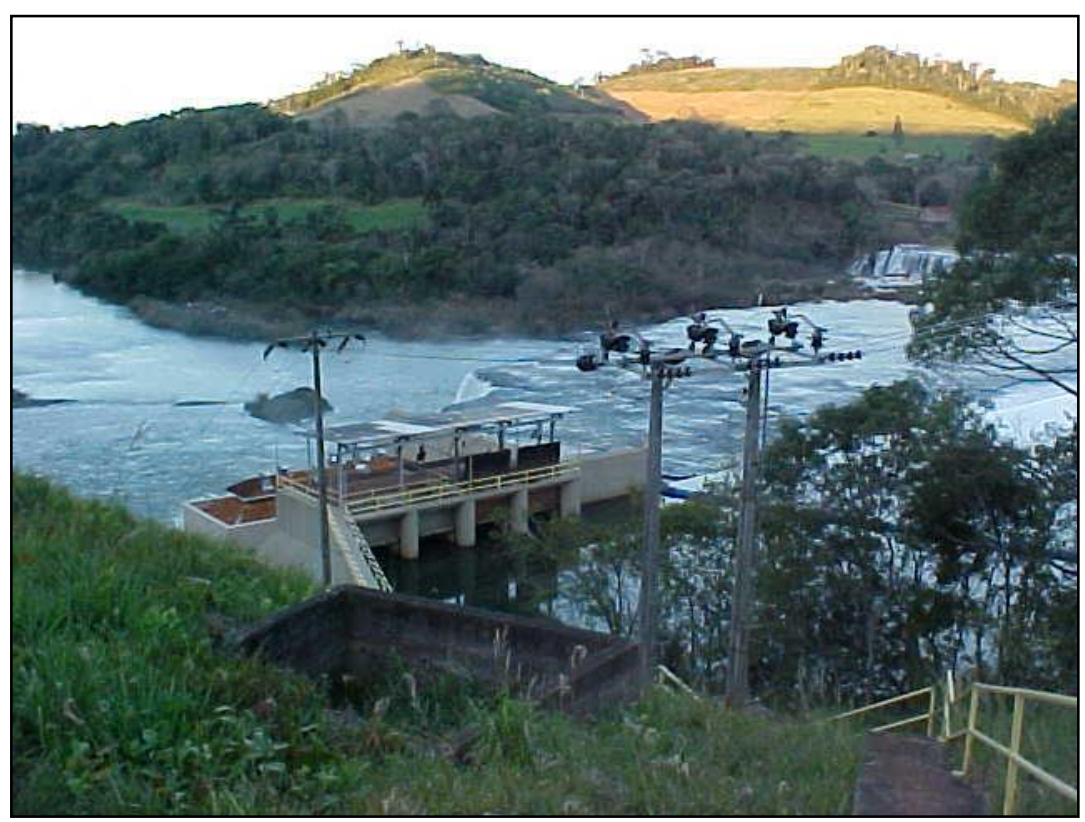

Fonte: Elaborada pelo autor. 
O diagrama da Figura 38 mostra o sistema de proteção, mínimo, instalado em alimentadores com conexão de GD, onde se observa as seguintes funções de proteção:

Sobrecorrente de corrente alternada de fase e de neutro, instantâneas e temporizadas $-50 / 51-50 / 51 \mathrm{~N}$;

Sobre tensão (3 fases) - 59;

Sub Tensão (3 fases) - 27

Sobre e Sub Frequência $81 \mathrm{O} / \mathrm{U}$;

Vetor Jump (Salto de Vetor) - 78

Figura 38 - Proteções Mínimas para Conexão de GD

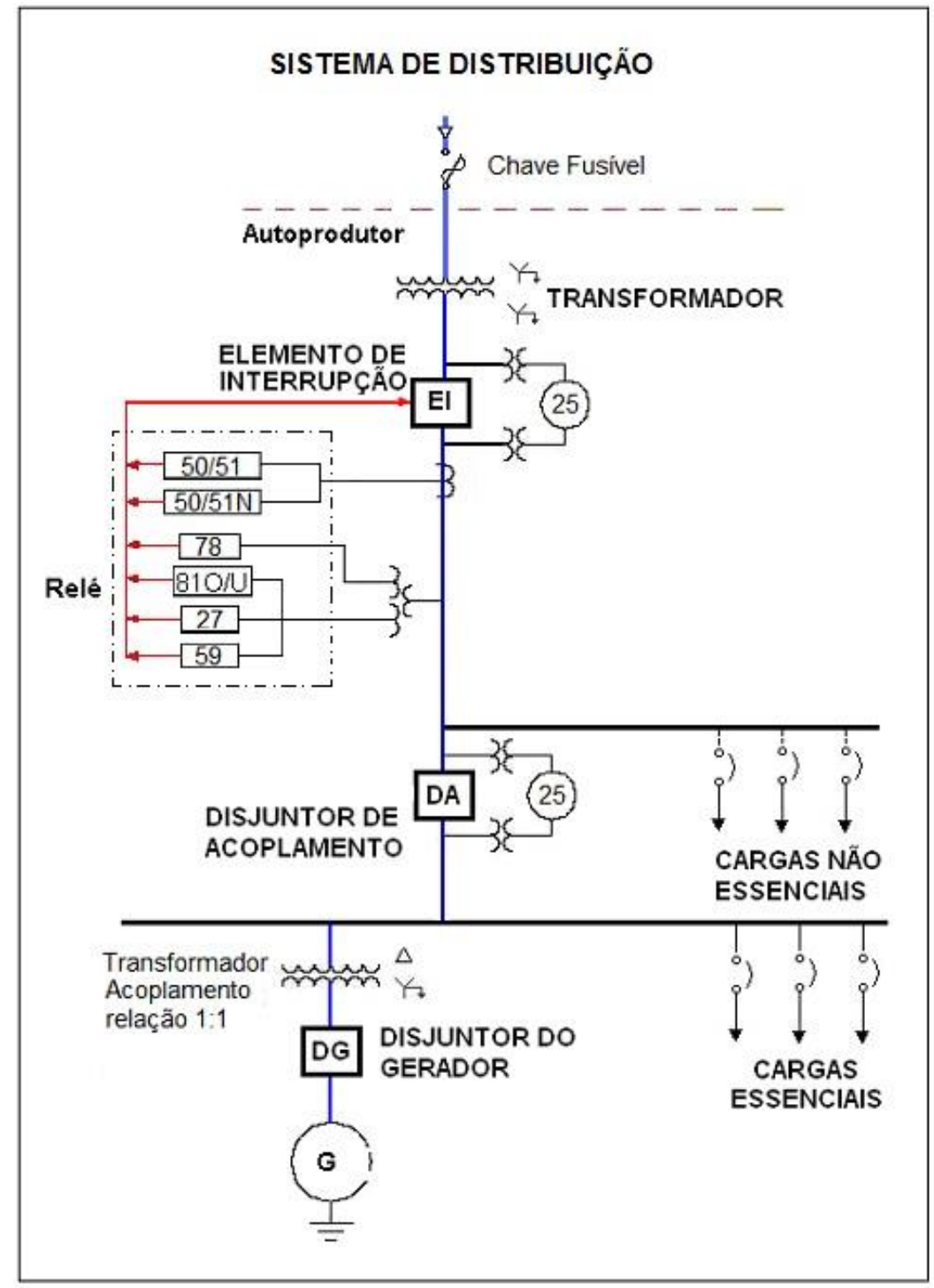

Fonte: Elaborada pelo autor 


\section{Testes de curto circuito realizados em campo e locais de testes}

Os testes foram realizados conforme os casos e locais descritos conforme a Tabela 12.

Tabela 12 - Tipos de defeito

\begin{tabular}{|c|c|c|}
\hline \multirow{2}{*}{$\begin{array}{ll}\text { TIPO } & \text { DE } \\
\text { DEFEITO } & \end{array}$} & \multicolumn{2}{|c|}{ PONTO DE DEFEITO } \\
\hline & $\begin{array}{l}\text { SE } \\
\text { FONTE }\end{array}$ & SE JUSANTE \\
\hline $\begin{array}{l}\text { Curto } \\
\text { fase/terra }\end{array}$ & CASO 1 & CASO 2 \\
\hline $\begin{array}{l}\text { Curto } \\
\text { fase/fase/terra }\end{array}$ & CASO 3 & CASO 4 \\
\hline $\begin{array}{l}\text { Curto trifásico } \\
\text { a terra }\end{array}$ & CASO 5 & CASO 6 \\
\hline $\begin{array}{l}\text { Uma fase } \\
\text { aberta }\end{array}$ & CASO 7 & CASO 8 \\
\hline $\begin{array}{l}\text { Duas fases } \\
\text { abertas }\end{array}$ & CASO 7A & CASO 8A \\
\hline $\begin{array}{l}\text { Alimentador } \\
\text { adjacente }\end{array}$ & CASO 9 & \\
\hline
\end{tabular}

Fonte: Elaborada pelo autor.

\section{Testes Caso 1}

Tipo de Teste - Curto fase - terra no Alimentador SE Jusante com GD.

Resultado esperado: Deve ocorrer a atuação das proteções no disjuntor do gerador, provocando sua saída de operação antes do religamento automático do alimentador, conforme mostra a oscilografia da Figura 39. Atuação do disjuntor em 89 ms.

Com a GD conectada no circuito alimentador primário de distribuição, foram executados testes reais de curto circuitos e anomalias no sistema de distribuição primário. Foram realizados 9 testes de curto circuito em campo.

Resultados dos testes de curto circuito 
O Teste 4 consistiu em colocar o grupo gerador em paralelo com a rede de distribuição primária.

AÇÃO: Promover um curto circuito monofásico na rede de distribuição, no ponto escolhido para teste, conforme diagrama unifilar da Figura 36, no lado fonte do circuito.

RESULTADO ESPERADO - deverá ocorrer à atuação das proteções no disjuntor do gerador provocando sua saída de operação, antes do religamento automático do alimentador.

RESULTADO DO TESTE - Ocorreu a abertura do disjuntor do alimentador por atuação do relé de proteção, com tempo de atuação de 61 mili-segundos, conforme mostra a oscilografia da Figura 39, interrompendo a corrente do gerador. O gerador continuou a girar a vazio e isolado da rede de distribuição.

Houve a abertura do religador do alimentador primário, na subestação Fonte, por atuação da proteção de sobre corrente de neutro, o qual está ajustado em $25 \mathrm{~A}$.

Figura 39 - Oscilografia de correntes e tensões - teste 4

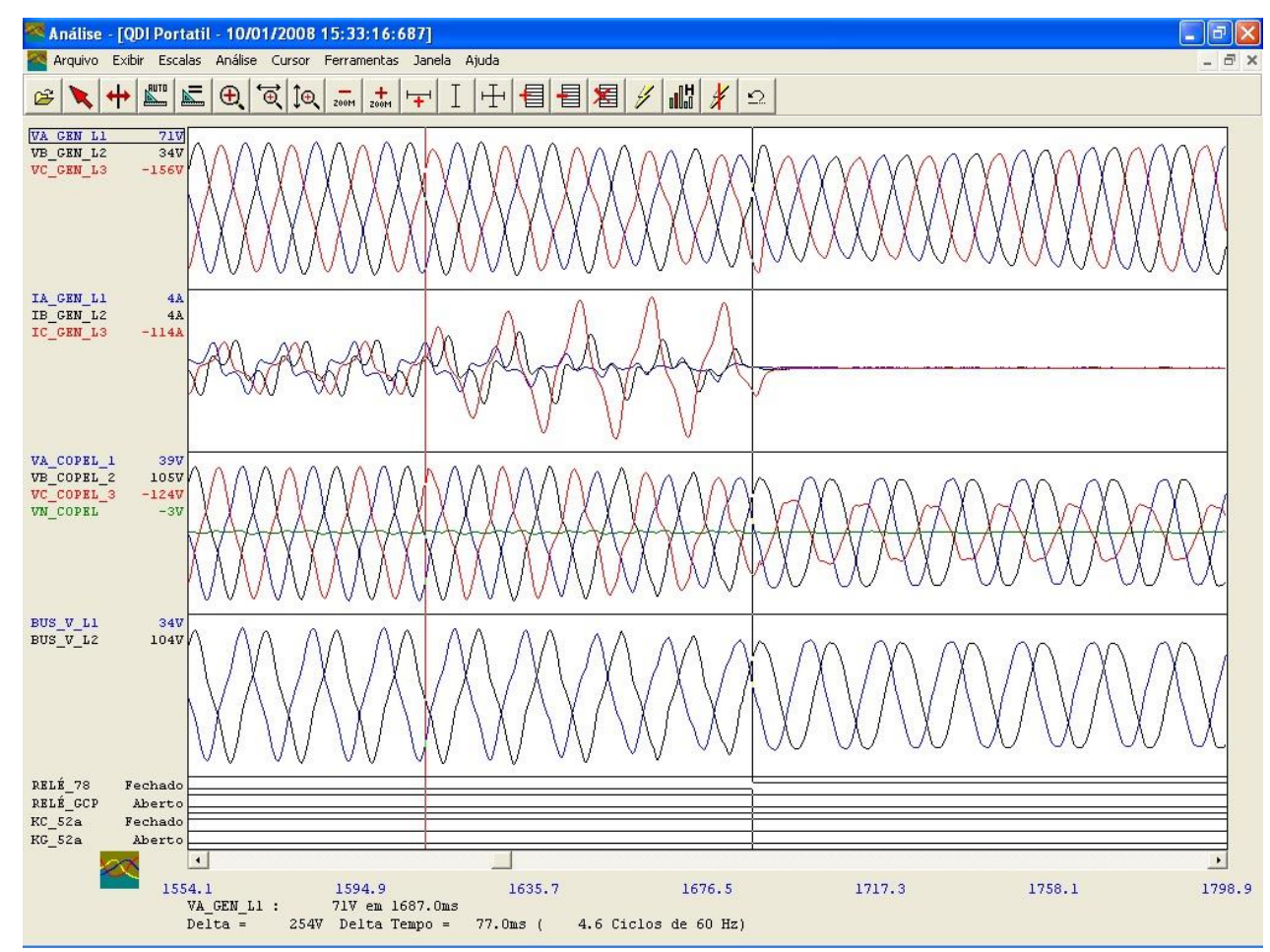

Fonte: Elaborada pelo autor. 
Na Tabela 13 são apresentados os tempos de atuação das proteções do disjuntor e qual a proteção que atuou durante os testes realizados em campo.

\section{Tabela 13 - Tempos de atuação dos relés de proteção}

\begin{tabular}{|c|c|c|}
\hline ENSAIO & $\begin{array}{c}\text { TEMPO DE SAIDA DO } \\
\text { GERADOR DO PARALELO } \\
\text { (ms) }\end{array}$ & PROTEÇAO QUE ATUOU \\
\hline TESTE 1 & 76 & Rele salto de vetor \\
\hline TESTE 2 & 00 & Oscilograma perdido \\
\hline TESTE 3 & 68 & Rele salto de vetor \\
\hline TESTE 4 & 61 & Rele salto de vetor \\
\hline TESTE 5 & 77 & Subtensão \\
\hline TESTE 6 & 144 & Rele salto de vetor \\
\hline TESTE 7 & 64 & Rele salto de vetor \\
\hline TESTE 8 & 64 & Subtensão \\
\hline TESTE 9 & 157 &
\end{tabular}

Fonte: Elaborada pelo autor.

A Figura 40 mostra a realização do teste de curto circuito fase terra, em solo de terra boa, com resistência de defeito na ordem de 20 ohms.

Neste teste a geração distribuída está conectada em paralelo com o circuito alimentador primário de distribuição.

O condutor da fase A, foi derivado do alimentador primário de distribuição, e, através do cesto de um caminhão de linha viva, o condutor da fase $A$ foi deixado cair ao solo, provocando o curto circuito, como ocorre quando há um condutor rompido.

Durante o período de pré-falta e falta, foram oscilografados todos os valores analógicos de tensão e corrente, assim como os sinais digitais de atuações dos elementos de proteção, nos equipamentos de proteção da subestação e no do gerador distribuído. 
Figura 40 - Curto circuito com GD.

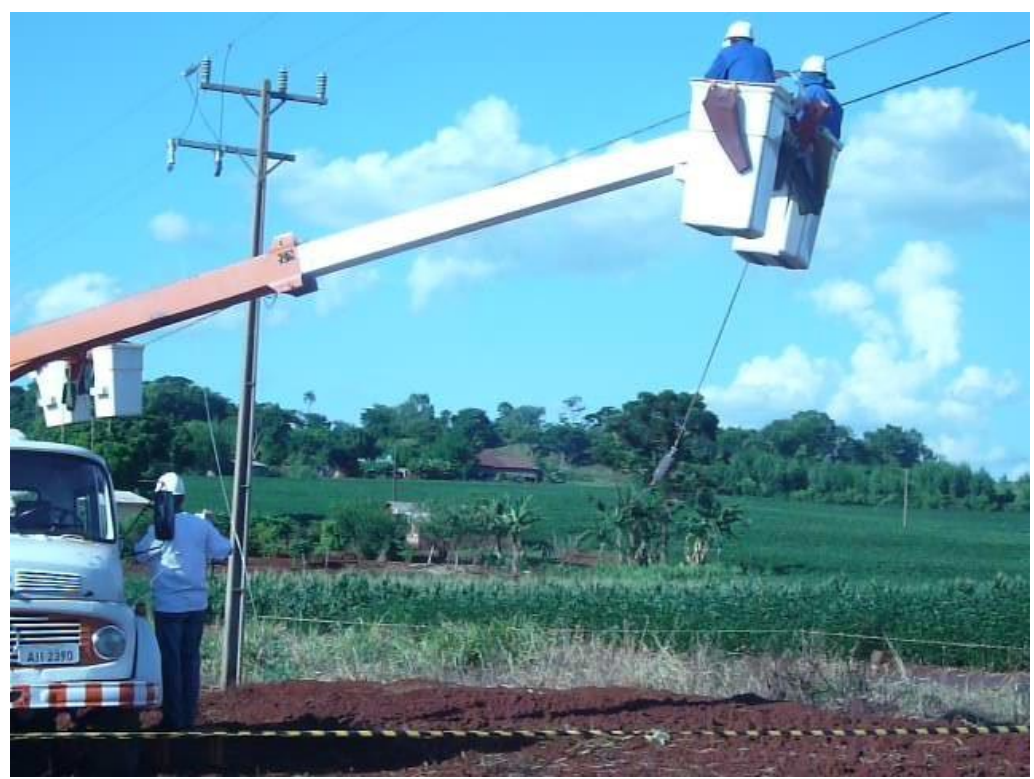

Fonte: Elaborada pelo autor.

Para este teste, ocorreu a atuação do relé de proteção da subestação, com a geração da oscilografia, isto é, a corrente de curto circuito foi maior do que a corrente de ajuste do relé, de $25 \mathrm{~A}$.

A Figura 41 mostra uma pequena central hidroelétrica - PCH que se conecta em um alimentador primário de distribuição, como geração distribuída.

Figura 41 - PCH como GD.

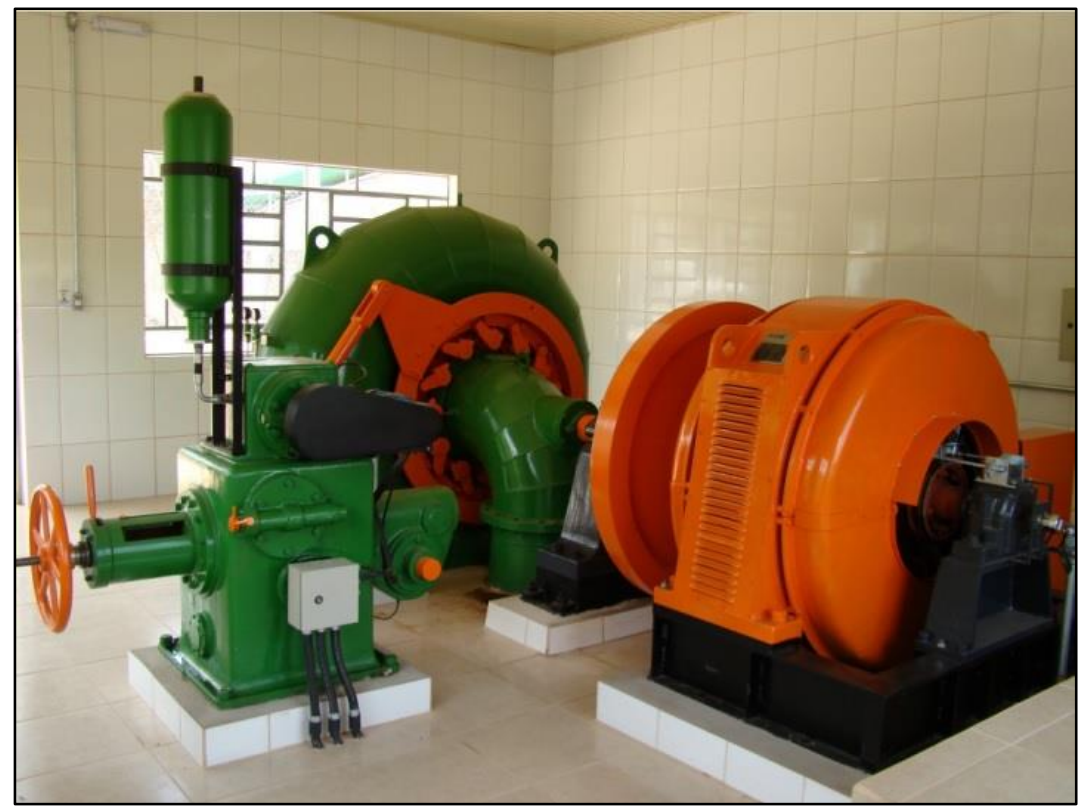

Fonte: Elaborada pelo autor. 


\section{Conclusões}

Através da análise dos oscilogramas e dos resultados das medições realizadas e dados levantados durante a realização dos testes de campo, pode-se verificar que em $90 \%$ dos testes realizados, ocorreu a atuação da proteção do GD do relé utilizado para os diversos tipos de testes realizados.

Foram realizados curtos-circuitos fase-terra do lado da fonte, curto circuitos faseterra do lado da carga, abertura de fases no circuito alimentador, curto circuitos fasefase-terra, os quais provocaram a retirada do grupo gerador do paralelo com 0 sistema de distribuição, sendo o tempo de atuação das unidades de proteção ficaram entre 60 a 80 mili-segundos.

Nos curtos-circuitos realizados, após a saída do GD, ocorreu a atuação da proteção do relé do circuito alimentador primário, o qual é ajustado para uma corrente de partida de neutro de $25 \mathrm{~A}$, comprovando que, a inserção de GD nos circuitos alimentadores, não afetaram as atuações das proteções primárias.

Com isto, pode-se demostrar que, para estes tipos de defeitos e com GD, no alimentador, as faltas podem ser localizadas na rede primária de distribuição, utilizando-se a metodologia heurística, proposta na tese, através da análise dos dados oscilografados pelos relés de proteção. 